\title{
EFFECTS OF FILTRATION TEMPERATURE AND HEAT TREATMENT ON COMPOSITION AND RHEOLOGICAL PROPERTIES OF WHOLE MILK ULTRAFILTRATION RETENTATES
}

\author{
A thesis \\ Presented to the faculty of \\ California Polytechnic State University, San Luis Obispo
}

In Partial Fulfillment

Of the Requirements for the Degree

Master of Science in Agriculture, with a Specialization in Dairy Products Technology

By

John William Montella

October 2008 


\section{Copyright Page}

I grant permission for the reproduction of this thesis, in its entirety or any of its parts, without further authorization from me. 


\section{COMMITTEE MEMBERSHIP PAGE}

TITLE: $\quad$ EFFFECTS OF FILTRATION TEMPERATURE AND HEAT TREATMENT ON COMPOSITION AND RHEOLOGICAL PROPERTIES OF WHOLE MILK ULTRAFILTRATION RETENTATES

AUTHOR: John W. Montella

SUBMITTED: October 24, 2008

Dr. Phillip S. Tong

Committee Advisor

Dairy Products Technology Center

Professor, Dairy Science Department

Dr. Ray Fernando

Committee Member

Chair

Polymer and Coatings Program

Professor, Department of Chemistry

Dr. Robert Smidt

Committee Member

Department of Statistics 


\section{ABSTRACT \\ Effects of Filtration Temperature and Heat Treatment on Composition and Rheological Properties of Whole Milk Ultrafiltration Retentates John William Montella}

For the first part of my thesis, the effects of filtration temperature and heat treatment on the compositional properties of whole milk Ultrafiltration retentate (UF) were studied. Ultrafiltration is primarily run at temperatures in the range of $50-55^{\circ} \mathrm{C}$ but more and more plants are starting to filter at refrigeration temperatures. In the ultrafiltration of milk, filtration temperature can affect the composition of the retentate by affecting the chemistry of milk components. The application of a pasteurization step can also affect the chemistry of milk components. There were two filtration temperatures used: $10^{\circ} \mathrm{C}$ and $50^{\circ} \mathrm{C}$. The effect of stage in the filtration process in which the pasteurization step is applied (before UF vs. after UF) is also studied. The heat treatment used was a batch pasteurization treatment of $63^{\circ} \mathrm{C}$ for 30 minutes. The milk was concentrated to a Volume Concentration Ratio (VCR) of 3X through a 10,000 Molecular Weight Cut Off polysulfone membrane. Compositional analysis was performed on permeate and retentate. According to my results, there were significant treatment effects on the retention of true protein (both casein and whey protein nitrogen), total protein, non-casein nitrogen, minerals (including $\mathrm{Ca}$ ) and $\mathrm{pH}$ of the retentate. The chemistry of the milk components were considered as possible reasons for these differences. The week of processing did not affect the results.

For the second part, the effect of composition of the retentate on their viscosity and flow properties was observed. Rheological properties are very important in process design and for consumer acceptability. Flow and viscosity data was collected using a dynamic stress rheometer. 
Three analytical temperatures were used during the rheological measurements: $10^{\circ} \mathrm{C}, 40^{\circ} \mathrm{C}$, and $70^{\circ} \mathrm{C}$. A shear rate of $500 \mathrm{~s}^{-1}$ was used for viscosity analysis. Flow properties were also observed using the same three temperatures. According to the results, all the retentate displayed shear thinning behavior and this behavior became more pronounced as the testing temperature increased. As the shear rate increased, there was a shear thickening effect that became more pronounced as temperature increased. There was a significant effect of treatment on the viscosities of the retentate. Compositional differences in the retentate are possible contributors to observed results. The week of processing had no effect on the results.

For the final part, the effect of filtration temperature and heat treatment on rennet coagulation time of retentate was observed. A $22 \mu \mathrm{l}$ aliquot of chymosin was added to $100 \mathrm{ml}$ of retentate heated to $30^{\circ} \mathrm{C}$ prior to analysis. Rennet coagulation time was monitored using a dynamic stress rheometer. The rennet coagulation time was recorded as the time at which the G' value reached $1 \mathrm{~Pa}$. There was a significant effect of filtration temperature and heat treatment on the rennet coagulation time of the retentate. Compositional differences are all possible contributors to these differences.

From the observations from all three studies, the following conclusions can be made: (1) There were significant differences observed with respect to filtration temperature and heat treatments on chemical composition of the retentate; (2) The retentate displayed a shear thinning behavior and the chemical composition of the retentate could be a contributing factor as well as the sample testing temperature. There was also a significant treatment effect on the viscosity of the retentate; and (3) Significant differences in rennet coagulation times were observed, possibly due to compositional differences of retentate. Processing week did not have a significant effect on my results. 


\section{ACKNOWLEDGEMENTS}

I would like to thank to Dr. Phillip S. Tong for giving me the opportunity to come to Cal Poly in order to work and complete my Master's thesis and for all his support and help during this time.

I would like to thank my committee members, Dr. Ray Fernando and Dr. Robert Smidt for their support, help, and interest in my thesis project.

I would like to thank Dr. Rafael Jimenez-Flores for helping me stay strong and focused when I needed it the most. I would like to thank Dr. Dane Jones of the Department of Chemistry and Biochemistry, Cal Poly State University, San Luis Obispo, for his help in trying to design the methodology for my thesis project. I would like to thank Dr. Albert Censullo of the Department of Chemistry and Biochemistry, Cal Poly State University, San Luis Obispo, for allowing my to use his lab to perform Atomic Adsorption Spectroscopy. I would like to thank Mr. Sean Vink and Mr. Jerry Mattas of the DPTC for their help in the completion of the pilot plant trials and instruction in analytical methods used in my thesis.

I would like to thank my parents for giving me moral support and I would especially like to thank Linnea A. Swenson and Linnea R. Swenson for all their love during my most challenging times.

I would like to thank California Dairies, Inc. for their help in the funding of this thesis project. 
Dedicated To

Linnea Reneé Swenson, my love, my inspiration 


\section{Table of Contents}

\section{Page}

List of figures

$1 \mathrm{X}$

List of tables

$\mathrm{X} 1$

Chapter

1.0 Introduction to thesis

2.0 Effect of Filtration Temperature and Heat Treatment on Composition of UF Retentate 
3.0 Effect Composition of UF Retentate Affects Rheological Properties

4.0 Effects of Composition of Retentate on Their Renneting Properties

6.0 Appendix A Introduction to Casein Micelles 109

7.0 Appendix B MINITAB Printouts 


\section{List of Figures}

Page

Figure 2.1: Bar graph of $\%$ total ash retained with respect to filtration temperature and heat treatment of whole milk UF retentate

Figure 2.2: Bar graph of the \% calcium retained with respect to filtration temperature and heat treatment of whole milk UF retentate

Figure 2.3: Bar graph of $\%$ total protein retained with respect to filtration temperature and heat treatment for whole milk UF retentate

Figure 2.4: Bar graph for \% non-protein nitrogen retained with respect to filtration temperature and heat treatment of whole milk UF retentate

Figure 2.5: Bar graph of the \% non-casein nitrogen $(\mathrm{NCN})$ retained with respect to filtration temperature and heat treatment of whole milk UF retentate

Figure 2.6: Bar graph of the $\%$ true protein nitrogen retained with respect to filtration temperature and heat treatment of whole milk UF retentate

Figure 2.7: Bar graph of the \% casein nitrogen retained with respect to filtration temperature and heat treatment of whole milk UF retentate

Figure 2.8: Bar graph of \% whey protein nitrogen retained with respect to filtration temperature and heat treatment of whole milk UF retentate

Figure 2.9: Bar graph of $\mathrm{pH}$ of whole milk UF retentate with respect to filtration and heat treatment of whole milk UF retentate

Figure 2.10: Bar graph of \% fat retained with respect to filtration temperature and heat treatment of whole milk UF retentate 
Figure 2.11: Photo of UF system used in the production of retentate during pilot processing trials

Figure 2.12: Photo of PMS small scale processing system used in the pasteurization of milk and retentate during pilot trials.

Figure 2.13: Process flow diagram for processing trials

Figure 3.1: $\log _{10}$ viscosity vs. $\log _{10}$ shear rate at $10^{\circ} \mathrm{C}$ with respect to filtration temperature and heat treatment for whole milk UF retentate

Figure 3.2: $\log _{10}$ viscosity vs. $\log _{10}$ shear rate at $40^{\circ} \mathrm{C}$ with respect to filtration temperature and heat treatment for whole milk UF retentate

Figure 3.3: $\log _{10}$ viscosity vs. $\log _{10}$ shear rate at $70^{\circ} \mathrm{C}$ with respect to filtration temperature and heat treatment for whole milk UF retentate

Figure 3.4: Photo of dynamic stress rheometer used in the rheological testing of the retentate

Figure 3.5: Photo of cup and used by the dynamic stress rheometer used in rheological testing of the retentate

Figure 3.6: Photo of the temperature collar used in temperature regulation during rheological testing of retentate

Figure 4.1: Bar graph of rennet coagulation time of whole milk UF retentate subjected to different filtration temperatures and heat treatments 


\section{List of Tables}

Page

Table 2.1: Composition Chart of Retentate Processed Under

Various Filtration Temperatures and Heat Treatments

Table 2.2: Nitrogen Distribution Data

Table 3.1: Viscosities of whole milk UF retentate at $500 \mathrm{~s}^{-1}$ at $10^{\circ} \mathrm{C}$

Table 3.2: Viscosities of whole milk UF retentate at $500 \mathrm{~s}^{-1}$ at $40^{\circ} \mathrm{C}$

Table 3.3: Viscosities of whole milk UF retentate at $500 \mathrm{~s}^{-1}$ at $70^{\circ} \mathrm{C}$

Table 4.1: Rennet Coagulation Times for whole milk UF retentate 


\begin{abstract}
For the first part of my thesis, the effects of filtration temperature and heat treatment on the compositional properties of whole milk Ultrafiltration retentate (UF) were studied. Ultrafiltration is a versatile process that is used to produce a wide variety of products from milk powders to cheese. The end products serve many functions from ingredient substitution to milk standardization. Ultrafiltration is primarily run at temperatures in the range of $50-55^{\circ} \mathrm{C}$ but more and more plants are starting to filter at lower temperatures (refrigeration temperatures). In the ultrafiltration of milk, filtration temperature can affect the composition of the retentate by affecting the chemistry of components such as protein and minerals. The application of a pasteurization step can also affect the chemistry of milk components. There were two filtration temperatures used: $10^{\circ} \mathrm{C}$ and $50^{\circ} \mathrm{C}$. The affect of stage in the filtration process in which the pasteurization step is applied (before UF vs. after UF) is also studied. The heat treatment used was a batch pasteurization treatment of $63^{\circ} \mathrm{C}$ for 30 minutes. The milk was concentrated to a Volume Concentration Ratio (VCR) of 3X through a 10,000 Molecular Weight Cut Off polysulfone membrane. Compositional analysis was performed on permeate and retentate. According to my results, there were significant treatment effects on the retention of true protein (both casein and whey protein nitrogen), total protein, non-casein nitrogen, minerals (including $\mathrm{Ca}$ ) and $\mathrm{pH}$ of the retentate. The chemistry of the milk components were considered as possible reasons for these differences. There was not an effect of week of processing on the results.

For the second part of my thesis, the effect of composition of the retentate on their viscosity and flow properties was observed. Rheological properties are very important in process design and for consumer acceptability. Flow and viscosity data was collected using a dynamic stress rheometer. Three analytical temperatures were used during the rheological measurements:
\end{abstract}


$10^{\circ} \mathrm{C}, 40^{\circ} \mathrm{C}$ and $70^{\circ} \mathrm{C}$. A shear rate of $500 \mathrm{~s}^{-1}$ was used for viscosity analysis. Flow properties were also observed using the same three temperatures. According to the results, all the retentate displayed shear thinning behavior and this behavior became more pronounced as the testing temperature increased. As the shear rate increased, there was a shear thickening effect that became more pronounced as temperature increased. There was a significant effect of treatment on the viscosities of the retentate. Compositional differences in the retentate are possible contributors to observed results. The week of processing on the retentate had no effect of the results.

For the final part of my thesis, the effect of filtration temperature and heat treatment on rennet coagulation time of retentate was determined. A $22 \mu \mathrm{l}$ aliquot of chymosin was added to $100 \mathrm{ml}$ of retentate heated to $30^{\circ} \mathrm{C}$ prior to analysis. Rennet coagulation time was monitored using a dynamic stress rheometer. The rennet coagulation time was recorded as the time at which the G' value reached $1 \mathrm{~Pa}$. There was a significant effect of filtration temperature and heat treatment on the rennet coagulation time of the retentate. Compositional differences in protein, minerals (especially $\mathrm{Ca}$ ) and $\mathrm{pH}$ are all possible contributors to these differences.

From the observations from all three studies, the following conclusions can be made: (1) There were significant differences observed with respect to filtration temperature and heat treatments on chemical composition of the retentate; (2) The retentate displayed a well-defined shear thinning behavior and the chemical composition of the retentate is a contributing factor as well as the sample testing temperature. There was also a significant effect of filtration temperature and heat treatment on the viscosity of the retentate; and (3) Significant differences in rennet coagulation times were observed, possibly due to compositional differences of retentate. Processing week did not have a significant effect on my results. 


\subsection{Introduction to Thesis}

Ultrafiltration is a process involving a semi-permeable membrane to selectively fractionate and concentrate components of a feed stream. In the case of milk, fat and proteins are concentrated and separated from low molecular weight components such as lactose and minerals. This process has a lot of versatility and the end products produced can be used in the production of milk powder, whey products and cheese. This process is normally run at $50^{\circ} \mathrm{C}$ but lower temperatures (e.g., refrigeration temperature) can also be used as well. The temperature at which milk is ultrafiltered (as well as a pasteurization step) affects the chemistry of the milk components, especially milk protein and calcium levels. The application of a pasteurization step and the stage in the process at which it is applied (before UF vs. after UF) can also affect the composition of the retentate by affecting milk chemistry. There has been very little research done that compared both the filtration temperature and the stage of the process in which the heat treatment was applied on compositional differences in the retentate. For the first part of my thesis, I studied the effect of filtration temperature and heat treatment on composition of whole milk ultrafiltration retentate.

Rheology is the study of the deformation or flow of a material. In terms of food, processing, rheological properties involve viscosity and textural properties such as elasticity, cohesiveness, crunchiness, just to name a few. The rheological properties of a food product can be used to maintain quality assurance and control of a product as well as in the design or modification of a processing system or procedure. One important rheological property of food products is its viscosity. Viscosity refers to the resistance of a fluid to flow. Rheological properties are affected by many compositional factors. As mentioned earlier, the filtration temperature and the application of a heat treatment (as well as the stage in the process in which it 
is applied) will affect compositional factors, which in turn can affect its rheological properties. There is very little work done that compares the affect of filtration temperature and heat treatment on flow properties and viscosities of the retentate. For the second part of my thesis project, I studied the effect of filtration temperature and heat treatment on rheological properties of whole milk ultrafiltration retentate.

One of the uses of ultrafiltration is in the production of cheese. This process allows for increased cheese yield and better control of cheese weight. The filtration temperature and the application of heat treatment affect cheese making by altering the composition of milk as well as modifying its chemical properties. Since this process is a continuous one and that most of the cheeses produced are coagulated by chymosin (or rennet), an important parameter is the amount of time that it takes for the retentate to coagulate. The composition of the retentate can contribute significantly to rennet coagulation time and the filtration parameters can affect composition. For the third part of my thesis, I studied the effect of filtration temperature and heat treatment on the renneting properties of whole milk UF retentate. 


\section{0: Effect of Filtration Temperature and Heat Treatment on Composition of UF \\ Retentate}

\section{1: A Brief Introduction to Ultrafiltration}

Ultrafiltration is one of several membrane separation processes commonly used in the food processing industry. This process is usually run with liquid foods at various temperatures $\left(10-55^{\circ} \mathrm{C}\right)$, and pressures $(172-310 \mathrm{kPa})$. The primary functions of ultrafiltration are threefold: separation, clarification, and selective concentration. Ultrafiltration systems at these temperatures and pressures separate high molecular weight components from lower molecular weight components with the latter components permeating membranes along with water (McGregor, 1986). During ultrafiltration, a liquid feedstock flows directly across a membrane or molecular sieve.

According to a review of literature by van der Host and Hanemaaijer (1990), dead-end filtration(where the feed stream flows perpendicular to the membrane) is only economically feasible when applied to relatively clean feed streams (ones containing low solids levels). There are three factors that limit the capacity of a dead-end filtration system: the resistance due to the filter medium, the resistance due to the internal clogging of the filter itself, and to the build-up of a cake layer near the membrane surface. To keep constant capacity in the course of the filtration processing, the applied pressure to the membrane is increased. When the total resistance has reached a limited value, the membrane system is cleaned.

In cross flow filtration, there is a shearing effect on the feed that is flowing tangential across the membrane surface. This type of flow reduces the tendency for concentration polarization, adsorption of particles to the membrane and the formation of a "cake" layer near the surface of the membrane (van der Host and Hanemaaijer (1990)). 
In order to control fouling of the membrane, where the buildup near the membrane surface can cause irrepairable damage, it is necessary to develop membranes with high pore density, narrow pore size distribution, and an asymmetric morphology (van der Host and Hanemaaijer (1990)).

The retention of some components and the passage of others during direct ultrafiltration results in selective concentration. For example, in ultrafiltration, water and low molecular weight solutes such as lactose, soluble salts, and non-protein nitrogen (NPN) pass through the membrane under low pressure, producing a clear fluid known as permeate. Larger molecular weight components such as fat, true protein, and insoluble salts are retained in a decreasing pool of milk serum to give a liquid concentrate or retentate. The time, temperature, pressures, and flow rate depend on the nature of food and its condition, the membrane type, equipment design, and various dual or multiple interactions of food components (McGregor, 1986).

\subsubsection{Some Important Terminology}

Before getting into the details of the filtration system, some terminology must be presented. Since one of the functions of membrane separation is fractionation of components of a feed stream, the membrane displays semi-permeable (selectively permeable) characteristics. Semi- permeable means that the membrane allows some components to move through the membrane while the rest stays in the feed stream.

This concept of semi-permeability introduces two important end products of ultrafiltration: permeate and the retentate. Permeate is the portion of the feed stream that passes through the membrane pores. The portion of the feed that is rejected by the pores is known as the retentate (NIRD, 1985). One of the factors that determine the permeability of the membrane is molecular weight cut off (MWCO). The molecular weight cut off is a numerical representation of the semi- 
permeability of a membrane. A common molecular weight cut off for a polysulfone ultrafiltration membrane used in dairy processing is 10,000 Daltons. This means that all components under 10,000 Daltons should easily pass through the membrane pores while no components over 10,000 Daltons generally will pass through (NIRD, 1985).

Since one of the other functions of membrane separation is concentration, another important term commonly used is volume concentration ratio (VCR). VCR is a ratio of the total weight (volume) of the feed divided by the amount of feed in the retentate. VCR can also be determined based on the concentrations of various components that are to be retained.

The retention factor $(\mathrm{R})$ represents the amount of a component of a feed stream that is retained by the membrane and is represented by the equation $\mathbf{R}=(\mathbf{C f}-\mathbf{C p}) / \mathbf{C f}$. The retention factor was established for membranes to compromise between retention of solids and highest permeability (NIRD, 1985). Another term similar to retention factor is the rejection factor (Re). The rejection factor is used when the fraction of interest is permeate (as opposed to the retentate being the fraction of interest for the retention factor) and is expressed by the equation: $\mathbf{R e}=\mathbf{1 -}$ $\left(\mathbf{C p} / \mathbf{C}_{\mathbf{f}}\right)$. In both the retention factor and the rejection factor, $\mathrm{C}_{\mathrm{f}}$, which represents the concentration of a component in the feed stream and $\mathrm{Cp}$, is the concentrations of a component in permeate. There is a stipulation for using this term: it cannot be used directly in a multicomponent system where some of the feed components are completely retained by the membrane (e.g. fat and protein in the ultrafiltration of milk) (NIRD, 1985).

\subsubsection{Uses of Membrane Separation in Food Processing}

There is a wide variety of uses of ultrafiltration in the food industry. In the production of fruit juices, apple, pear, orange and grape juices can be effectively clarified without fining agents like pectinase. Other food industries, which use ultrafiltration, include wine making and animal 
protein isolation and processing (McGregor, 1986). The majority of this discussion will focus primarily on two specific dairy products: milk and whey.

Application of ultrafiltration on milk and milk products began early and many large installations are in operation throughout the world today. Milk products concentrated by ultrafiltration include whole milk, skim milk, whey and buttermilk. The primary goal is selective concentration. In milk, the presence of approximately $3.5 \%$ total protein and $4.0 \%$ fat make concentration more difficult than in most other food beverages because of increased concentration polarization and increased fouling. Milk processing is also subject to extremely strict sanitation regulations and the equipment must be designed with sanitation as the top priority (NIRD, 1985).

The ultrafiltration of skim and whole milk leads to retentate that are selectively concentrated and have an appearance of light to heavy cream. A clear, greenish-yellow permeate devoid of true protein is the other end product. Milk ultrafiltration is usually conducted at 52$54^{\circ} \mathrm{C}$ under an inlet pressure $172-310 \mathrm{kPa}$ in polysulfone membranes with a MWCO of about 10 20,000 daltons. Retentate from fresh milk are generally at pH 6.7 (McGregor, 1986). The viscosity (thickness) of the retentate drops at temperatures above $30^{\circ} \mathrm{C}$ or under high pumping velocities, but increase significantly with concentration. The rationale for this is as the temperature of a fluid is increased, thermal energy causes the molecules to move very fast, causing the fluid to become thinner and having faster flow rates. The same applies to higher pressure. The more pressure that you apply to the membrane, the more feed that the system is going to pump through the membrane. This increases the flow rate and the feed becomes thinner (less viscous). During the concentration step, the amount of solids increases due to the particulate matter being clumped closer to one another. Because of this, it will take more force to get the 
fluid to flow through the membrane. This increase in flow resistance makes the feed thicker (more viscous) (McGregor, 1986).

Standardization of milk components is one use of milk ultrafiltration. At the time of a study by Poulsen (1978), the only component of milk that had been standardized was fat via a centrifugal separator. The reason that standardization of protein in dairy products has not been feasible was that it was quite difficult to standardize the protein content of milk without severely affecting the concentration of other components and affecting the flavor (Poulsen, 1978). There are several reasons why protein contents in milk may need to be standardized (e.g. increased or decreased). These reasons include equalizing the seasonal and regional differences in protein content in milk for production of milk powder, cheese or even fluid milk, the fortification of milk with total milk proteins for increased nutritional value and for the production of total milk protein concentrates for specialty products. By using either ultrafiltration or reverse osmosis (RO), the protein content can be adjusted by altering the total solids non-fat or to carry out a specific adjustment of the protein (Puhan,1995).

Membrane filtration represents a relatively simple physical separation, which can be carried out at a sufficiently low temperature to avoid alterations in proteins and other heat sensitive constituents of the milk. According to a study by Poulson (1978), protein content can be adjusted within a broad range without detectable organoleptic defects.

Ultrafiltration can be used to tailor milk for cheese making. One of the problems is that there are high amounts of lactose and minerals present that affect buffering capacity and textural properties of the cheese. With the use of diafiltration, acidification, and heat treatment, the lactose and mineral content can be reduced (Sutherland and Jameson, 1981). According to a study by Vyas and Tong (2002), ultrafiltration can also be used to retain important minerals such 
as calcium by the use of $\mathrm{pH}$ adjustment and heat treatment, both of which strongly bind calcium to milk proteins, preventing permeation through the membrane.

Ultrafiltration retentate can also be used for ingredient substitution. As mentioned earlier, ultrafiltration can be used to standardize protein and fat contents in milk. The retentate can be used to standardize milk itself as a substitution for the use of dairy powders. According to a study by de Boer and Koenraads (1995), liquid retentate have been used in production of puddings, custards, and yogurt in Europe to substitute for skim milk powder. The primary reason for this is cost as the value of skim milk powder varies from country to country. The uses of these liquid retentate are limited by standards of identity for the products in each country and by some undesirable taste defects. However, pasteurization and homogenization of the retentate have been shown to improve sensory attributes and improve product quality.

Ultrafiltration milk retentate can be used as feed stream for making milk powders. By adjusting the pore size and the molecular weight cut-off (MWCO), different proteins can be separated and fractionated from the liquid concentrate and then spray dried (Novak, 1995). Pretreatments such as acidification or heat treatment can be used to assist in separation.

Composition of the powders can also be modified by the use of a membrane separation process before spray drying. However, the functionality of the powder can be affected by fractionation or any feed treatment. Gelation, foaming ability and emulsion stability are all effected by the way that the powder is produced (Harper, 1995).

\subsection{3: Types of Membranes}

The primary component of an ultrafiltration system is the membrane. The membranes have a thin surface layer, or skin, where permeation occurs. Most membranes have an open, 
porous interior or backing to support the surface skin. Originally, the membrane was made of cellulose acetate. Complex polymers, designed as thin film composites supported on polysulfone membranes have been replacing cellulose acetate membranes. Cellulose acetate membranes are sensitive to temperature extremes, $\mathrm{pH}$ and chlorine concentration. As a result of these limitations, time-consuming cleaning procedures are required, with strict limitations set on $\mathrm{pH}$, temperature, and chlorine concentration. Polysulfone membranes are relatively insensitive to these parameters, show more satisfactory concentration polarization levels, and higher permeate flux rates (time required to concentrate a food product to a certain level) (McGregor, 1986).

The next generation of ultrafiltration membranes is a metallic one, made of zirconium oxide, with improved qualities over polysulfone. These membranes are capable of operating over the complete $\mathrm{pH}$ scale and up to $400^{\circ} \mathrm{C}$ and 40 bars (580 psig) (McGregor, 1986). Currently, these membranes are used outside the food industry but are appearing now, and again in cheese making plants.

When used for milk processing, effective cleaning of membranes is important. Membranes are designed in numerous configurations. Some forms include flat sheet and plate, spiral wound and hollow fiber (McGregor, 1986). A spiral wound membrane is one where the membrane material is simply wound up very tightly into a tube and is held together by an adhesive. A hollow fiber membrane is when the feed flows through hollow tubes. These tubes are normally polysulfone. Flat sheet and plate membranes are ones where a sheet is membrane material is placed on to a backing (plate) and the permeate goes through the membrane into the plate (McGregor, 1986). 


\subsection{4: Membrane Filtration System Designs}

There are three system designs used in the ultrafiltration of liquid food: single-pass, batch, or continuous. In a single-pass system, product is concentrated in a single movement through the membrane (a factor limiting the achievement of high concentrations) (McGregor, 1986). The batch system involves the recycling of product until the desired concentration is attained. In the mean time, permeate is collected in a separate tank. In order to achieve a high concentration, there is long residence time of retentate in the storage tank. One must be cautious because this can lead to an increase in microbial load (McGregor, 1986). The continuous system involves a modular concept combined with recycling. In this method, retentate moves into a first module and, prior to entering other modules, is bypassed into a loop where individual pumps raise the pressure before it moves into succeeding modules. The constant pressure maintains high flux. Modules are arranged in series or in parallel formation, and the retentate becomes concentrated to high levels as it moves through the system, with minimum residence time (McGregor, 1986).

\subsection{5: Modifications to Ultrafiltration Procedure}

The ultrafiltration procedure has two modifications: diafiltration and simultaneous fermentation. Diafiltration is the controlled addition of water to the retentate during ultrafiltration, either in a continuous or step-wise cycle. This application removes lower molecular weight components. For example, water applied to the retentate washes out lactose and additional salts. The amount of water used usually equals the amount of permeate removed, but specific amounts depend on the degree of purification sought (McGregor, 1986).

Simultaneous fermentation is a practice common in ultrafiltration of milk to lower calcium levels and reduce the buffering capacity of retentate. Temperatures are temporarily 
adjusted for optimum lactic acid bacterial growth, usually $30^{\circ} \mathrm{C}$. Next, a $1 \%$ inoculum of a starter culture containing lactic acid bacteria is introduced into the feedstock. Ultrafiltration continues until the $\mathrm{pH}$ (initially 6.6) declines to a predetermined level, but not low enough to coagulate the milk (McGregor, 1986). To maintain a safety margin, the pre-determined $\mathrm{pH}$ level is 5.5 or above. Once the desired $\mathrm{pH}$ is reached, the processing temperature is raised to a normal range, $52-54^{\circ} \mathrm{C}$, where most lactic acid bacteria do not grow. Ultrafiltration is continued until the desired concentration is reached (McGregor, 1986). This procedure solubilizes calcium but may also lead to higher levels of dormant bacteria in the final product. These bacteria autolyze and provide active microbial enzymes which may accelerate flavor development in ripened cheese (McGregor, 1986).

\subsection{6: Critical Indicators of Performance}

In membrane separation of foods, critical performance indexes of performance include flux, retention efficiency, product yield, stability, and quality. Product flux is influenced by the membrane material and condition, temperature, flow velocity, concentration, and to a small extent, pressure. Abnormal amounts of fibers, proteins, and salts collecting on or embedded in membranes decrease flux and operational efficiency. Flux levels are returned to normal by proper cleaning procedures. The retention efficiency of solutes greatly depends on the proper selection and condition of the membranes. Problems are often avoided by periodic inspections and replacement of highly used membranes. The normal life span of membranes that are used daily is 12-18 months. Product yields depend on loss of solids through excessive permeation and through careless handling of food before, during, and after membrane separation. Yield is increased by proper choice of membranes, rejection of damaged membranes, and the careful collection of food material. The stability and quality of product undergoing membrane 
separation are aimed at retaining original flavor, texture and color (McGregor, 1986).

\subsection{7: Technical Information on Flux}

Of all the critical parameters, flux is the most important. Flux is defined as the rate of permeate flow across a unit area of membrane. The units for flux are $1 / \mathrm{m}^{2} / \mathrm{h}$ or the flow rate divided by the surface area of the membrane. Several factors affect the flux rate of membrane. First is the rate that the feed is fed into the system (or the pump speed). The faster the pump speed, the higher the flux and vice versa (NIRD, 1985). According to a study by Belfort (1984), high fluid turbulence and high wall shear act to scour the membrane surfaces and minimize accumulation of solute near the membrane. However, after time, the flux begins to decrease and a buildup layer of concentrated matter (a phenomenon known as concentration polarization) develops which could lead to a critical problem known as fouling. Fouling can cause damage to the membrane. However, concentration polarization can lead to detrimental fouling of membrane only if proper sanitation procedures are not withheld.

Critical flux is achieved when particle transport away from the membrane wall is balanced by particles moving towards the wall. Therefore, no deposit is formed on the surface and irreversible fouling is negligible. Particle transport away from the membrane is therefore very important. Cross flow, velocity is an important hydrodynamic factor involved with these mechanisms. There are two forms of critical flux. The 'strong' form of critical flux exists if the flux of the suspension is identical to the flux of clean water at the same transmembrane pressure (Youravong et al., 2002). The 'weak' form exists if the relationship between flux and transmembrane pressure is linear. The strong form of critical flux was obtained if feed particle size was much greater than the molecular weight cut off of the membrane, thus internal fouling is not expected (Youravong et al., 2002). 
For both whey protein concentrate and sodium caseinate suspensions, it is possible that irreversible fouling, reversible fouling, and concentration polarization were responsible from flux deviation from water flux. It is probable that increase flux above the critical flux leads to an increase in thickness of the concentration polarization layer and particle deposit layer and thus flux approaches limiting flux, where permeate flux is controlled by the rate of back transportation. Since the particle size of the caseinate is much larger than that of whey protein, the rate of back transport would also be expected to be higher (Wu et al., 1999).

Composition of the feed also has an effect on flux. According to a study by Barbano et al. (1989), in the ultrafiltration of milk, a unit change in protein percentage had the greatest influence on flux rate followed by lactose and milk fat. According to the same study, seasonal variation in composition had an effect. In fall and winter, when both fat and protein are high, flux will be the highest. In summer, when fat and protein percentages are low, the opposite effect is true.

Other properties that affect flux rates include $\mathrm{pH}$, feed viscosity, calcium solubility, protein charge, and solubility. According to a study by Rao et al. (1994), reducing the $\mathrm{pH}$ to 5.0 and lower gave large increases in viscosity, which may have resulted from proteins becoming more unstable at low $\mathrm{pH}$ and eventually precipitating close to their isoelectric point. Jelen (1979) also noticed that adjusting the pH values to higher (e.g. 8.0) also resulted in increased viscosity, which may have resulted from a higher proportion of bound calcium. As the ultrafiltration process continues, the feed becomes more and more concentrated.

According to a study by Tong et al. (1988), flux decline during the ultrafiltration of whole milk occurs in two stages: a severe flux decline due to adsorption to the membrane in the beginning followed by a gradual decline due to concentration polarization. Howell et al. (1981) 
suggested that flux decline during ultrafiltration of protein solutions resulted initially from a build up of protein at the membrane surface due to concentration polarization. As the concentration proceeded, the viscosity (resistance to flow) increased and at a certain concentration, the protein formed a gel on the surface, which restricted permeate flow even further.

According to Fane (1986), the build up near the membrane (concentration polarization) is reversible with proper sanitation procedures. The proportion of calcium associated with the micelle was responsible for the strength of the concentration polarization layer during ultrafiltation of milk (Kessler et al., 1982). According to a previous study with buttermilk when the $\mathrm{pH}$ of buttermilk was reduced, a lower proportion of micellar calcium would lead to a weaker concentration polarization layer and a higher initial flux (MacGregor, 1986). In sweet whey, which has a lower protein concentration of protein than buttermilk and no casein micelles, the effect of concentration polarization on initial flux is much lower and the effect of calcium distribution on strength of concentration polarization layer would be much less significant than in buttermilk (MacGregor, 1986).

The increase in initial flux at higher $\mathrm{pH}$ in sweet whey could be due to changes in the status of whey proteins. For example, $\alpha$-lactalbumin exists as octomers at $\mathrm{pH} 3.5-5.2$ but dissociates into monomers under alkaline conditions (Nillson, 1990). The more rapid decline in flux indicated a higher degree of fouling at higher $\mathrm{pH}$ levels of sweet whey. It is important to remember that whole milk and skim milk have much different flux declines than whey products (either sweet or acid). It was hypothesized that the higher concentration of casein plays a role in flux decline during ultrafiltration of milk (Rao et al., 1994). According to Tong et al. (1988), the deposit formed by the ultrafiltration of whole milk was due to the presence of $\beta$-lactoglobulin 
and $\alpha$-lactalbumin but not casein. Koutake et al. (1992) found that during ultrafiltration of skimmed milk that resistance caused by adsorption fouling was greatest and that caused by surface deposition was slight.

An alternative explanation for the lower initial fluxes in milk could be that colloidial calcium caseinate might have formed a concentration-polarized layer as soon as ultrafiltration began, causing almost instantaneous flux reduction. In whey products, calcium caseinate levels are almost negligible. In whey products, when casein is absent, $\beta$-lactoglobulin and $\alpha$ lactalbumin along with soluble calcium phosphate were responsible for long-term flux decline. Merin and Cheryan (1980) found that for whey proteins, $\alpha$-lactalbumin had the strongest gel forming tendencies and that $\beta$-lactoglobulin produced the worst long-term fouling effects during ultrafiltration of cottage cheese whey. In sweet whey, it was found that glyco-macropeptides arising from the action of chymosin on $\kappa$-casein act as a major membrane foulant (Hickey et al., 1980).

Most of the calcium in whey is soluble. It is possible that this calcium phosphate precipitates out within the pores of the membrane to cause flux decline. Calcium also tends to produce considerable hardening of the deposited protein layer (Merin and Cheryan, 1980). However, crystallization of amorphous calcium phosphate may be prevented by crystallization inhibitory substances such as peptides (Nelson et al., 1989). These results suggest that the type of soluble constituents in the feed determined the nature of the flux decline in milk and whey. A higher proportion of soluble constituents such as whey proteins and soluble calcium give rise to a type of fouling characterized by deposit formation, adsorption, and pore plugging whereas a higher proportion of relatively insoluble and bound micellar caseinate promoted flux reduction, mostly due to a concentration polarization layer strengthened by calcium (Rao et al., 1994). 


\subsection{8: Chemical Aspects of Fouling}

Fouling is caused primarily by the build-up of protein and minerals at the membrane surface. Protein deposition is known to play an important role in fouling. Protein composition also has an effect on fouling. Casein is the predominant protein in this layer (Lee and Merson, 1975). However, Lee and Merson (1975) also observed BSA and $\beta$-lactoglobulin formed protein sheets on the surface of the membrane, especially near the entrance to the pores. In further research, Lee and Merson also discovered that large components (microorganisms, globulins and protein polymer complexes) bind together to form lattice-like structures on the surface of the membrane. The spaces in the lattice network are then filled with smaller proteins, which are trapped to form to form a second "protein membrane". With protein-based solutions such as milk, the range of pore sizes where plugging occurs is affected by more than just steric effects, as is commonly believed. Once a surface layer is formed, the selectivity of the membrane is dominated by the surface layer, regardless of the original pore sizes.

Protein build-up on the membrane occurs by adsorption. Protein-membrane interactions are usually irreversible. Norde (1986) stated, "Protein adsorption is an irreversible process and is usually entropically driven by the structural arrangements of the absorbed protein molecules". Binding occurs in several steps including charge redistribution in the overlapping electrical double layers of the protein and solid surface, dehydration of the solid surface and protein, and structural rearrangement of the absorbed protein molecules. Protein adsorption is influenced by membrane hydrophobicity and charge influence protein adsorption (Norde, 1986).

In order to discuss hydrophobicity as a factor for protein adsorption, we must discuss a very important chemical aspect: the hydrogen bond. Water molecules form hydrogen bonds, both with themselves and hydrophilic surfaces. The introduction of another surface or molecule, 
especially a hydrophobic one, disrupts the organized structure and is energetically unfavorable. An entropy gain can be obtained if contact with hydrophobic components can be minimized and this gives rise to strong attractive hydrophobic interactions. This type of interactions occurs between proteins, which contain hydrophobic groups, and membranes that are hydrophobic, such as polysulfone (Marshall and Daufin, 1995).

Many studies have shown that it would seem logical that less protein fouling and higher permeate flux rates would occur on a hydrophilic membrane. Sheldon et al. (1991) have shown that the tertiary structure of protein is disrupted on a polysulfone membrane (hydrophobic) but not a cellulose acetate membrane (hydrophilic). In spite of these results, commercial hydrophilic polymer membranes do not foul less than hydrophobic ones (van der Horst and Hanemaajier, 1990), indicating that hydrophobicity is not the only factor involved in protein fouling. It has also been observed that, where concentration polarization and protein deposition are high, the effect of hydrophobicity is masked (Rolchigo et al., 1989).

Ionic interactions play the other important role in protein fouling. Except at their iseoelectric point, all proteins carry a charge. If both the membrane and the protein have similar charge, there will be an electrostatic repulsion. Likewise, if they have opposite charge there will be an attraction. Operation with a membrane with the same charge as the protein has been shown to improve flux (Nystrom and Lindstrom, 1988). According to Nystrom (1989), due to confusing and complicated discrepancies in the results, it is not possible to explain differences in membrane fouling by electrostatic interactions by protein and membrane alone. It would appear that charge on the protein, rather than the difference in charge between membrane and protein, determines the degree of protein deposition (Marshall and Daufin, 1995). Further analysis by electron microscopy, Le and Howell (1983), discovered that membrane fouling by protein occurs 
in two parts: physical adsorption in a monolayer followed by further protein build-up via intermolecular disulfide bonding and hydrophobic interactions.

McDonogh et al. (1990), found that by vary cross-flow conditions, they were able to distinguish between protein strongly bound to the membrane (not removed by flushing), protein loosely bound to the membrane (removed by scrubbing) and protein dynamically bound to or in concentration polarization layer (removed by flushing). The largest quantity of protein was associated with the membrane, in both dynamic and loose association with the membrane at the isoelectric point. Flux was also the lowest at these electrostatic conditions. Well away from the isoelectric point in either direction, there was the least dynamically and loosely held protein, but more that is strongly associated with the membrane. Thus, it appears that permeate flux is dominated by protein that is loosely or dynamically bound rather than by protein adsorbed to the membrane, where charge or hydrophobic effects might influence the strength of the proteinmembrane interaction (Marshall and Daufin, 1995).

\subsection{9: Chemical Pre-Treatments to Prevent Fouling}

Since the membrane is the most significant piece of equipment in the filtration system, the design must be in such a way to prevent membrane fouling. An efficient strategy to prevent long-term fouling must include options for pre-treatment of the feed. Since the primary purpose of pre-treatment is to inactive the chemical components of fouling, physico-chemical properties must be understood. The compositional factors, which induce fouling, can be divided into two categories: residues from upstream processing and unstable reactive physico-chemical systems (calcium phosphate salts, ionic calcium, and soluble caseins) (Pouliot and Jelen, 1995).

There are wide varieties of physical and chemical pre-treatments used in ultrafiltration. Some physical pre-treatments include pre-filtration, centrifugation, and heat treatment. These 
treatments remove casein fines, residual fat, bacteria, calcium, and phosphorous compounds, respectively (Pouliot and Jelen, 1995). The chemical pre-treatments used to minimize long-term fouling include $\mathrm{pH}$ adjustment, sequestering of calcium, and increasing the ionic strength. The $\mathrm{pH}$ adjustment controls the solubility of calcium phosphate, controls the level of ionic calcium, and controls the solubility of whey proteins. Many studies with whey have shown that permeate flux is lowest at the isoelectric point and increases as the $\mathrm{pH}$ is adjusted on either side of the isoelectric point (Muller et al., 1973; Hayes et al. 1974). The decrease in flux at the isoelectric point is generally attributed to increased deposition of protein or changes in the porosity of the membrane. According to Fane et al. (1983), the protein molecule (e.g. BSA) is in its most compact state and has no charge at the isoelectric point, thus providing the least permeable deposited layer. Away from the isoelectric point, the BSA molecule acquires significant net charge and enlarges due to electrostatic repulsion. The use of a sequestering agent such as EDTA lowers the level of ionic calcium and solubilizes calcium phosphate salts (Pouliot and Jelen, 1995). This is a very significant treatment effect because calcium causes fouling and any addition of calcium will contribute to a considerable decrease in flux rate. Kessler et al. (1982) suggested that the addition of calcium resulted in hardening of the fouling layer due to the changes in the structure of the casein micelles in order to create a partial network between the individual casein micelles. Vetier et al. (1988) elaborated further by concluding that the most important role of calcium and phosphate salts present in the soluble phase of milk is to act as cement between micelles and the membrane and the micelles themselves.

Increasing the ionic strength has the same effects as a sequestering agent on inhibition of fouling. Alterations in ionic strength have been shown to effect the quantity of protein deposited and the permeate flux. Fane et al. (1983) concluded that, at the isoelectric point (IEP) in the 
presence of ions, anion binding leads to an increase in the size of the proteins, thus increasing the porosity of the deposited layer. Away from the isoelectric point, added salts tend to reduce electrostatic repulsion by shielding charges, causing molecular contraction and thereby decreasing permeability. According to the results by Palacek et al. (1993), protein layer permeability is determined by the balance between the compressive pressure associated with filtration and the electrostatic repulsion between the negatively charged proteins in the deposit.

In industrial practice, the decision making process for the selection of a suitable pretreatment will be simplified by extraneous factors. First, and foremost, most of the commercial equipment for membrane separation will be offered with an integrated pre-filter since membrane manufacturers want to ensure optimum performance of their product (Pouliot and Jelen, 1995). Second, most of the suppliers of membrane systems can provide some technical guidelines to their users resulting in optimum processing performance of the membrane for a given product or product category. Naturally, lack of availability of suitable industrial equipment may limit the feasibility of various pre-treatments. The compositional factors should be examined sequentially starting from the physical phenomena (e.g. coarse vs. fine particles), followed by chemical aspects of complex systems (e.g. salt balance) (Pouliot and Jelen, 1995).

The feed is not the only component that can be pre-treated prior to processing. In order to decrease membrane fouling via protein absorption, membranes can be modified by physical and/or chemical modification. Several studies have shown that adsorption of surface active solutes to the membrane surface prior to filtering improves the properties of the membrane with respect to fouling (Brink et al., 1990). Specific examples have shown that immobilized food grade proteinases on the membrane can decrease fouling rate (Le and Howell, 1983), and flux recovery was improved by polyethylene glycol. Non-ionic coatings lead to a decrease in protein 
adsorption and a decrease in flux decline. Ionic coatings lead to increase in protein adsorption and fouling. The performance of treated membranes appears to be affected by molecular configuration and size of the polymer as well as the interfacial structure. Due to the fact that non-ionic coatings are preferred to ionic coatings, the conclusion can be made that electrostatic interactions are important in protein adsorption and that prevention of interactions prevents adsorption (Brink et al., 1993; Nystrom, 1989). Protein adsoption to the membrane is partly prevented by sealing the pores off by polymer molecules presorbed at the membrane surface. For example, coating the membrane with PVME decreased protein fouling during ultrafiltration compared to untreated membranes. In order to obtain a membrane that actually improves flux after coating, it is very important to pay attention to the molecular wt. of the coating/pore size ratio (van der Horst, 1995). At high ratios, the increase in resistance caused by the coating is more than the increases caused by the fouling proteins. At low ratios, the shielding of the pore is insufficient to prevent proteins from entering the pores. A lot of research has studied the efficacy of polymer coatings in reducing membrane fouling. As a result, several manufacturers developed "hydrophilic" UF-membranes. The flux of water and whey increased compared to unmodified membranes.

Unfortunately, fouling decreases rejection of protein along with reduction of protein flux. Therefore, to obtain desirable protein rejection levels and flux levels, the membrane should not only have small pore sizes as well as a greater pore density (van der Horst, 1995).

Other parameters that affect flux and fouling rate are cross-flow velocity (CFV) and transmembrane pressure. According to a study by Vyas et al. (2000), the increase in steady state flux with increase in cross-flow velocity is due to the thinner cake (layer) formation as a result of higher forces carrying particles away from the membrane under high velocity. Observed 
changes in surface fouling and cake mass confirmed this theory. Time and transmembrane pressure also affect steady state flux. Under constant transmembrane pressure at constant crossflow velocity, the forces on the particles acting toward the membrane surface decrease with time due to membrane fouling. Depending on the level of cross-flow velocity, the forces moving toward the membrane and away from the membrane reach an equilibrium at a certain level of fouling where steady state flux is obtained. Thus, at higher cross-flow velocity, there is less fouling at steady state and, therefore, takes less time to reach steady state flux.

One method of increasing the pore size is by UV-Irradiation of the membrane. This method was previously tested on a polysulfone membrane (van der Horst, 1995). The pore size increased due to the formation of carboxylic and sulfonic acid groups on the membrane, which caused an increase in the internal repulsion of the pores. This led to a decrease in flux due to pore blocking by the macromolecules. The high level of protein rejection levels can be explained by the electrostatic repulsion of negatively charged proteins and the negatively charged modified membrane, thus enlarging the pores and preventing the passage of the proteins (Nystrom, 1989). A direct relationship was found between irradiation time and permeability. Results have shown that only when flux increased over $25 \mathrm{~kg} / \mathrm{m}^{2} / \mathrm{h}$, thus creating large pores, was there a decrease in protein rejection. The improvement of whey permeate flux started after 10 minutes and increased to $110-150 \%$ of the permeate flux for an untreated membrane with only a slight loss in rejection (van der Horst, 1995).

According to Vyas et al. (2000), steady state flux increased with increasing transmembrane pressure and reached a critical point at $100 \mathrm{kPa}$. This is the result of the equilibrium between increase in flux force and increase in fouling (Matsumoto, Kawahara and Ohya, 1988), and overall fouling resistance, reversible fouling and irreversible fouling increased 
linearly with transmembrane pressure. Cake height and mass increased with increase in transmembrane pressure but there was no significant difference in porosity. Cake particle size also increased with increase in transmembrane pressure above $50 \mathrm{kPa}$. A higher initial flux but faster decline in flux was observed at higher transmembrane pressure. This behavior has been a common occurance in cross-flow microfiltration (CFMF) and is due to the higher driving forces of particles toward the membrane at higher transmembrane pressure. The increase in irreversible fouling with increasing transmembrane pressure can attribute to better penetration of small particles at these higher pressures. The increase in cake mass and cake height is due to the increased driving force toward the membrane at higher transmembrane pressure. Although the cake particle size distribution (PSD) was different for different transmembrane pressure, there was no significant effect on cake packing. However, there was a significant effect of transmembrane pressure on particle size distribution in the range of 50-100 $\mathrm{kPa}$. Increasing the pressure did not cause a change in the forces toward the membrane enough to cause a change in cake particle size distribution. This could be due to additional forces acting towards the membrane, namely the adhesive for holding the membrane together.

\subsubsection{0: Effect of processing temperature on composition}

The temperature range for membrane processing via UF is $10-55^{\circ} \mathrm{C}$. There are numerous papers in the literature on the effect of processing temperature on retentate composition. However, most of these papers use temperatures in the higher range of the temperature scale. (e.g. $\left.50-55^{\circ} \mathrm{C}\right)$ However, very few papers have explored the composition of retentate at low temperatures. According to Pompei et al. (1973), low temperatures allow satisfactory control of microbial growth without denaturation of proteins, but result in very low permeation rates, especially at high concentrations. This effect is due to the increase in viscosity that enhances the 
concentration polarization phenomena at the membrane-solution interface. This is in concurrence with Rash (1976), who observed that since viscosity is inversely proportional to temperature and directly proportional to feed concentration, an increase in viscosity of the milk increases the thickness of the laminar layer and, hence, increases deposit formation. According to Breslav and Kilcullen (1977), decreasing the temperature (and subsequently increasing the viscosity), results in a flux decrease averaging $3 \%$ per ${ }^{\circ} \mathrm{C}$. Thus, if the use of lower temperatures is to control microbial growth during ultrafiltration of skim milk, it is important to compensate for loss in flux rates. According to Kapsimalis and Zall (1981), it was hypothesized that permeation rate could be increased by using larger pore cellulose acetate membranes for ultrafiltration of skim milk at refrigerated temperatures. Large pore membranes might compensate for the decreased permeation flux by increased boundary resistance and viscosity. According to Kapsimalis and Zall (1981), microbial counts were reduced in lower temperature $\left(15^{\circ} \mathrm{C}\right)$ than at normal temperatures $\left(50^{\circ} \mathrm{C}\right)$. This indicates that refrigerated temperatures essentially controlled microbial growth during 4-hour ultrafiltration runs. Permeation flux rates were almost four times as greater at $45^{\circ} \mathrm{C}$ than at $15^{\circ} \mathrm{C}$, regardless of pore size. This suggests that increasing pore size to increase flux rate is not a feasible idea. Permeates obtained at $45^{\circ} \mathrm{C}$ were cloudy in appearance compared to permeate obtained at $15^{\circ} \mathrm{C}$ using large pore membranes. The cloudy appearance may be colloidial particles of sufficient size to scatter visible light, probably protein molecules, or colloidal calcium phosphate. The higher conductivities and total solids of the permeates indicate that more solutes and solutes of higher molecular weight passed through Ultrafiltration membranes at $45^{\circ} \mathrm{C}$ than at $15^{\circ} \mathrm{C}$. This suggests that temperature of the feed may alter the membranes configuration in such a way that the effective molecular weight cut-off is changed, alter the grouping of the molecules, or affect material deposit formations on 
the membrane accumulated during ultrafiltration. At lower temperatures, membranes trend to be tighter, prohibiting the passage of particles with higher molecular weight. In terms of flux inhibition, Carroll et al. (1967), observed at lower temperatures, some of the $\beta$-casein readily dissociates from the casein micelle and enters the serum phase with $\kappa$-and $\alpha$-casein together. These results correlate with a study by Lee and Merson (1975), who showed that the major deposit on membranes in ultrafiltration of skim milk was casein micelles linked by bridges to form a lattice. They also reported that chemical analysis of these deposits confirmed that they contained high casein content and that calcium phosphate had precipitated in the deposit throughout the membrane. Temperatures in the range of $50-55^{\circ} \mathrm{C}$ are relatively safe for both proteins and membranes and have been used extensively in ultrafiltration of milk and whey (Maubois and Mocquot, 1971). However, at these temperatures, thermophilic bacteria may grow and therefore time of operation must be limited (Pompei et al., 1973).

Filtration temperature affects the composition of the milk due to changes in the chemistry of milk's most complex component: the casein micelle. The casein micelle is a complex molecule of milk's two major proteins: casein and whey held together by van der Waals and hydrodynamic forces as well as by salt bridges of calcium phosphate. As the temperature of the milk increases, the calcium goes from ionic form (in serum) to a colloidial form (bound to protein). This causes an increase in the retention of calcium in the retentate (Bastian et al., 1991). If the temperature is high, there is significant thermal denaturation of whey proteins, which can either bind to the casein micelle or bind with other proteins. Denaturation can also lead to increased levels of these proteins. The $\mathrm{pH}$ can also be affected by filtration temperature. As the temperature of milk increases, the $\mathrm{pH}$ increases by the removal of $\mathrm{CO}_{2}$. This effect is counteracted upon heat treatment by hydrogen ions liberated by the insolubilization of the 
calcium and the phosphate. In some cases, these two opposing factors so nearly counterbalance each other so that there is no net change in $\mathrm{pH}$.

When milk is cooled, the opposite effects occur. The calcium goes from colloidial to serum form caused by the dissociation from the micelle. Therefore, there should be lower levels of calcium in the retentate. Since there is little or no opportunity for denaturation, there should be lower levels of whey proteins in the retentate (Walstra et al., 1999).

\subsubsection{1: Rationale and Objectives}

Ultrafiltration of fluid milk is commonly run at temperatures of $50-55^{\circ} \mathrm{C}$ and there have been studies of the composition of retentate at these temperatures. However, dairy processing plants are starting run ultrafiltration at refrigeration temperatures $\left(10^{\circ} \mathrm{C}\right.$ and lower). There are fewer studies of composition of retentate at these temperatures. The milk feed streams for ultrafiltration can be run as raw or pasteurized whole milk. However, I have not read any literature, which study the effect of the time of pasteurization during the process (before or after the filtration process). Due to chemistry of the casein micelle, there are likely to be some compositional differences due to filtration temperature and the application of a pasteurization step. These processing parameters can lead to differences in composition that may be crucial to the production of various dairy products. Therefore, the purpose of this experiment is to study the effect of filtration temperature, heat treatment and the point in the process where the heat treatment is applied (i.e., before ultrafiltration or after ultrafiltration) on the composition of whole milk ultrafiltration retentate.

\section{2: Methodology}

Pilot Trial Procedure Summary

Milk for processing was collected from the University Creamery at the Cal Poly State 
University, San Luis Obispo. See figure 2.13 for flow diagram. 30-gallon lots of milk were collected and processed four days a week for a two week period, each day using a different filtration temperature/heat treatment combination. The four combinations used were as follows: cold filtration/no heat treatment $(\mathrm{CF} / \mathrm{Raw})$, cold filtration/milk pasteurized before filtration (CF/PB), cold filtration/milk pasteurized after filtration (CF/PA) and hot filtration/milk pasteurized before $\mathrm{UF}(\mathrm{HF} / \mathrm{PB})$. The heat treatment applied was a batch pasteurization treatment of $63^{\circ} \mathrm{C}$ for 30 minutes. (See figure 2.12 for photo of system) The filtration unit consists of a single module membrane system with a polysulfone membrane with a molecular weight cut-off of 10,000 Da. (see figure 2.11 for picture of system). The volume concentration factor used was $3 \mathrm{X}$ based on the amount (lbs.) of milk used. Cold filtration was run at $10^{\circ} \mathrm{C}$ and hot filtration was run at $50^{\circ} \mathrm{C}$. There was an increase in filtration temperature during processing caused by heat from running the equipment. The temperature can be maintained by putting cold water across the membrane until temperature was reached. This was only an issue during hot filtration where it is necessary to keep the temperature across the membrane below $60^{\circ} \mathrm{C}$. The pasteurization procedure was performed using a PMS mini-food processor. All filtration and pasteurization procedures were run in the pilot plant at the Cal Poly Dairy Products Technology Center under the guidance of Mr. Jerry Mattas. The methodologies used for the compositional analysis were run at the Dairy Products Technology Center and under the guidance of Mr. Sean Vink. Dr. Albert Censullo of the Dept. of Chemistry and Biochemistry also assisted me with compositional analysis. Each combination of filtration temperature/heat treatment was performed in duplicate. Each analytical test was performed in triplicate per set of pilot trials. Statistical analysis was run using Minitab Version 13 Statistical software using a General Linear Model of a two-way ANOVA with Tukey's Pairwise Comparisons. The two factors used were 
filtration temperature/heat treatment combinations and week of processing (1 and 2). See Appendix B for MINITAB Printouts. The milk samples were standardized to $24.75 \%$ for further testing. The compositional data will be presented as a percent retained value. Since all these measurements are determined in percentage values, to better demonstrate the retention characteristics, I converted the percentage values to concentration in grams of component per lbs. of either permeate or retentate. Then I multiplied this value by the number of lbs. of retentate or permeate to get the number of grams of each component in the retentate and permeate. The percent retained was calculated as the weight of a component (in grams) divided by the total amount of the component (in both the retentate and permeate), also in grams and multiplied by 100 .

\section{Compositional Analysis of the Retentate}

Fat content was determined using the Mojonnier Method as mentioned in the Standard Methods for the Examination of Dairy Products (Marshall, 1992). The retentate samples were diluted 1:1 with DI water prior to analysis. The test was repeated in duplicate for each sample for both sets of pilot trials.

Ash content was determined by incineration of 5+/-0.01 grams of retentate that is diluted 1:1 with DI water in a ceramic crucible. The weight of the sample was recorded for use in the ash content calculation. The crucibles were placed in a dry air oven at $105^{\circ} \mathrm{C}$ for 5 hours to dry the sample. The crucibles were placed in an incinerator oven at $550^{\circ} \mathrm{C}$ for 20 hours. After this time, the crucibles were placed in a dessicator to cool for approximately 30 minutes. The crucibles were weighed and the weights were recorded. The \% Ash in the sample is calculated by the following equation: 


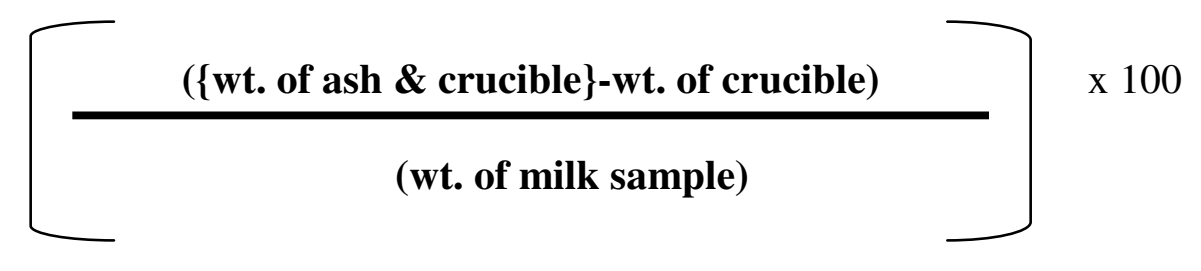

Total Solids were determined using a CEM Lab Wave 9000 total Solids Analyzer. Retentate samples were diluted 1:1 with DI water prior to measurement. The scale in the oven was tared using sample weighing pads and 3.5 to 4.0 grams of sample was applied to the pads in a snake-like motion and carefully placed onto the base inside the oven and covered. The analysis was run $100 \%$ power for 4 minutes. The oven automatically calculated the $\%$ Total solids.

Calcium content was measured using an IL 551 Atomic Absorption Spectrophotometer under the guidance of Dr. Albert Censullo of the Department of Chemistry and Biochemistry. The samples were diluted 1:500 with a solution of 0.1\% lanthanum nitrate in DI water. A 1000 ppm Ca stock solution was created by diluting $\mathrm{CaCO}_{3}$ into a $0.1 \%$ lanthanum nitrate in DI water solution. From this stock solution, standards of 1, 2, 5 and $10 \mathrm{ppm} \mathrm{Ca}$ were created. These standards were used to create a standard curve used to calculate the concentration of $\mathrm{Ca}$. Ionic calcium was also determined via Atomic Absorption except that there are 2 centrifugation steps: one at $4000 \mathrm{rpm}$ for 20 minutes at $20^{\circ} \mathrm{C}$ to skim the milk sample using an Eppendorf Centrifuge 5810R. Another centrifugation step occurred at 25,000 rpm for 90 minutes at $20^{\circ} \mathrm{C}$ using a Beckman L7-35 ultracentrifuge. The supernatant attained represents the ionic Ca. The supernatant was diluted 1:500 in a 0.1\% lanthanum nitrate in DI water solution. The same standards and standard curve were used to calculate ionic calcium concentration (Udabage et al., 2001).

The $\mathrm{pH}$ values were determined with a properly calibrated $\mathrm{pH}$ meter (Orion Model 410) using reference standards of $\mathrm{pH} 4$ and 7. The $\mathrm{pH}$ values were measured at $30^{\circ} \mathrm{C}$. The $\mathrm{pH}$ values 
were recorded in duplicate for each retentate for both sets of pilot trials.

Total Nitrogen, non-protein nitrogen and non-casein nitrogen were all determined by the Kjehldahl Method using AOAC Methods 991.20 and 991.21 for total nitrogen and non-protein nitrogen, respectively. Non-Casein Nitrogen was determined using the International Dairy Federation (IDF) method (International Dairy Federation, 1964). From these results, the true protein nitrogen, casein nitrogen and whey protein nitrogen values for the retentate were determined.

\section{3: Results and Discussion}

The results of the study are summarized in Table 2.1, 2.2 and 2.3 and Figures 2.1 through 2.10. The error bars on these figures represent a $95 \%$ confidence interval for the data points. The letters $a, b$ and $c$ are used to represent whether or not a significant difference exists between two results. Two results that have the same letter (e.g., both have the letter a), are not significantly different from one another. On the other hand, if two results have two different letters (i.e., one has a letter a, and another has the letter b), the results are significantly different from one another. The p-value is used to indicate whether a significant difference exists at all. Since I used the $\alpha$-value of 0.05 , any p-value that is less than 0.05 indicates a significant difference exists. The opposite effect holds true for a p-value greater than 0.05 . Since there was no significant effect of week on the results, the values on the bar graphs and charts are the average of all the measurements combined for both weeks $(n=4)$.

There is a significant effect of filtration temperature/heat treatment combinations $(\mathrm{p}=0.010)$ on $\%$ retention of ash in the retentate (see Figure 2.1). According to Table 2.1, the $\mathrm{CF} / \mathrm{Raw}$ retentate retained $52.5 \%$ of the total ash in the retentate, the $\mathrm{CF} / \mathrm{PB}$ treatment retained $56.0 \%$ of the total ash, the $\mathrm{CF} / \mathrm{PA}$ retained $56.3 \%$ of the total ash and the HF/PB treatment 
retained $61.9 \%$ of the total ash in the retentate. There was a significant difference found between the $\mathrm{CF} / \mathrm{Raw}$ and the HF/PB treated retentate. There was not a significant effect of the week of milk collected and processed on the results $(\mathrm{p}=0.577)$.

The significant differences in total ash retained concur with a study by Brule and Fauquant (1981), who observed that low processing temperatures displaced the equilibrium of minerals from colloidial fraction toward the soluble fraction. During the UF procedure at cold temperatures, soluble minerals went through the UF membrane and accumulated in permeate (St. Gelais et al., 1992). Therefore, it is possible that the significant differences in ash are due to the above mentioned phenomena.

There was a significant treatment effect $(\mathrm{p}<0.001)$ on the amount of calcium retained. (See figure 2.2) According to Table 2.1, the CF/PB treatment resulted in $81.8 \%$ retention of total calcium in retentate. The $\mathrm{CF} / \mathrm{Raw}$ treatment resulted in $82.3 \%$ of the total calcium in the retentate, the CF/PA treatment resulted in $84.5 \%$ retention of total calcium in the retentate, and the $\mathrm{HF} / \mathrm{PB}$ treatment resulted in $88.6 \%$ retention of the total calcium in the retentate. Significant differences were found between the $\mathrm{HF} / \mathrm{PB}$ treatment and the CF/PA, CF/PB and CF/Raw. Significant differences were also found between the CF/PA treatments and the CF/PB and $\mathrm{CF} / \mathrm{Raw}$. There was not a significant difference found $(\mathrm{p}=0.098)$ in the lots of milk collected during the two-week period. These results concur with a study by Mattews et al. (1976), where they attributed a higher retention of calcium in the retentate to the strong association of ionic $\mathrm{Ca}$ with colloidial milk proteins at higher temperatures. Since there were differences found between the $\mathrm{CF} / \mathrm{PB}, \mathrm{CF} / \mathrm{PA}$ and $\mathrm{CF} / \mathrm{Raw}$ treatments, there is a possible effect of heat treatment and the stage in the process in which the heat treatment was applied on the amount of calcium retained. Further research is needed to study how these treatments affect calcium binding to protein and if 
there are other factors involved.

There was a significant treatment effect $(\mathrm{p}=0.025)$ on the amount of total protein retained $(\%$ total protein $=\%$ total nitrogen $\times 6.38)($ see figure 2.3$)$. According to Table 2.1 , the CF/PA treatment resulted in $93.8 \%$ retention of total protein, the $\mathrm{CF} / \mathrm{Raw}$ retained $93.9 \%$ retention of total protein, the HF/PB treatment resulted in $94.1 \%$ and the CF/PB treatment resulted in $95.2 \%$ retention of total protein. Significant differences were found between the CF/PB treatment and the $\mathrm{CF} / \mathrm{PA}$ and the $\mathrm{CF} / \mathrm{Raw}$ treatments. There was not a significant effect $(\mathrm{p}=0.828)$ between the lots of milk during the two weeks of production. According to Walstra et al. (1999), the application of heat to milk can lead to the attachment of proteins to the casein micelle. These proteins can be caseins, whey proteins or both. Besides binding to the micelle, these proteins can bind with each other, forming agglomerates, leading to an increase in total protein retention. According to a study by Murphy and Fox (1991), UF of raw milk can reduce the amount of protein in the retentate and attributed this observation to increased levels of $\beta$-casein in permeate. Perhaps, this is why the $\mathrm{CF} / \mathrm{Raw}$ treatment led to a lower retention of total protein compared to the $\mathrm{CF} / \mathrm{PA}$ and $\mathrm{CF} / \mathrm{PB}$ treatments. Before this analysis can happen, the effect of treatment on retention of non-protein nitrogen, non-casein nitrogen and true protein nitrogen was observed.

Non-protein nitrogen $(\mathrm{NPN})$ represents all nitrogen present that is left in the filtrate after the precipitation of protein with $12 \%$ trichloroactic acid. The nitrogen in this group comes from urea, protease-peptone and other sources. According to my analysis, there was not a significant treatment effect $(\mathrm{p}=0.454)$ on the amount of non-protein nitrogen obtained (see figure 2.4 ). According to Table 2.2, the CF/PA treatment lead to $84.2 \%$ retention of non-protein nitrogen, the $\mathrm{CF} / \mathrm{Raw}$ treatment led to $84.7 \%$ retention of non-protein nitrogen, the $\mathrm{CF} / \mathrm{PB}$ treatment led to $85.1 \%$ retention of non-protein nitrogen and the HF/PB led to $85.8 \%$ retention of non-protein 
nitrogen. There were significant differences found between the treatment and there was no effect of the week of milk collected and processed $(\mathrm{p}=0.890)$ on these results.

According to my results, there is a significant difference $(\mathrm{p}<0.001)$ in non-casein nitrogen (NCN) values between the retentate (see figure 2.5). NCN refers to the amount of nitrogen left in the filtrate after the precipitation of protein at $\mathrm{pH}$ 4.6. Nitrogen in the precipitated fraction consists of nitrogen from casein and any other proteins associated with the caseins. According to Table 2.2, the HF/PB treatment led to $77.9 \%$ retention of non-casein nitrogen, the $\mathrm{CF} / \mathrm{PB}$ treatment led to $79.4 \%$ retention of non-casein nitrogen, the CF/Raw treatment led to $82.5 \%$ retention of non-casein nitrogen and the $\mathrm{CF} / \mathrm{PA}$ treatment led to $83.0 \%$ retention of non-casein nitrogen. Significant differences were seen between $\mathrm{CF} / \mathrm{PB}$ and $\mathrm{CF} / \mathrm{PA}$, between treatment $\mathrm{HF} / \mathrm{PB}$ and $\mathrm{CF} / \mathrm{PA}$, between $\mathrm{CF} / \mathrm{PB}$ and $\mathrm{CF} / \mathrm{Raw}$ and between $\mathrm{CF} / \mathrm{Raw}$ and $\mathrm{HF} / \mathrm{PB}$. There was not an effect of the milk of the week of processing on these values $(\mathrm{p}=0.475)$. When working with non-casein nitrogen values, it is crucial to remember that a filtrate is being analyzed after casein has been precipitated out at $\mathrm{pH}$ 4.6. High $\mathrm{NCN}$ values indicate that there was a lower amount of nitrogen precipitated. The opposite holds true for low NCN values. A possible explanation for this observation for the significant differences between the HF/PB treatment and the $\mathrm{CF} / \mathrm{PB}$ treatments is that hot filtration temperature was severe enough for whey protein denaturation and attachment to casein micelles or in the formation of agglomerates. Higher temperatures also cause additional serum casein to attach to the micelle or form agglomerates. According to a study by Pompei et al. (1973), temperatures high enough to stop microbial growth $\left(>60^{\circ} \mathrm{C}\right)$ can cause protein denaturation. Further research is needed to determine the percent of whey protein denaturation for each treatment and to further research to observe particle size distribution of casein micelles and any potential protein agglomerates. 
The significant differences between $\mathrm{CF} / \mathrm{PA}$ and treatment $\mathrm{CF} / \mathrm{PB}$ and between $\mathrm{CF} / \mathrm{PB}$ and $\mathrm{CF} / \mathrm{Raw}$ indicate that a pasteurization step before the UF procedure affects NCN values. Pasteurization of milk before UF can lead to the denaturation of whey proteins in the milk serum, causing them to either bind with casein micelles or form agglomerates with other serum proteins. As a result, there is an increased possibility that these proteins will be retained during the filtration procedure, and will lead to an increase in protein that is precipitated out at $\mathrm{pH} 4.6$, leading to lower NCN values. Since the CF/PA treatment is filtered raw and pasteurized after UF, the treatment can be considered the same. Therefore, the reasons for the differences between these two treatments are the same as the reasons for differences between the HF/PB and CF/Raw.

True Protein Nitrogen represents the nitrogen that is contributed from the two main classes of milk proteins: casein and whey. This value is obtained by subtracting the amount of non-protein nitrogen from the amount of total nitrogen. According to my results, there is a significant treatment $(\mathrm{p}=0.023)$ effect on true protein nitrogen values (see figure 2.6). According to Table 2.2, the CF/PA treatment led to the retention of $94.0 \%$ retention of true protein nitrogen, the $\mathrm{CF} / \mathrm{Raw}$ treatment led to $94.1 \%$ retention of true protein, the $\mathrm{HF} / \mathrm{PB}$ treatment led to $94.4 \%$ retention of true protein nitrogen and the $\mathrm{CF} / \mathrm{PB}$ led to $95.5 \%$ retention of true protein nitrogen. As was the case with total protein, there are significant differences between treatment $\mathrm{CF} / \mathrm{PB}$ and treatments $\mathrm{CF} / \mathrm{PA}$ and $\mathrm{CF} / \mathrm{Raw}$. Since there is not a significant treatment effect on NPN levels, it is likely that the differences in total protein are not attributable to NPN. There also was not a significant effect $(\mathrm{p}=0.809)$ in the milk during week processed on these values. Only one question remains: are these differences attributed to casein nitrogen, whey protein nitrogen or both? 
To start the investigation, I observed the treatment effect on the retention of casein nitrogen. Casein nitrogen was determined as the difference between true protein nitrogen and whey protein nitrogen. According to my results, there was a significant treatment effect $(p=0.016)$ on the amount of casein nitrogen retained (see figure 2.7). According to Table 2.2, the CF/PA treatment led to $97.0 \%$ retention of casein nitrogen, the $\mathrm{CF} / \mathrm{Raw}$ treatment led to $97.3 \%$ retention of casein nitrogen, the $\mathrm{HF} / \mathrm{PB}$ treatment led to $97.6 \%$ retention of casein nitrogen and the $\mathrm{CF} / \mathrm{Raw}$ led to $99.1 \%$ retention of casein nitrogen. There was not a significant effect of the milk of the week processed $(\mathrm{p}=0.586)$ on the results. Significant differences were found between the $\mathrm{CF} / \mathrm{PA}$ treatment and the $\mathrm{CF} / \mathrm{PB}$ and $\mathrm{CF} / \mathrm{Raw}$ treatments. These results concur with the total protein findings, and can be listed as a possible reason for differences in total and true protein observed.

To determine if whey protein nitrogen content is a possibility for the differences in total protein, I observed the effect of treatment on the amount of whey protein nitrogen retained. Whey protein nitrogen content was determined as the difference between the amounts of noncasein nitrogen minus the amount of non-protein nitrogen. According to the results in Table 2.2, there was a significant treatment effect $(\mathrm{p}<0.001)$ on the amount of whey protein nitrogen retained (see figure 2.8). There was not a significant effect on the milk of the week processed $(\mathrm{p}=0.459)$. The $\mathrm{HF} / \mathrm{PB}$ treatment led to $76.4 \%$ whey protein nitrogen retained, the $\mathrm{CF} / \mathrm{PB}$ treatment led to $78.4 \%$ whey protein nitrogen retained, the $\mathrm{CF} / \mathrm{Raw}$ treatment led to $82.2 \%$ whey protein nitrogen retained and the CF/PA led to $82.9 \%$ whey protein nitrogen retained. Significant differences were found between the $\mathrm{CF} / \mathrm{PB}$ treatment and the $\mathrm{CF} / \mathrm{PA}$ and $\mathrm{CF} / \mathrm{Raw}$ treatments. $\mathrm{A}$ significant difference was also found between the CF/Raw and the HF/PB treatments. The calculation of whey protein nitrogen content was determined using derived non-casein nitrogen 
results and because of this, the percentages listed and must be interpreted the same way as noncasein nitrogen results. The lower percentages indicate that a higher amount of whey protein nitrogen precipitated out with the caseins, and is potentially attached to the proteins. There is also a possibility for agglomerate formation between the precipitated proteins, leading to these significant differences. The opposite holds true with the higher percentages of whey protein nitrogen retained. The results show that the differences in whey proteins between treatments $\mathrm{CF} / \mathrm{Raw}, \mathrm{CF} / \mathrm{PA}$, and $\mathrm{CF} / \mathrm{PB}$ are likely contributors to the differences in true protein. The significant difference between treatment $\mathrm{HF} / \mathrm{PB}$ and $\mathrm{CF} / \mathrm{Raw}$ indicate that the filtration temperature has the potential to affect whey protein denaturation and the ability to form agglomerates and bind to the casein micelle. Further research is needed to look into this possibility.

There was not a significant treatment effect $(\mathrm{p}=0.641)$ on the amount of fat levels retained (see figure 2.9). According to Table 2.1, the CF/PA treatment led to $89.3 \%$ retention of fat, the $\mathrm{CF} / \mathrm{PB}$ treatment led to $92.5 \%$ retention of fat, the $\mathrm{CF} / \mathrm{Raw}$ treatment led to $88.9 \%$ retention of fat and the HF/PB led to $89.0 \%$ retention of the fat. There were not any significant differences between the treatments and there was not an effect of milk of the week of processing $(\mathrm{p}=0.076)$ on these values. This was to be expected because the pore size is adequate to keep most of the fat in the retentate. This is in agreement with the results of Green et al. (1984). This has to do with the fact that the pore size of the membrane is small enough to retain most of the fat in the membrane.

There was a significant difference $(\mathrm{p}<0.001)$ in the $\mathrm{pH}$ values of the retentate (see figure 2.10). According to Table 2.1, the $\mathrm{CF} / \mathrm{raw}$ treatment led to a retentate with a $\mathrm{pH}$ of 6.52 at $30^{\circ} \mathrm{C}$, the $\mathrm{CF} / \mathrm{PA}$ treatment led to a retentate with a $\mathrm{pH}$ of 6.53 at $30^{\circ} \mathrm{C}$. The $\mathrm{CF} / \mathrm{PB}$ treatment led to a 
retentate with a pH of 6.66 and the HF/PB treatment led to a pH value of 6.69. Significant differences were observed between the $\mathrm{CF} / \mathrm{PA}$ and the $\mathrm{CF} / \mathrm{PB}$ and $\mathrm{HF} / \mathrm{PB}$ treatments, between $\mathrm{CF} / \mathrm{PB}$ and $\mathrm{CF} / \mathrm{Raw}$ and $\mathrm{HF} / \mathrm{PB}$ treatments. A significant difference was also seen between the $\mathrm{CF} / \mathrm{Raw}$ and HF/PB treatments. There wasn't a significant effect of week of processing $(\mathrm{p}=1.000)$ on the $\mathrm{pH}$ values A possible explanation for these $\mathrm{pH}$ differences can be attributed to buffering capacity differences caused by compositional differences from the treatments (especially whey protein and mineral content). Studies have shown that the ionizable groups of casein and $\beta$-lactoglobulin exert considerable buffering action in the $\mathrm{pH}$ range of 4.6 to 8.3. According to a study by Ma and Barbano (2002), the reason for the $\mathrm{pH}$ decrease was related to shifts in the degree of association of calcium phosphate. Further research is needed to observe if the compositional differences in these treatments affect buffering capacity of these retentate. 


\subsection{Conclusion}

According to the results of this study, there was a treatment effect of filtration temperature and pasteurization temperature on the composition of the retentate. These differences were seen in mineral and calcium content, protein nitrogen content and $\mathrm{pH}$ values. The significant differences seen can be attributed to tendency for mineral equilibrium (especially Ca) to change from a serum ionic state to a bound colloidial state. In terms of protein nitrogen, the significant treatment differences can be attributed to the binding of serum proteins to casein micelles or in the formation of agglomerates with one another. The affect of temperature on micelle chemistry is another possibility for these differences. The $\mathrm{pH}$ value differences are possibility due to differences in buffering capacity due to mineral and protein differences. There were no significant effects attributed to the week of processing on the results, indicating that there was not an effect of day to day milk variation on the results. 


\subsection{References Used}

AOAC. Official Methods of Analysis for AOAC International 17th edition. Arlington, Va. 2000.

Barbano, D.M., Rudan, M.A. and Rasmussen, R.R. Influence of Milk Composition, Somatic Cell and Psychrotrophic Bacteria Counts on Ultrafiltration Flux. Journal of Dairy Science vol 72 pp 1118-1123. 1989.

Bastian, E.D., Collinge, S.K. and Ernstrom, C.A. Ultrafiltration: Partitioning of Milk Constituents into Permeate and Retentate. Journal of Dairy Science vol 74 pp. 2423-2434. 1991.

Belfort, G. Membranes methods in water and wastewater treatment: an overview. In Synthetic membrane processes: fundamentals and water applications. Academic Press, Inc. Orlando, FL. 1984.

Breslav, B.R. and Kilcullen, B.M. Hollow fiber ultrafiltration of cottage cheese whey: a performance study. Journal of Dairy Science vol 60: 1379-1386. 1977.

Brink, L.E.S. and Romijn, D.J. Reducing the fouling of polysulfone surfaces and polysulfone membranes: optimization of the type of presorbed layer. Desalination vol $78 \mathrm{pp}$. 209-233. 1990.

Brink, L.E.S., Elbers, S.J.G., Robbertson, T. and Both, P. The anti-fouling action of polymers preabsorbed on ultrafiltration and microfiltration membranes. Journal of Membrane Science vol 76 pp. 281-291. 1993.

Brule, G. and Faquant, J. Mineral balance in skim milk and milk retentate: effect of physicochemical characteristics of the aqueous phase. Journal of Dairy Research vol 48: 91-97. 1981.

Carroll, R.J., Thompson, M.P., Bruuner, J.R. and Kolar, C. Aggregation of the casein micelles prepared by low temperature centrifugation of skim milk. Journal of Dairy Science vol 50: 941.1967.

Chaplin, L.C. and Lyster, R.L. Effect of temperature on the $\mathrm{pH}$ of skim milk. Journal of Dairy Research vol 55 pp. 277-280. 1988.

De Boer, R. and Koenraads, J.P.J.M. Incorporation of liquid ultrafiltration-whey retentates in dairy desserts and yogurts. In New Applications of Membrane Processes IDF Special Issue No. 9201. 1995.

Fane, A.G., Fell, C.J.D. and Waters, A.G. Ultrafiltration of protein solutions through partially permeable membranes-the effect of adsorption and solution environment. Journal of membrane Science vol 16 pp. 211-224. 1983. 
Fane, A.G. Ultrafiltration: Factors Influencing flux and rejection. In Progress in Filtration and Seperation pp. 101-179. R.J. Elsevier Publishing Co. Oxford, UK. 1986.

Fox, P.F. and McSweeney, P.L.H. Dairy Chemistry and Biochemistry. Blackie Academic \& Professional. New York, NY. 1998.

Green, M.L., Scott, K.J., Anderson, M., Griffin, M.C.A. and Glover, F.A. Chemical Characterization of milk concentrated by ultrafiltration. Journal of Dairy Research vol 51 pp. 267-278. 1984.

Harper, W.J. Functional properties of whey protein concentrates \& their relationship to ultrafiltration. In New Applications of the Membrane Processes IDF Special Issue No. 9201. 1995.

Hayes. J.F., Dunkerley, J.A.. Muller, L.L. and Griffin, A.T. Studies on whey processing by ultrafiltration. II. Improving permeation rates by preventing fouling. Australian Journal of Dairy technology vol 29 pp. 132-140. 1974.

Hickey, M.W., Hill, R.D. and Smith, B.R. Investigations into the ultrafiltration and reverse osmosis of wheys. I. the effects of certain pre-treatments. New Zealand Journal of Dairy Science and Technology vol 15 pp 109-121. 1980.

Howell, J.A., Velicangil, A, Le, M.S. and Zepellin, A.L.H. Ultrafiltration of protein solutions. Annual New York Academy of Science pp. 355-366. 1981.

International Dairy Federation. Determination of the casein content of milk. International Dairy Federation Standard No. 29. International Dairy Federation. Brussels. 1964.

Le, M.S. and Howell, J.A. The fouling of ultrafiltratiom membranes and its pretreatment. In Progress in Food Engineering. Forster-Verlag Publishing. Kusnacht. 1983.

Lee, D.N. and Merson, R.L. Examination of cottage cheese whey proteins by scanning electron microscopy: relationship to membrane fouling during ultrafiltration. Journal of Dairy Science vol 58 pp. 1423-1432. 1975.

Jelen, P. Physicochemical properties of milk in whey and membrane processing. Journal of Dairy Science vol 62 pp. 1343-1351. 1979.

Kapsimalis, D.J. and Zall, R.R. Ultrafiltration of skim milk at refrigerated temperatures. Journal of Dairy Science vol 64 pp 1945-1950. 1981.

Kessler, H.G., Gernedel, G. and Nakanishi, K. The effect of low molecular weight milk constituents on the flux in ultrafiltration. Milchwissenschaft vol 37 pp. 584-587. 1982. 
Koutake, M., Matsuno, I., Nabetani, H., Nakajima, M., Watanabe, A. Classification of the resistance of permeation caused by fouling during ultrafiltration of whey and skim milk. Biosci Biotech Biochem vol 56(5) pp. 697-700. 1992.

Ma, Y. and Barbano, D.M. Milk pH as a function of $\mathrm{CO} 2$ concentration, Temperature, and Pressure in a Heat Exchanger. Journal of Dairy Science vol 86 pp. 3822-3830. 2002.

Marshall, A.D. and Daufin, G. Physico-chemical aspects of membrane fouling by dairy fluids. In Fouling and Cleaning in Pressure Driven Membrane Processes. IDF Bulletin. 1995.

Marshall, Robert T., Ed. Standard Methods for the Examination of Dairy Products 16th edition. American Public Health Association. Washington, D.C. 1992.

Matsumoto, K., Kawahara, M. and Ohya, H. Cross-flow filtration of yeast by microporous ceramic membrane with backwashing. Journal of Fermentation Technology vol 66(2) pp 199-205. 1988.

Mattews, M.E., So, S.E., Amundson, C.H. and Hill, Jr., C.G. Cottage Cheese from ultrafiltered skim milk. Journal of Food Science vol 41 pp.619-623. 1976.

Murphy, J.M. and Fox, P.F. Fractionation of Sodium Caseinate by Ultrafiltration. Food Chemistry vol 39 pp. 27-38. 1991.

Maubois, J.L. and Mocquot, G. Preparation of cheese from liquid pre-cheese obtained by ultrafiltration of milk. Le Lait vol 51:495. 1971.

McDonogh, R.M., Bauser, H., Stroh, N. and Chmiel, H. Concentration polarization and adsorption effects in cross-flow ultrafiltration of proteins. Desalination vol 79 pp 217-231. 1990.

McGregor, W. Courtney, Ed. Membrane Seperations in Biotechnology. Marcel Dekker Publishing. New York. 1986.

Merin, U. and Cheryan, M. Factors affecting mechanism of flux decline during ultrafiltration of cottage cheese whey. Journal of Food Preservation vol 4:183-198. 1980.

Muller, L.L., Hayes, J.F. and Griffin, A.T. Studies on whey processing by ultrafiltration. 1. Comparative performance of various ultrafiltration modules on whey from hydrochloric acid casein and cheddar cheese. Australian Journal of Dairy technology vol 28 pp. 70-77. 1973.

National Institute for Research in Dairying. Ultrafiltration and Reverse Osmosis for the Dairy Industry. Technical Bulletin No. 5. 1985. 
Nelson, L.S., Holt, C. and Hukins, D.W.L. Phosphopeptide dissociation from micellar calcium phosphate preparations does not induce crystallization. Journal of Dairy Research vol 56 pp 669-673. 1989.

Nillson, J.L. Protein fouling of ultrafiltration membranes: causes and consequences. Journal of Membrane Science vol 52 pp. 121-142. 1990.

Norde, W. Adsorption of proteins from solution at the solid-liquid interface. Advanced Colloid Interface Science vol 25 pp.267-340. 1986.

Novak, A. Milk Protein Concentrate. In New Applications of Membrane Processes IDF Special Issue No. 9201. 1995.

Nystrom, M. and Lindstrom, M. Optimal removal of chlorolignin by ultrafiltration achieved by pH control. Desalination vol 70 pp. 145-156. 1988.

Nystrom, M. Fouling of unmodified and modified polysulfone membranes by ovalbumin. Journal of Membrane Science vol 44 pp. 183-196. 1989.

Palacek, S.P., Mochizuki, S. and Zydney, A.L. Effect of ionic environment on BSA filtration and the properties of BSA products. Desalination vol 90 pp. 147-159. 1993.

Pappas, C.P. and Rothwell, J. Ultrafiltration as a valuable method in calcium-binding studies with milk proteins. Food Chemistry vol 44 pp. 93-101. 1992.

Pompei, C., Resmini, P. and Peri, C. Skim milk protein recovery and purification by ultrafiltration. Influence of temperature on permeation rate and retention. Journal of Food Science vol. 38: 867. 1973.

Pouliot, J. and Jelen, P. Pre-treatments of dairy fluids to minimize long-term fouling. In Fouling and Cleaning in Pressure Driven Membrane Processes. IDF Bulletin. 1995

Poulsen, P.R. Feasibility of Ultrafiltration for Standardizing Protein in Milk. Journal of Dairy Science vol 61 pp 807-814. 1978.

Puhan, Z. Standardization of the milk protein content by membrane processes for product manufacture. In New Applications of Membrane Processes IDF Special Issue No. 9201. 1995.

Rao, H.G.R., Lewis, M.J. and Grandison, A.S. Effect of $\mathrm{pH}$ on flux during ultrafiltration of sweet whey and buttermilk. Journal of Dairy Research vol 62 pp. 441-449. 1994.

Rao, H.G.R., Lewis, M.J. and Grandison, A.S. Effect of soluble calcium on fouling of ultrafiltration membranes. Journal of the science of Food and agricultrure. Vol 65 no. 2. pg. 249-246. 1994. 
Rash, K. Studies on the behavior and prevention of enteropathogenic E. coli and other coliforms in Camambert cheese made by the ultrafiltration process. PhD Thesis, Cornell University. Ithaca, NY. 1976.

Rolchigo, P.M., Raymond, W.A. and Hildebrandt, J.R. Improved control of ultrafiltration using vorticular thermodynamics and hydrophilic membranes. Process Biochemistry vol 24 (2): pro Bio-Tech iii-vii. 1989.

Sheldon, J.M., Reed, I.M. and Hawes, C.R. The fine structure of ultrafiltration membranes. II. Protein fouled membranes. Journal of Membrane Science vol 62 pp. 87-102. 1991.

St.-Gelais, D., Hache, S. and Gros-Louis, M. Combined Effects of Temperature, Acidification and Diafiltration on Composition of Skim Milk Reteantate and Permeate. Journal of Dairy Science vol 75: 1167-1172. 1992.

Sutherland, B.J. and Jameson, G.W. Composition of Hard Cheese manufactured by Ultrafiltration. Australian Journal of Dairy Technology vol 36: 136. 1981.

Tong, P.S., Barbano, D.M. and Jordan, W.K. Permeate Flux During the Ultrafiltration of Whey: Influence of Milk Coagulant Used for Cheese Manufacture. Journal of Dairy Science vol 71 pp. 2342-2348. 1988.

Udabage, P., McKinnon, I.R. and Augustin, M.A. Effect of mineral salts and calcium chelating agents on the gelation of renneted milk. Journal of Dairy Research vol 84(7) pp.15691575. 2001.

Van der Horst, H.C. Fouling of organic membranes during the processing of dairy liquids. In Fouling and Cleaning in Pressure Driven Membrane Processes. IDF Special Issue 9504. 1995.

Van der Horst, H.C. and Hanemaajier, J.H. Cross-flow microfiltration in the food industry. State of the art. Desalination vol 77 pp. 235-258. 1990.

Vetier, C., Bennasar, M. and Tarodo de la Fuente, B. Study of the fouling of inorganic membranes by acidified milks using scanning electron microscopy and physicochemical analyses in the processing of milk. Journal of Dairy Research vol 55 pp 381-400. 1988.

Vyas, H.K., Bennet, R.J. and Marshall, A.D. Influence of operating conditions on membrane fouling in cross-flow microfiltration of particulate suspensions. International Dairy Journal vol 10(7) pp 477-487. 2000.

Vyas, H.K. and Tong, P.S. Process for Calcium Retention during Skim Milk Ultrafiltration. Journal of Dairy Science vol 86 pp. 2761-2766. 2002. 
Walstra, P., Guerts, T.J., Noomen, A., Jellema, A. and van Boekel, M.A.J.S. Dairy Technology: Principles of Milk Properties and Processes. Marcel Dekker. New York. 1999.

Wu, D., Howell, J.A. and Field, R.W. Critical flux measurement for model colloids. Journal of membrane Science vol 152 pp. 89-98. 1999.

Youravong, W., Grandison, A.S. and Lewis, M.J. Effect of hydrodynamic and physicochemical changes on the critical flux of milk protein suspensions. Journal of Dairy Research vol 69 no3 pp. 443-455. 2002. 
Figure 2.1: Bar graph of \% total ash retained with respect to filtration temperature and heat treatment for whole milk UF retentates

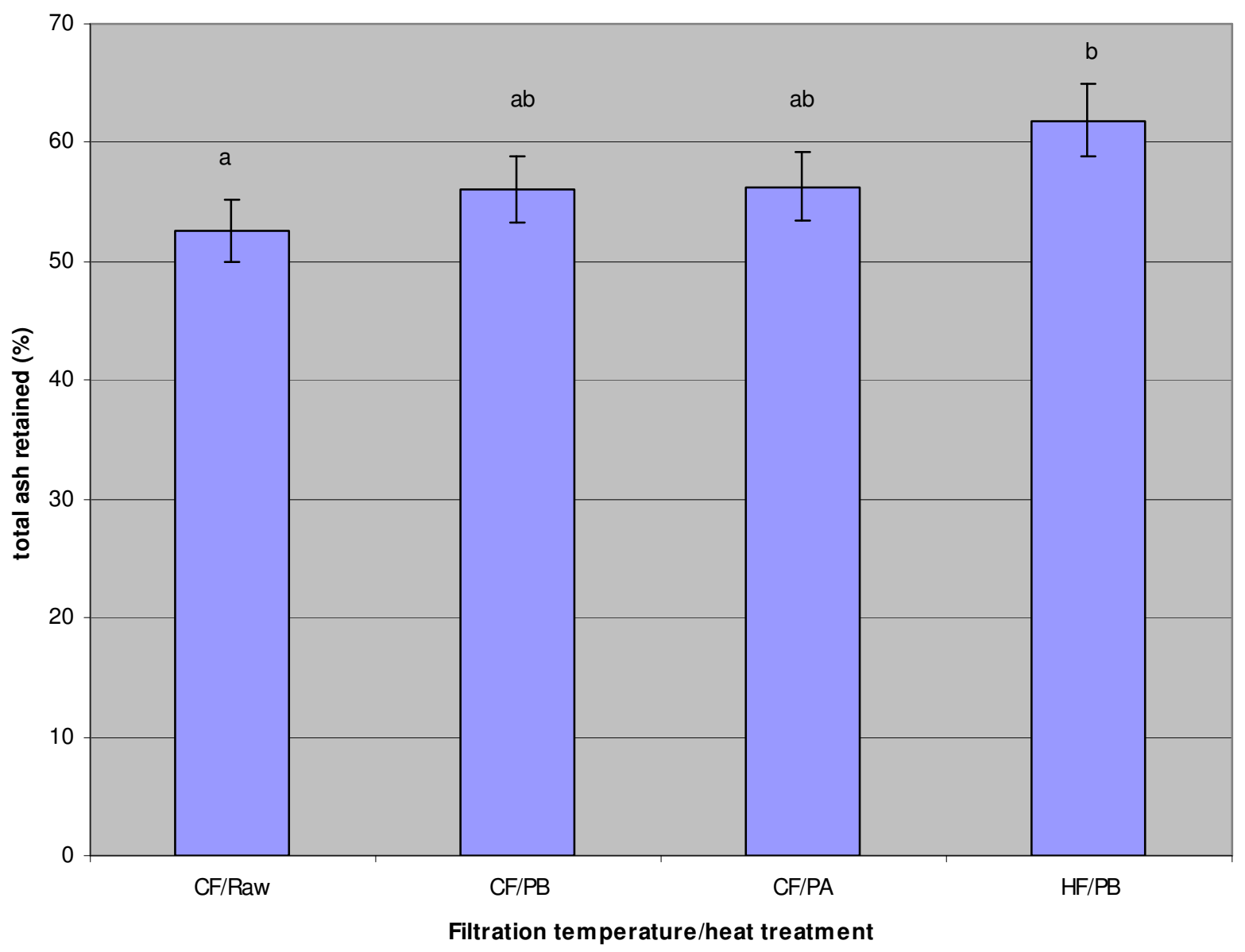

A significant difference exists when the letters between two bars are different (one has an "a" and another has a "b")

There is not a significant difference among samples when both bars have the letter "a"

$\mathrm{CF}=$ cold ultrafiltration $\left(10^{\circ} \mathrm{C}\right)$

$\mathrm{HF}=$ hot ultrafiltration $\left(50^{\circ} \mathrm{C}\right)$

Raw=no heat treatment

$\mathrm{PA}=$ retentate was heat treated after ultrafiltration

$\mathrm{PB}=$ milk was pasteurized before ultrafiltration 
Figure 2.2: Bar chart of \% calcium retained with respect to filtration temperature and heat treatment for whole milk UF retentates

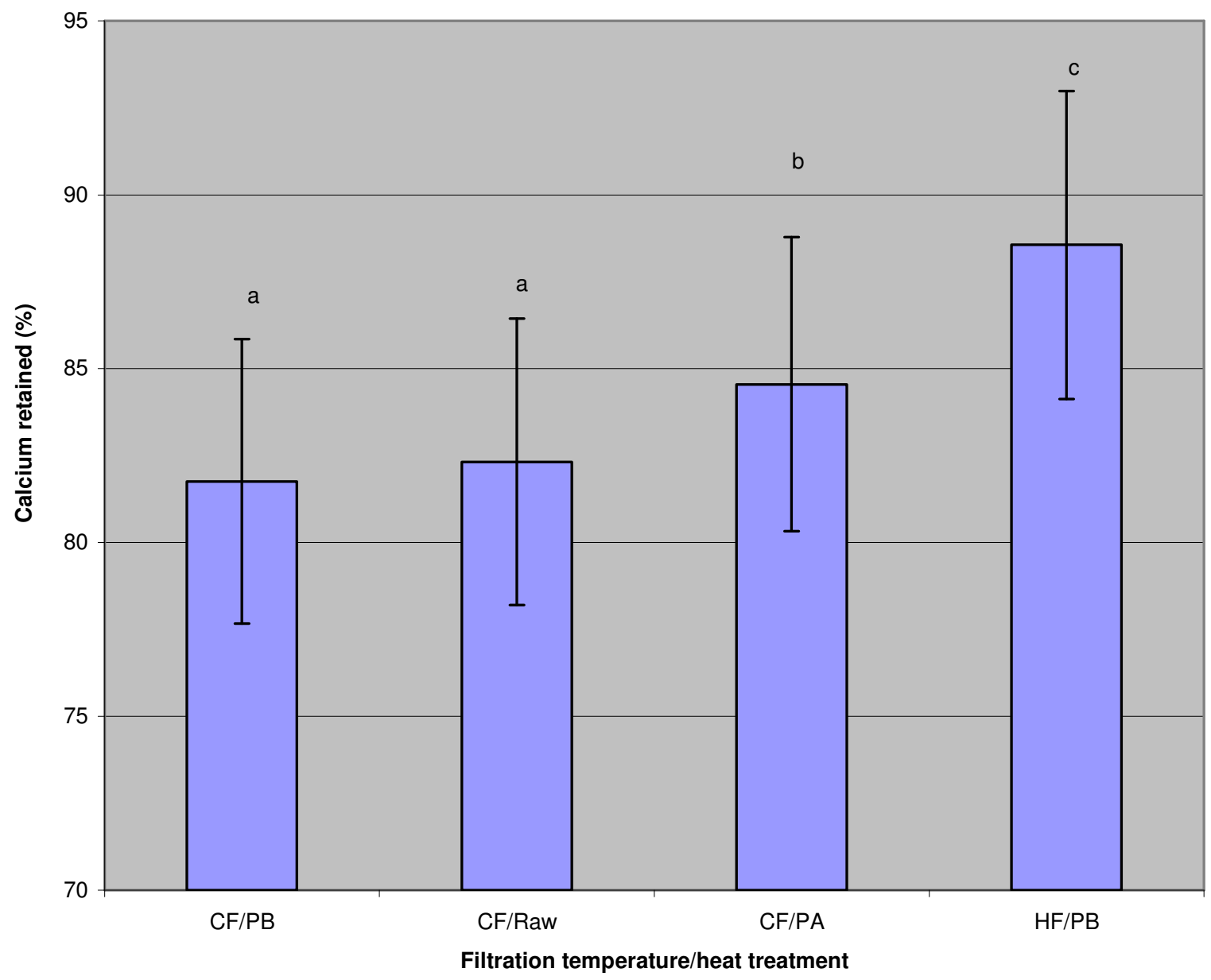

A significant difference exists when the letters between two bars are different (one has an "a" and another has a "b")

There is not a significant difference among samples when both bars have the letter "a"
$\mathrm{CF}=$ cold ultrafiltration $\left(10^{\circ} \mathrm{C}\right)$

$\mathrm{HF}=$ hot ultrafiltration $\left(50^{\circ} \mathrm{C}\right)$

Raw $=$ no heat treatment

$\mathrm{PA}=$ retentate was heat treated after ultrafiltration

$\mathrm{PB}=$ milk was pasteurized before ultrafiltration 
Figure 2.3: Bar graph of \% total protein retained with respect to filtration temperature and heat treatment for whole milk UF retentates

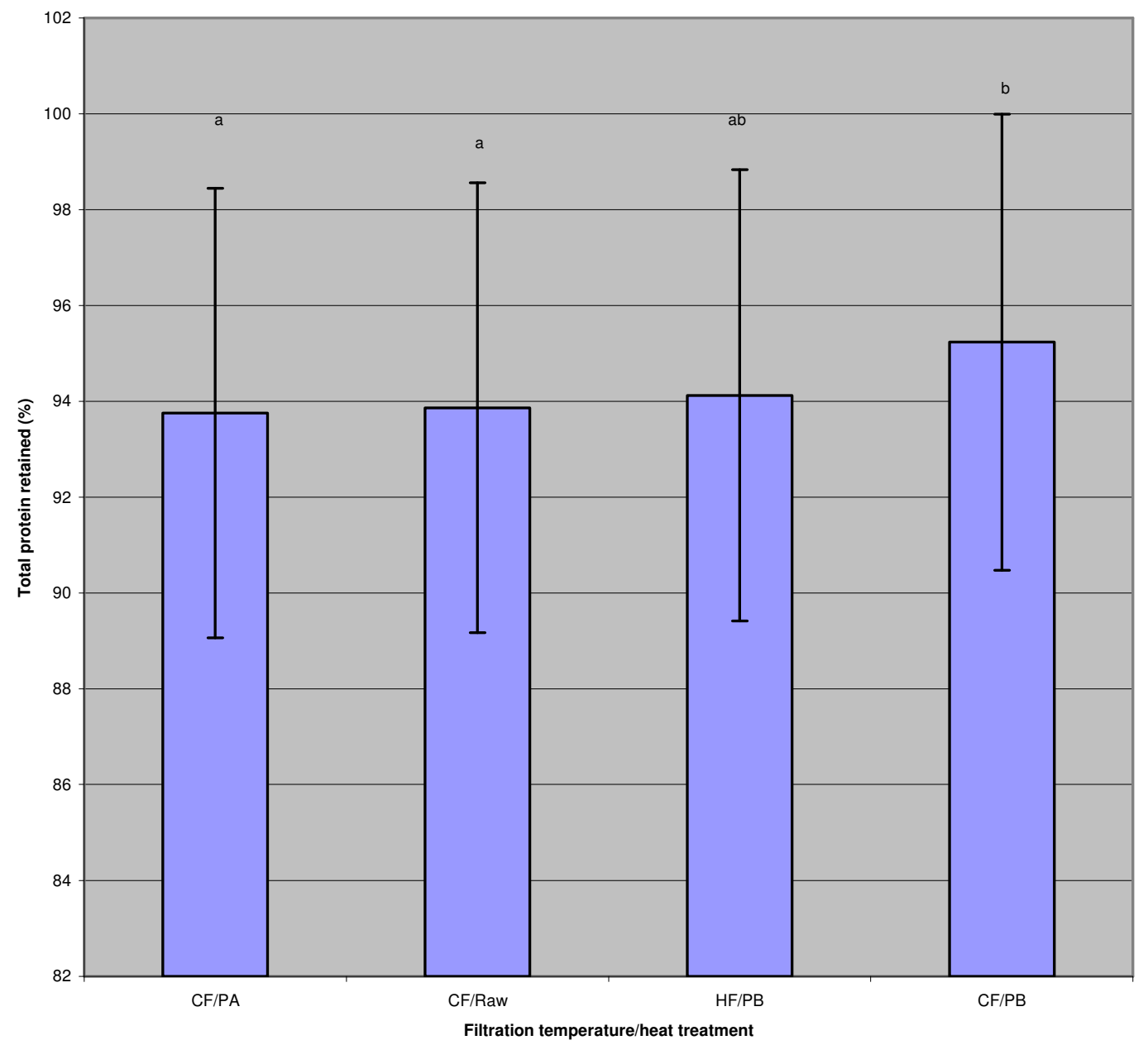

A significant difference exists when the letters between two bars are different (one has an "a" and another has a "b")

There is not a significant difference among samples when both bars have the letter "a"
$\mathrm{CF}=$ cold ultrafiltration $\left(10^{\circ} \mathrm{C}\right)$

$\mathrm{HF}=$ hot ultrafiltration $\left(50^{\circ} \mathrm{C}\right)$

Raw $=$ no heat treatment

$\mathrm{PA}=$ retentate was heat treated after ultrafiltration

$\mathrm{PB}=$ milk was pasteurized before ultrafiltration 
Figure 2.4: Bar graph of \% non-protein nitrogen (NPN) retained with respect to filtration temperature and heat treatment for whole milk UF retentates

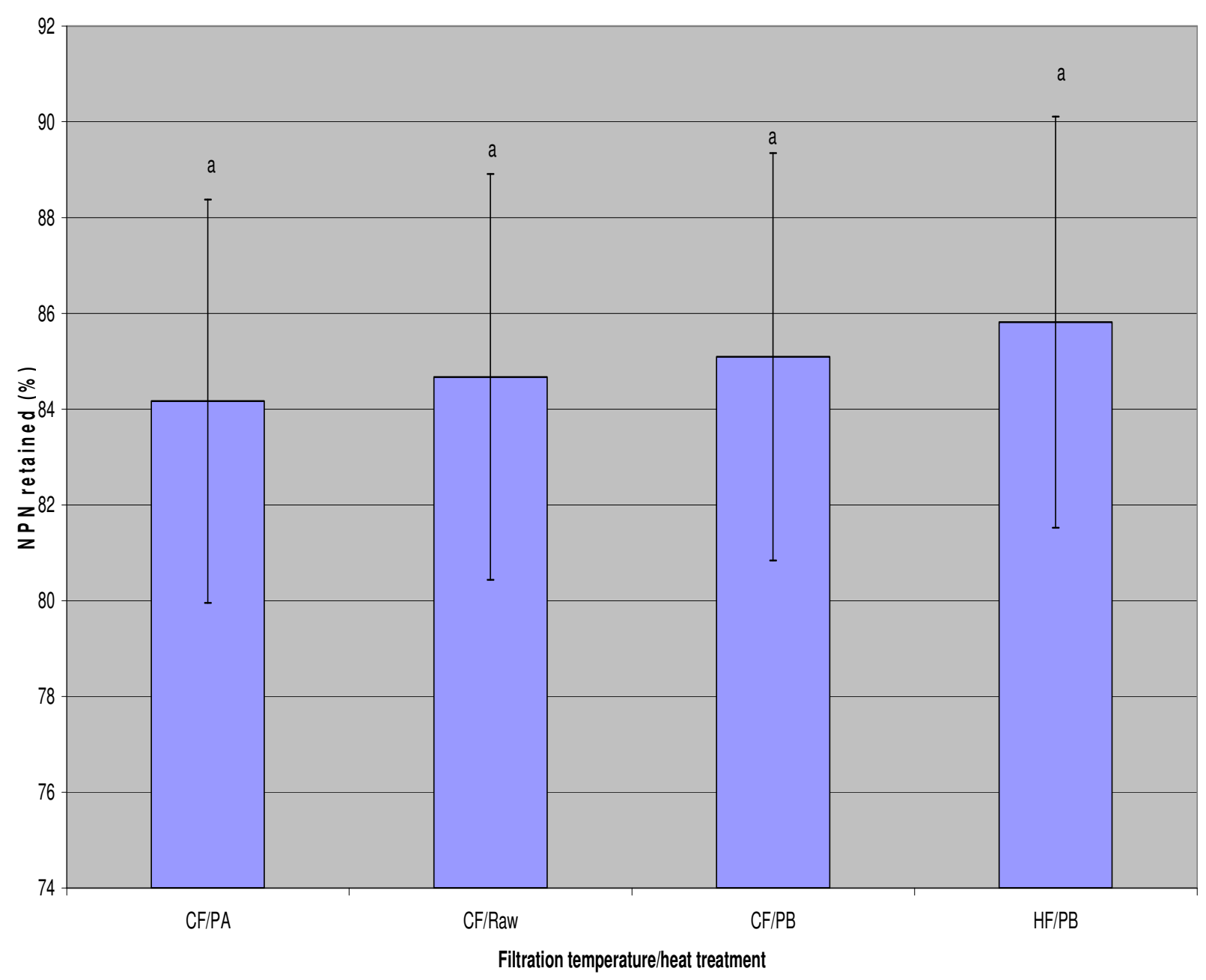

A significant difference exists when the letters between two bars are different (one has an "a" and another has a "b")

There is not a significant difference among samples when both bars have the letter " $a$ "
$\mathrm{CF}=$ cold ultrafiltration $\left(10^{\circ} \mathrm{C}\right)$

$\mathrm{HF}=$ hot ultrafiltration $\left(50^{\circ} \mathrm{C}\right)$

Raw $=$ no heat treatment

$\mathrm{PA}=$ retentate was heat treated after ultrafiltration

$\mathrm{PB}=$ milk was pasteurized before ultrafiltration 
Figure 2.5: Bar graph of \% non-casein nitrogen (NCN) retained with respect filtration temperature and heat treatment for whole milk UF retentates

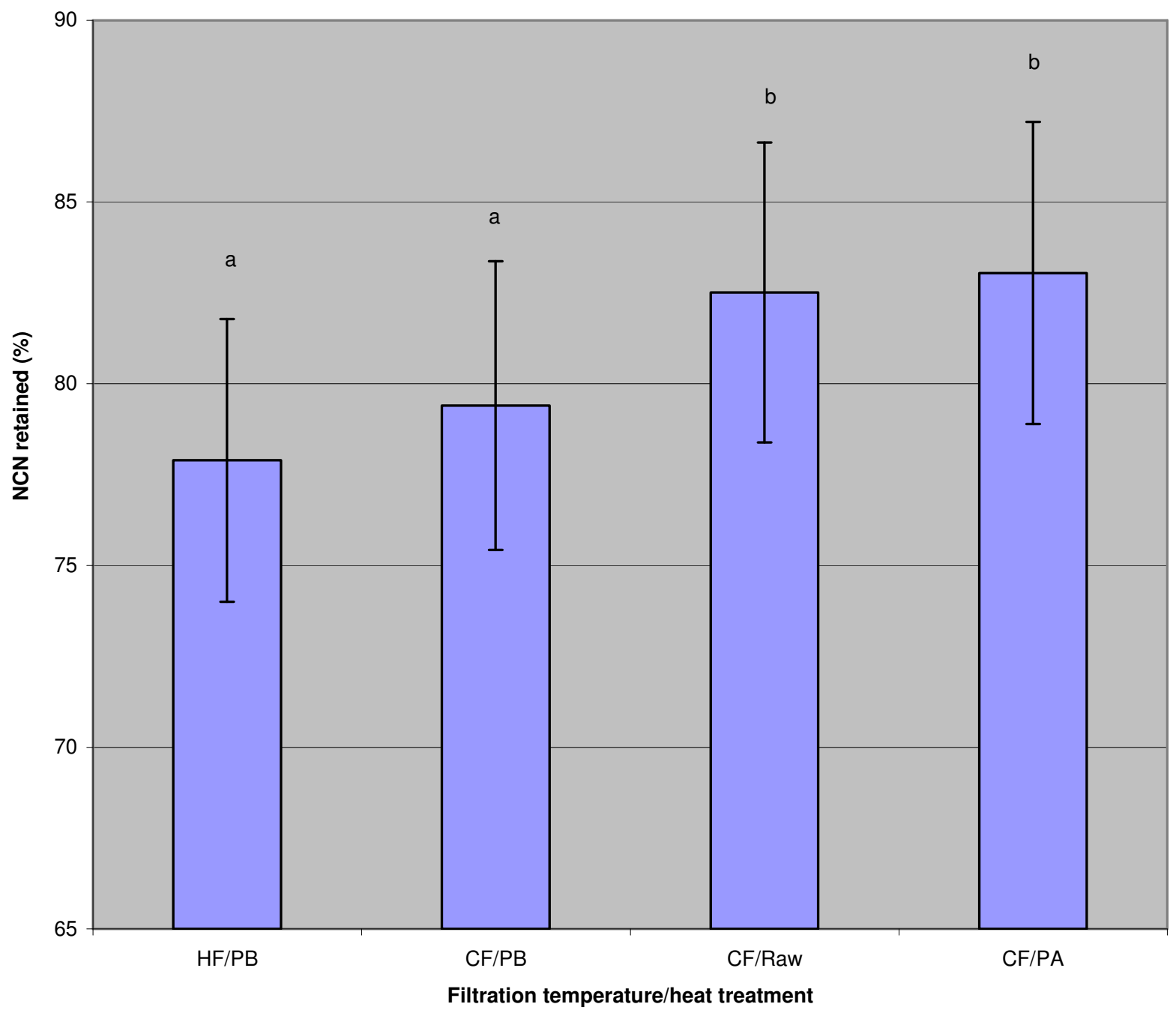

A significant difference exists when the letters between two bars are different (one has an "a" and another has a "b")

There is not a significant difference among samples when both bars have the letter "a"
$\mathrm{CF}=$ cold ultrafiltration $\left(10^{\circ} \mathrm{C}\right)$

$\mathrm{HF}=$ hot ultrafiltration $\left(50^{\circ} \mathrm{C}\right)$

Raw $=$ no heat treatment

$\mathrm{PA}=$ retentate was heat treated after ultrafiltration

$\mathrm{PB}=$ milk was pasteurized before ultrafiltration 
Figure 2.6: Bar graph of \% true protein nitrogen retained with respect to filtration temperature and heat treatment for whole milk UF retentates

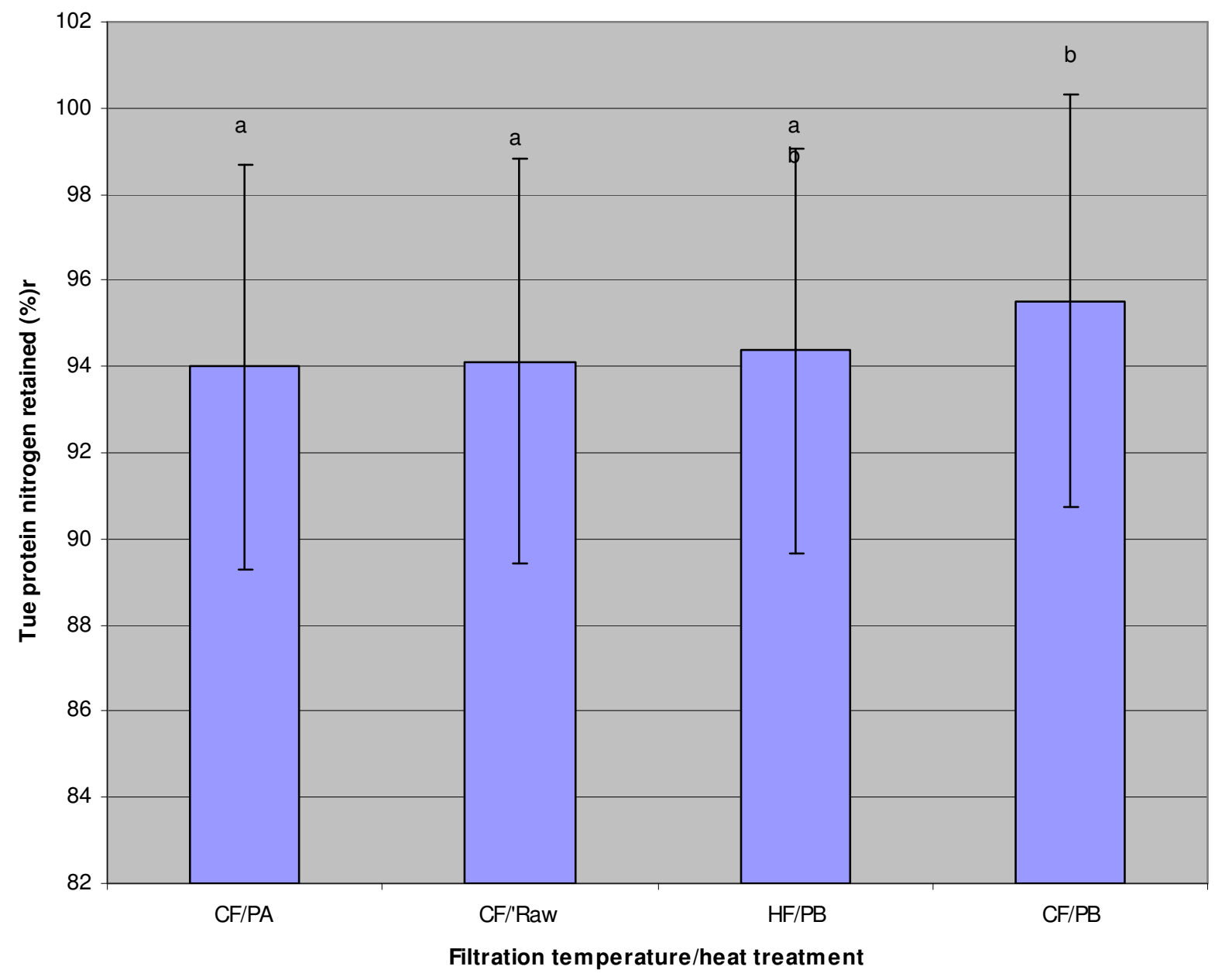

A significant difference exists when the letters between two bars are different (one has an "a" and another has a "b")

There is not a significant difference among samples when both bars have the letter "a"
$\mathrm{CF}=$ cold ultrafiltration $\left(10^{\circ} \mathrm{C}\right)$

$\mathrm{HF}=$ hot ultrafiltration $\left(50^{\circ} \mathrm{C}\right)$

Raw=no heat treatment

$\mathrm{PA}=$ retentate was heat treated after ultrafiltration

$\mathrm{PB}=$ milk was pasteurized before ultrafiltration 
Figure 2.7:Bar graph of \% casein nitrogen retained with respect to filtration temperature and heat treatment for whole milk UF retentate

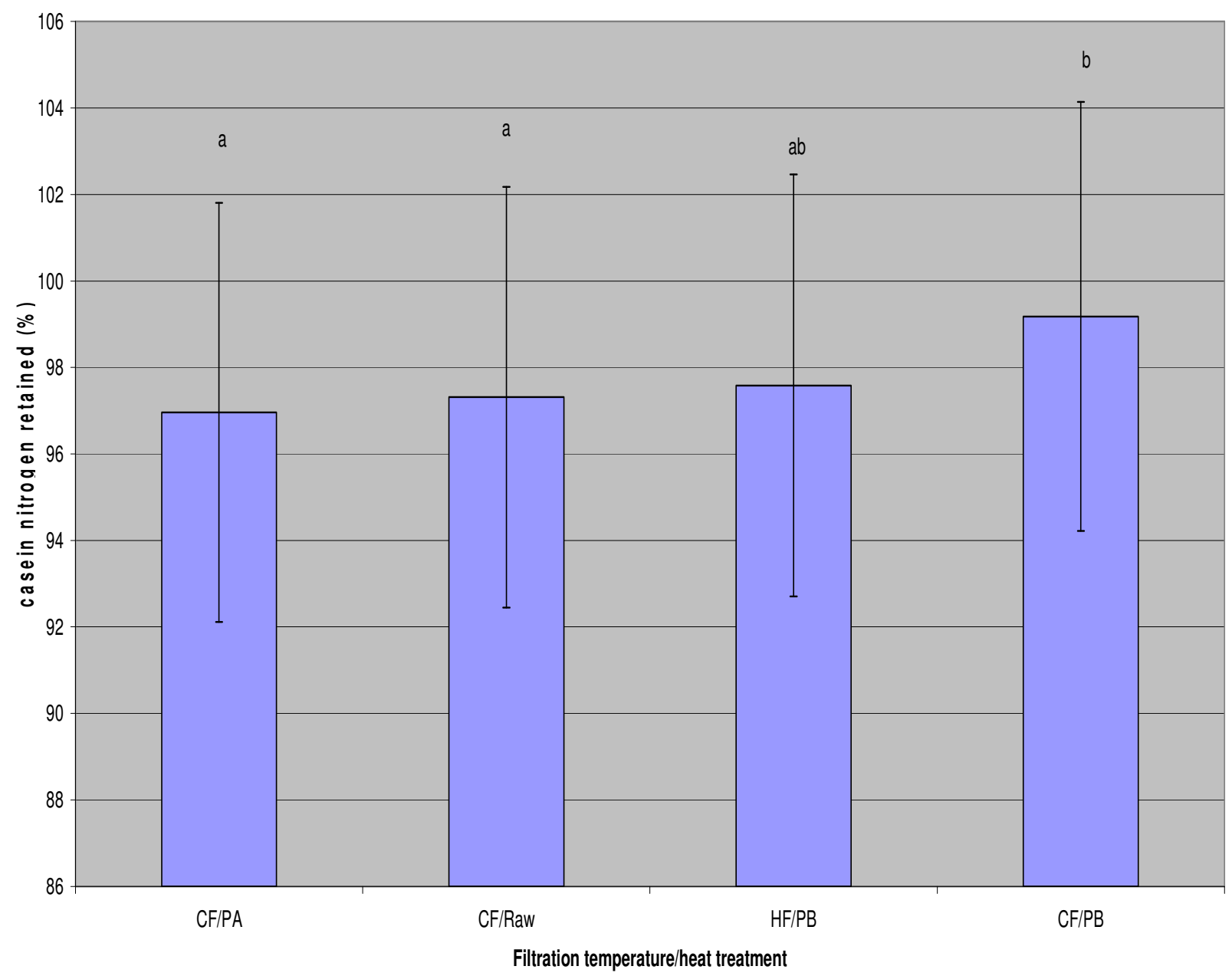

A significant difference exists when the letters between two bars are different (one has an "a" and another has a "b")

There is not a significant difference among samples when both bars have the letter "a"
$\mathrm{CF}=$ cold ultrafiltration $\left(10^{\circ} \mathrm{C}\right)$

$\mathrm{HF}=$ hot ultrafiltration $\left(50^{\circ} \mathrm{C}\right)$

Raw $=$ no heat treatment

$\mathrm{PA}=$ retentate was heat treated after ultrafiltration

$\mathrm{PB}=$ milk was pasteurized before ultrafiltration 
Figure 2.8: Bar graph of \% whey protein nitrogen retained with respect to filtration temperature and heat treatment for whole milk UF retentates

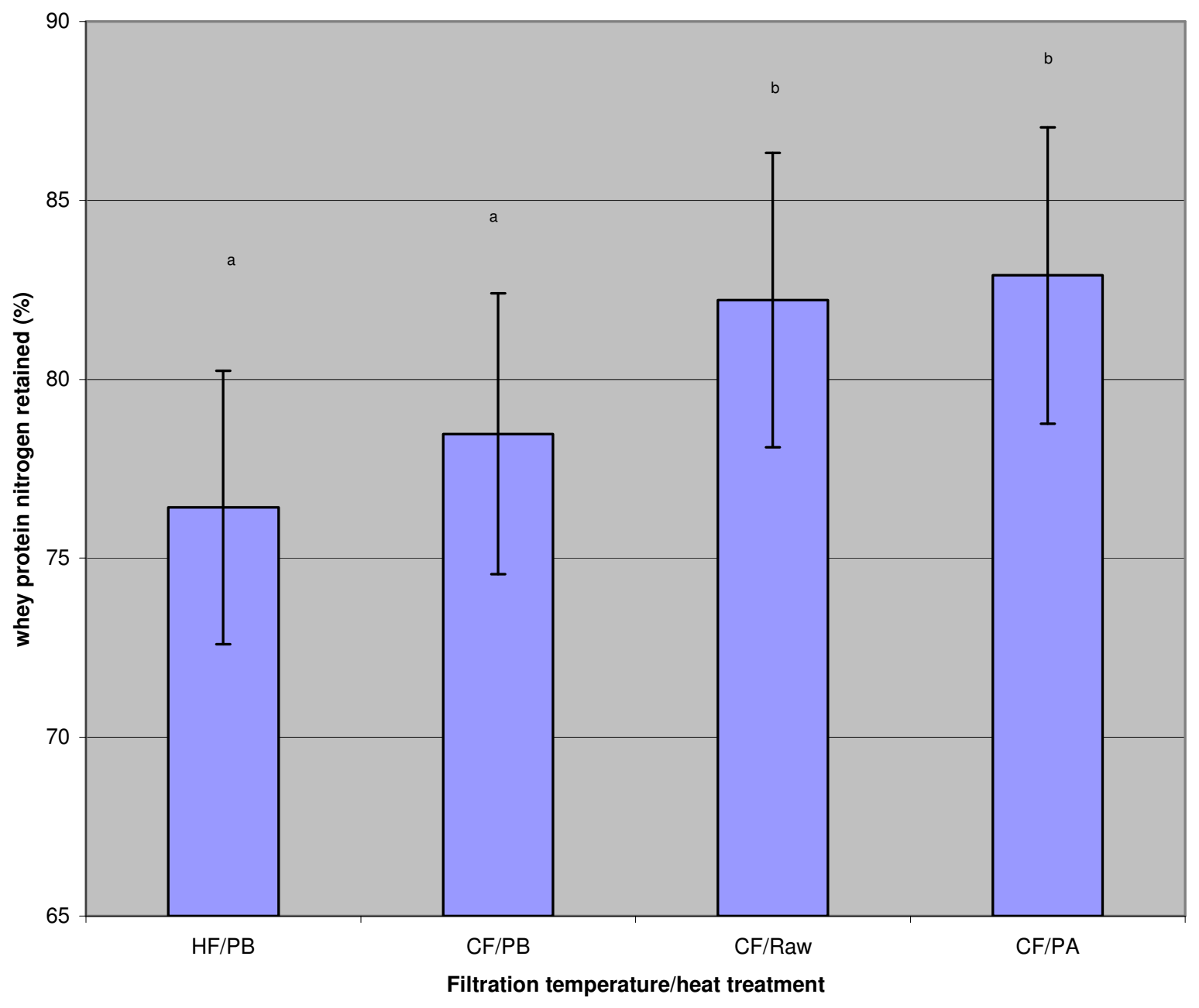

A significant difference exists when the letters between two bars are different (one has an "a" and another has a "b")

There is not a significant difference among samples when both bars have the letter "a"

$\mathrm{CF}=$ cold ultrafiltration $\left(10^{\circ} \mathrm{C}\right)$

$\mathrm{HF}=$ hot ultrafiltration $\left(50^{\circ} \mathrm{C}\right)$

Raw $=$ no heat treatment

$\mathrm{PA}=$ retentate was heat treated after ultrafiltration

$\mathrm{PB}=$ milk was pasteurized before ultrafiltration 
Figure 2.9: Bar graph of retentate $\mathrm{pH}$ at $30^{\circ} \mathrm{C}$ with respect to filtration temperature and heat treatment for whole milk UF retentates

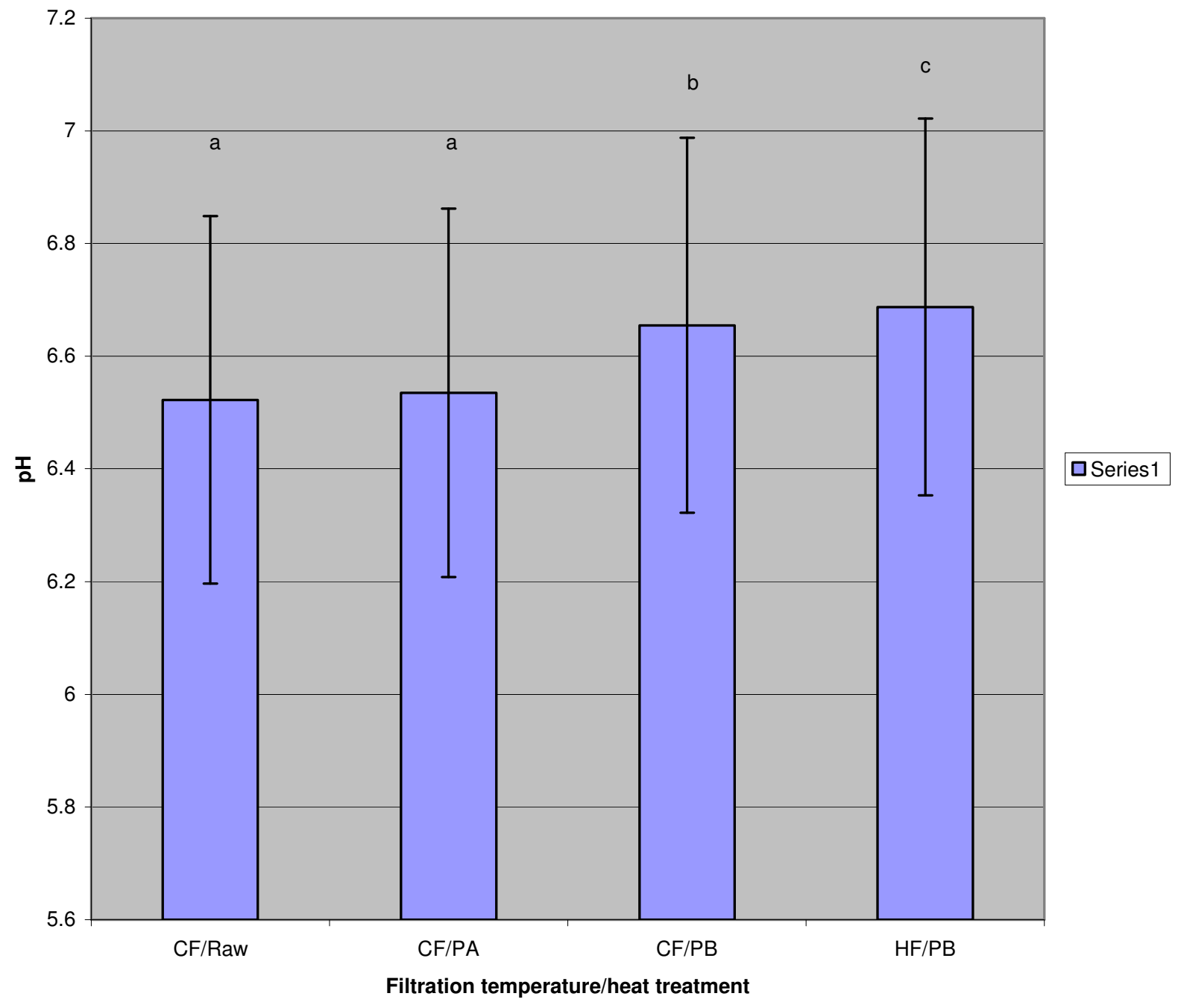

A significant difference exists when the letters between two bars are different (one has an "a" and another has a "b")

There is not a significant difference among samples when both bars have the letter " $a$ "
$\mathrm{CF}=$ cold ultrafiltration $\left(10^{\circ} \mathrm{C}\right)$

$\mathrm{HF}=$ hot ultrafiltration $\left(50^{\circ} \mathrm{C}\right)$

Raw $=$ no heat treatment

$\mathrm{PA}=$ retentate was heat treated after ultrafiltration

$\mathrm{PB}=$ milk was pasteurized before ultrafiltration 
Figure 2.10: Bar chart of \% total fat retained with respect to filtration temperature and heat treatment for whole milk UF retentate

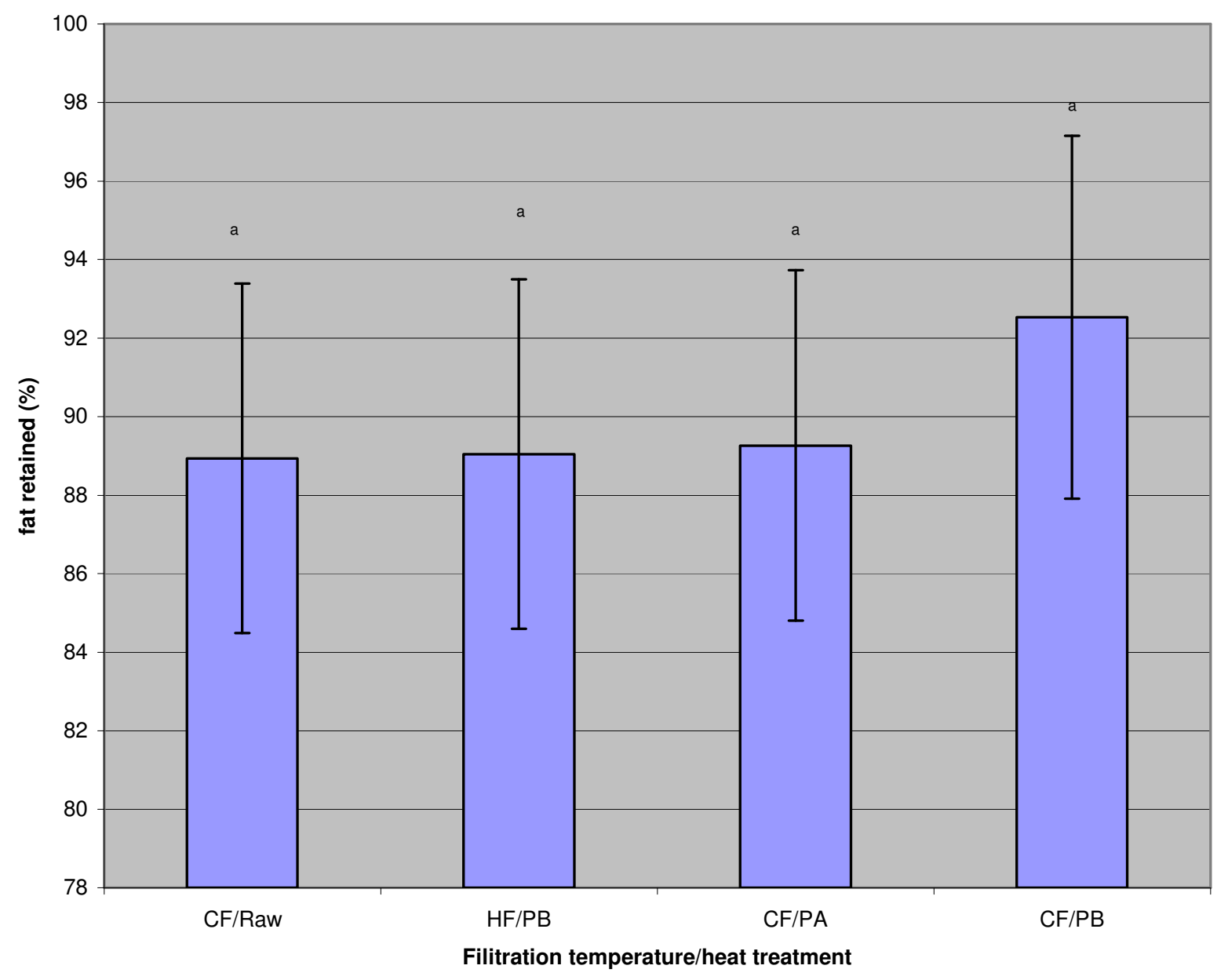

A significant difference exists when the letters between two bars are different (one has an "a" and another has a "b")

There is not a significant difference among samples when both bars have the letter "a"

$\mathrm{CF}=$ cold ultrafiltration $\left(10^{\circ} \mathrm{C}\right)$

$\mathrm{HF}=$ hot ultrafiltration $\left(50^{\circ} \mathrm{C}\right)$

Raw $=$ no heat treatment

$\mathrm{PA}=$ retentate was heat treated after ultrafiltration

$\mathrm{PB}=$ milk was pasteurized before ultrafiltration 
Table 2.1:Composition Summary Table

\begin{tabular}{|c|c|c|c|c|c|}
\hline Treatment & $\%$ Ash retained & Treatment & $\%$ fat retained & Treatment & $\%$ Total Protein Retained \\
\hline CF/Raw & $52.5(1.809)^{\mathrm{a}}$ & CF/Raw & $88.9(3.215)^{a}$ & CF/PA & $93.8(0.501)^{\mathrm{a}}$ \\
\hline CF/PB & $56.0(0.949)^{\mathrm{ab}}$ & $\mathrm{HF} / \mathrm{PB}$ & $89.0(4.970)^{\mathrm{a}}$ & CF/Raw & $93.9(0.226)^{\mathrm{a}}$ \\
\hline CF/PA & $56.3(3.707)^{\mathrm{ab}}$ & CF/PA & $89.3(7.507)^{\mathrm{a}}$ & $\mathrm{HF} / \mathrm{PB}$ & $94.1(0.483)^{\mathrm{ab}}$ \\
\hline $\mathrm{HF} / \mathrm{PB}$ & $61.9(4.256)^{b}$ & CF/PB & $92.5(3.308)^{\mathrm{a}}$ & CF/PB & $95.2(0.964)^{b}$ \\
\hline Treatment & retentate $\mathrm{pH}\left(\right.$ at $\left.30^{\circ} \mathrm{C}\right)$ & Treatment & $\%$ Serum Ca w/respect to total $\mathrm{Ca}$ & Treatment & \% Total Ca Retained \\
\hline CF/Raw & $6.52(0.005)^{\mathrm{a}}$ & $\mathrm{HF} / \mathrm{PB}$ & $39.66^{a}$ & CF/PB & $81.8(0.470)^{\mathrm{a}}$ \\
\hline $\mathrm{CF} / \mathrm{PA}$ & $6.53(0.0129)^{\mathrm{a}}$ & $\mathrm{CF} / \mathrm{PB}$ & $41.14^{\mathrm{a}}$ & CF/Raw & $82.3(0.815)^{\mathrm{a}}$ \\
\hline $\mathrm{CF} / \mathrm{PB}$ & $6.66(0.00577)^{b}$ & $\mathrm{CF} / \mathrm{PA}$ & $47.92^{b}$ & CF/PA & $84.6(1.100)^{b}$ \\
\hline HF/PB & $6.69(0.005)^{\mathrm{c}}$ & CF/Raw & $59.88^{c}$ & HF/PB & $88.6(0.133)^{\mathrm{C}}$ \\
\hline
\end{tabular}

*standard deviation in parenthesis

Table 2.2:Nitrogen Distribution Data

\begin{tabular}{|c|c|c|c|c|c|}
\hline Treatment & \% Total Nitrogen retained & Treatment & \% NPN retained & Treatment & \% NCN retained \\
\hline CF/PA & $93.8(0.501)^{\mathrm{a}}$ & CF/PA & $84.2(1.789)^{\mathrm{a}}$ & HF/PB & $77.9(1.565)^{\mathrm{a}}$ \\
\hline CF/Raw & $93.9(0.226)^{\mathrm{a}}$ & CF/Raw & $84.7(0.937)^{\mathrm{a}}$ & CF/PB & $79.4(1.745)^{\mathrm{a}}$ \\
\hline HF/PB & $94.1(0.483)^{\mathrm{ab}}$ & CF/PB & $85.1(1.634)^{\mathrm{a}}$ & CF/Raw & $82.5(0.565)^{\mathrm{b}}$ \\
\hline CF/PB & $95.2(0.964)^{\mathrm{b}}$ & HF/PB & $85.8(0.957)^{\mathrm{a}}$ & CF/PA & $83.0(0.854)^{\mathrm{b}}$ \\
\hline Treatment & $\%$ True Protein Nitrogen retained & Treatment & \% Casein Nitrogen Retained & Treatment & \% Whey Protein Nitrogen Retained \\
\hline CF/PA & $94.0(0.538)^{\mathrm{a}}$ & CF/PA & $97.0(0.985)^{\mathrm{a}}$ & HF/PB & $76.4(1.788)^{\mathrm{a}}$ \\
\hline CF/Raw & $94.1(0.225)^{\mathrm{a}}$ & CF/Raw & $97.3(0.306)^{\mathrm{a}}$ & CF/PB & $78.5(1.814)^{\mathrm{a}}$ \\
\hline HF/PB & $94.4(0.479)^{\mathrm{ab}}$ & HF/PB & $97.6(0.469)^{\mathrm{b}}$ & CF/Raw & $82.2(0.785)^{\mathrm{b}}$ \\
\hline CF/PB & $95.5(0.972)^{\mathrm{b}}$ & CF/PB & $99.2(1.193)^{\mathrm{b}}$ & CF/PA & $82.9(0.749)^{\mathrm{b}}$ \\
\hline
\end{tabular}




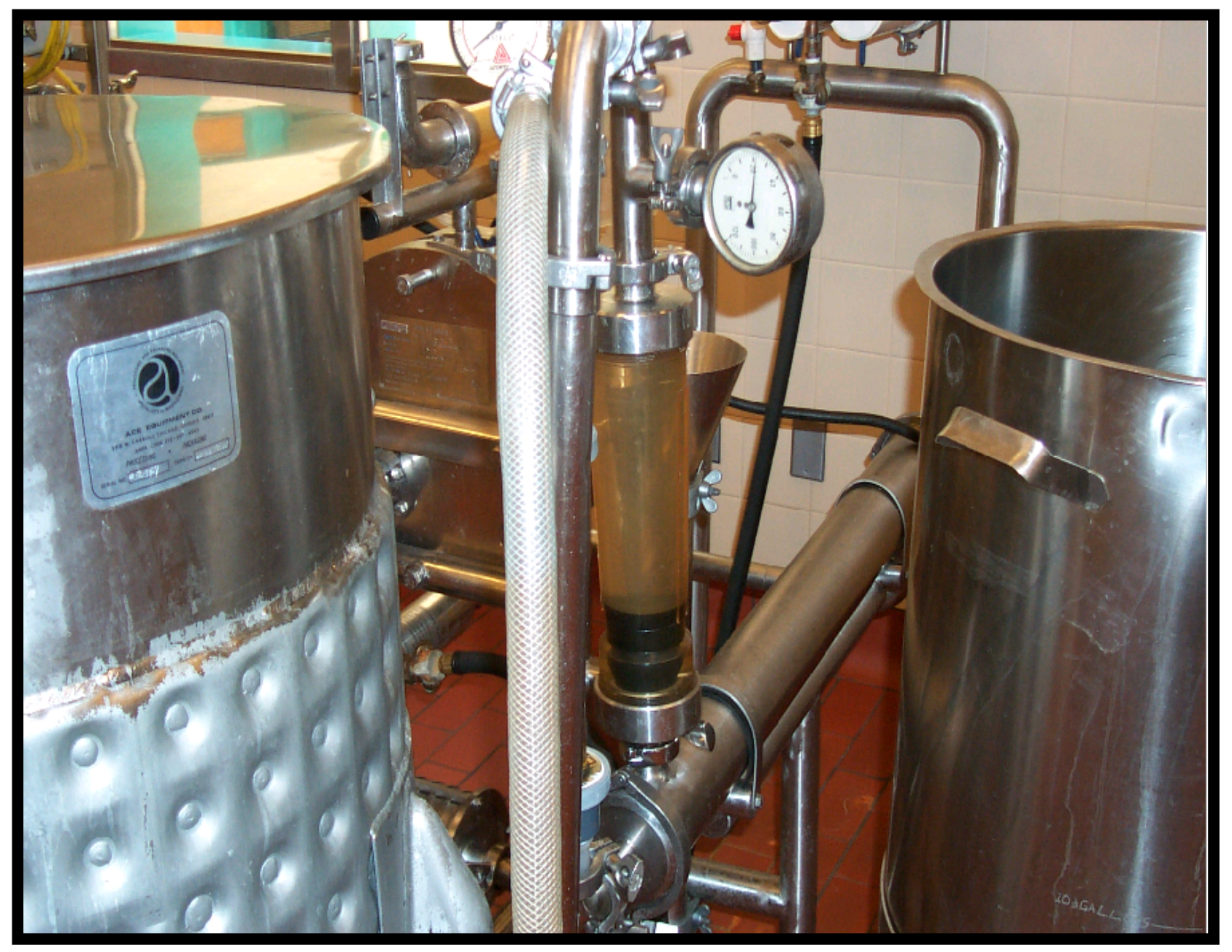

Figure 2.11: Photo of UF system used in pilot plant processing trials of whole milk UF retentate 


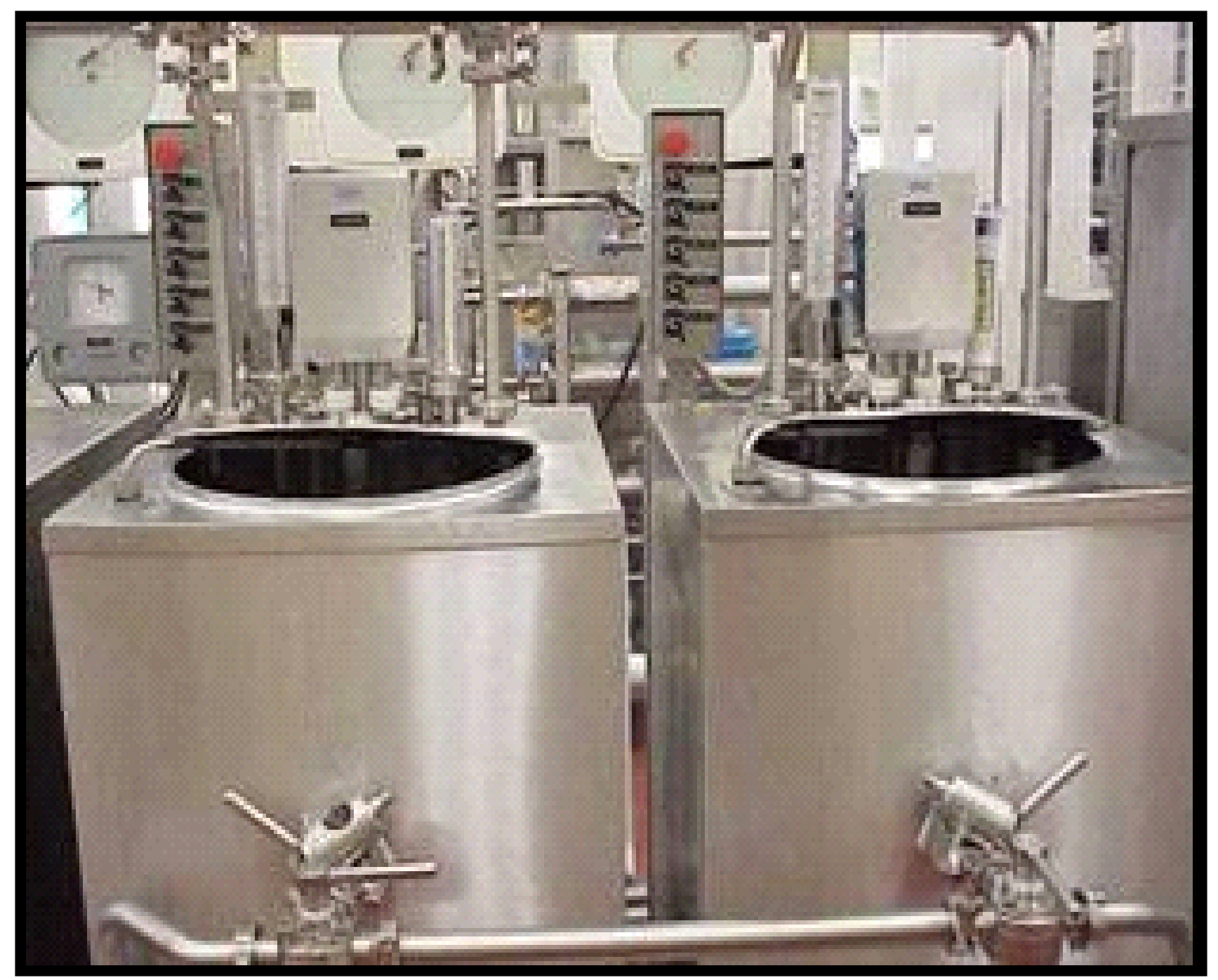

processing of whole milk UF retentates

Figure 2.12: Photo of PMS Mini-processing system used in the pasteurization of milk and retentate for pilot processing trials 


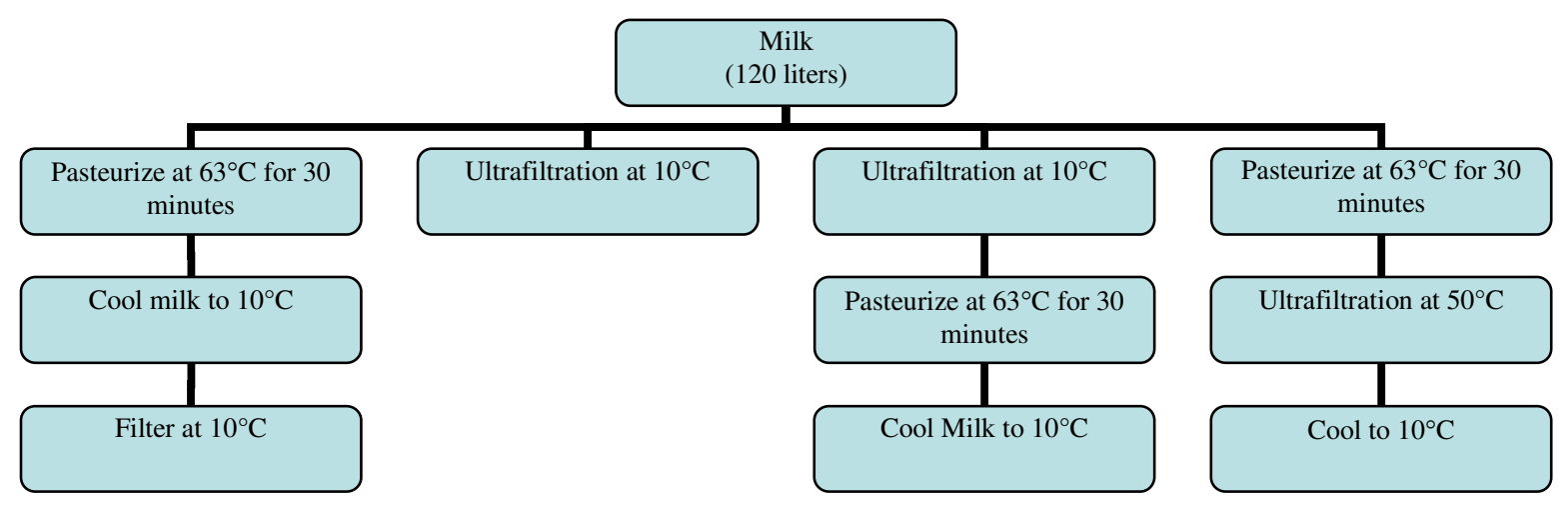

Figure 2.13: Process Flow Diagram for pilot processing trials of whole milk UF retentates 


\section{0: Effects of Composition of Retentate on Rheological Properties}

\section{1: Introduction to Rheology}

Rheology is a scientific field that studies the flow of fluids and deformation of matter (Shoemaker et al., 1992). Understanding the rheological behaviors of foods is important to the following aspects of food processing: quality control of ingredients and finished products, design and evaluation of process and unit operations management, characterization, and development of food products for consumer acceptability as well as the elucidation of the structure and relationship among structural and textural properties. In addition to rheological considerations, the structure of dairy products is intimately associated with texture, which is recognized as one of principal attributes in quality (Shoemaker et al., 1992).

Texture perception is related to the arrangement, disposition, and interactions between molecules of a given food product at the time it is exposed to a certain stress or stain. The constituents in milk, especially protein, fat and mineral content are important parts in the formation of a milk microstructure (Ruiz and Barbosa, 1997). The microstructure, in turn controls physical properties such as viscosity, elasticity, texture and firmness. Milk proteins have the capacity to form a gel consisting of a protein matrix with casein as the main structural element. The matrix may contain addition components such as whey proteins, fat globules, lactic acid bacteria, and other ingredients. The ability to immobilize milk serum or whey in a liquid phase is one of the most important characteristics of the gel matrix. In cheese or other coagulated milk products, casein micelles are one of the most important components of milk that make it possible to formulate a variety of products with very different characteristics, ranging from liquids such as evaporated milk, semi-liquids, such as liquids to semisolids, such as cheese. The ability of casein micelles to interact with whey proteins and aggregate and hydrolyze under 
the effects of low $\mathrm{pH}$, heat and the presence of proteolytic enzymes, is an important property for making dairy products (Prentice, 1992).

\subsection{1: Literature Review-Dairy Rheology}

Viscosity, an important rheological property, refers to the resistance of a material to flow under an applied stress. The more viscous a material is the more force is needed to get the product to flow and vice versa. Viscosity is affected by the composition of the feed and other properties such as heat and $\mathrm{pH}$ (Ruiz and Barbosa, 1997).

When dealing with liquid materials, there are two types of rheological behavior: Newtonian and non-Newtonian. Newtonian behavior appears if there is a linear relationship between the stress applied to the material and the shear rate applied to the material. In terms of liquid, this means that the viscosity does not change as more force is applied (material is under higher strain). Non-Newtonian behavior exists when there is not a linear relationship between stress and shear rate (Sperling, 2001). Two examples of this behavior are shear thinning and shear thickening. Shear thinning refers to the phenomenon in which the viscosity of the fluid decreases with increasing shear rate. In shear thickening, the viscosity increases with increased shear rate (Sperling, 2001). In liquid feed sources, shear thinning is the result of the increase in the volume fraction of the dispersed phase, the distance between the particles and the size distribution of the particles. When the molecules are in close proximity, when the molecules increase in size or when there is an increase in the number of molecules, there tends to be an increase in shear thinning. This is because there are more chain entanglements to be overcome in order to get to a desired flow rate.

Some suspensions or solutions of macromolecules are Newtonian. As a rule of thumb, if the macro-molecular chain in the liquid consists of less than 1000 atoms Newtonian flow 
properties are exhibited. However, the concentration of a solution is also important. At a low concentration, even a solution containing large molecules may exhibit Newtonian behavior. Asymmetrical (rod or plate shaped particles) may even show non-Newtonian behavior at a high dilution (Prentice, 1984).

Non-Newtonian liquids are usually very complex and consist of more than phase, although polymer solutions may be treated as a single phase. The two phase systems are usually made up of a continuous phase (usually a solvent) and the dispersed phase. Some early studies have shown that the relationship between rheology and structure of non-Newtonian liquids is really quite obscure (Prentice, 1984).

Qualitatively, the rheology of a dispersed system depends on properties of the continuous phase, the dispersed phase, and the interaction between the two. In the continuous phase, chemical composition, $\mathrm{pH}$, and electrolyte composition are of critical importance. In the dispersed phase, which may liquid or solid, volume fraction (percentage of one component in another), particle size, shape, size distribution and surface chemical composition play a role. The interaction between the two phases may be affected by the addition of surface active and stabilizing agents, which may modify the behavior (Prentice, 1984).

A wide range of rheological behaviors has been observed in dairy products. Milk and evaporated milk behave as Newtonian fluids, but concentrated milk behaves as a non-Newtonian fluid. Cream and yogurt are also non-Newtonian. Whey gels and some types of cheese have been characterized as elastic solids (Prentice, 1992). In addition, if time is considered a variable, some materials may show a thixotropic behavior. Thixotropy refers to a reversible decrease in apparent viscosity with time at constant shear rate. This is generally due to a reversible change in the structure of material with time under shear. Many studies have been performed, each one 
coming up with their own model for rheological behavior. However, factors such as experimental conditions can lead to debate, discrepancies, and disagreement among results (Velez-Ruiz and Barbosa-Canovas, 1997).

One other type of physical property that is important when working with foods that are gels is the concept of viscoelasticity. Viscoelastic materials range from the viscous liquid with elastic properties (Maxwell type) to the elastic solid with viscous properties (Kelvin-Voigt). Under normal conditions, elasticity in viscoelastic foods is due to the deformation of large molecules and particulate agglomerates. In viscoelastic foods, there is often only a partial recovery in a three-dimensional network because of breakdown under applied stress. The more complete and resistant to breakdown the network is, the more pronounced the elasticity. The viscoelastic properties are defined by two parameters: G' (the elastic modulus) and G' (the viscous modulus). During the formation of a network or a gel, the formation of bonds between the molecules adds some elasticity to the system. As a result, the elastic component $\left(\mathrm{G}^{\prime}\right)$ increases. When these elastic bonds are broken, the material begins to lose its elasticity. As a result, the viscous component (G”) increases. During viscoelastic measurements, the point where G' becomes greater than G', the material becomes more viscous in nature. The opposite holds true when G' becomes larger than G'.

The concept of G' and G' are derived from the dynamic testing methods used in viscoelastic analysis. Dynamic testing refers to the application of continuously changing stress or strain. Normally, the force applied in sinusoidial and the response to the varying stress or strain is measured. The two control variables in this measurement are the frequency and the maximum amplitude of the shear strain. The measured responses are the maximum amplitude of 
the shear stress and the phase difference between the applications of strain to the stress wave (Shoemaker et al., 1992).

Since purely elastic and viscous materials serve as the limits of viscoelastic materials, it is useful to consider the response of the material to dynamic strains. If stress response of an elastic material to a dynamic shear strain shows no phase angle $\left(\delta=0^{\circ}\right)$, then the relationship between the stress and strain at the maximum amplitude is:

$$
\sigma_{0}=G^{\prime}(\omega) \gamma_{0}
$$

where G' represents a dynamic elastic modulus called the storage modulus which depends on the frequency $\omega$ of the applied stress or strain (Shoemaker et al., 1992).

The same type of relationship exists for the application of a static stress or strain. For a purely viscous liquid, the stress response of a dynamic shear strain shows a phase shift of $90^{\circ}$, and the relationship between stress and strain at the maximum amplitude, $\gamma_{\mathrm{o}}$ is:

$$
\sigma_{0}=G^{\prime}(\omega) \gamma_{0},
$$

where G" represents a dynamic loss modulus which also depends on the frequency of the applied stress or strain (Shoemaker et al., 1992). Viscoelstic materials, which have both viscous and elastic structure, show intermediate phase shifts between 0 and $90^{\circ}$ and have the following general relationship between stress and strain:

$$
\sigma_{0}=G^{\prime} \gamma_{0} \sin \omega t+G^{\prime} \gamma_{0} \cos \omega t
$$

A method of measuring the ratio of viscous properties to elastic properties in a material is called $\tan \delta$ which equals the ratio of G": G' or G'/G' (Shoemaker et al., 1992). 


\subsection{2: Factors Affecting Rheological Behavior of Dairy Products}

So, what affects the rheological and physical properties of milk? The most obvious one is the amount of total solids in milk. That includes everything that is not water. These components include protein, fat, lactose and, minerals.

The viscosity of milk increases in a non-linear fashion as the total solids increases. At high concentrations (above 40\%), small additional changes in concentration lead to a very large change in viscosity. This change occurs because the removal of water causes an increase in volume fraction of the dispersed particles and increases the micelle-micelle interactions as the distance between the micelles becomes smaller. In milk processing, this could result in reduced flow rates, high pressure drops, decreased turbulence and severe fouling (in heating operations) (Bienvenue et al., 2003). In milk powder manufacture, the viscosity of the concentrated milk restricts the extent of concentration that can be attained by evaporation without adversely affecting the properties of the milk powder. The viscosity of concentrated milk depends largely on total solids, temperature, holding time of the concentrate preheat treatment, and milk composition. Shear thinning increases with decreasing temperature and increasing total solids. Snooeren et al. (1984) has shown that the viscosity of the concentrate increases upon storage, a phenomenon that is commonly referred to as "age-thickening". During age thickening, a socalled "structural" viscosity is developed during storage, which can be disrupted by agitation. The nature of the physicochemical changes in age thickening is unknown. It has been proposed that age thickening in highly concentrated systems could be due to the loosening of the casein micelles. As a consequence of concentration, the $\mathrm{pH}$ decreases and the ionic strength increases, both of which reduce the amount of calcium bound to the micelles. This, in turn, increases the solubility of $\beta$-casein, resulting in loosening of the micelle structure and increase in voluminosity 
of the micelle (Bienvenue et al., 2003). From observing the rheological behavior of fresh concentrated milks, it has been suggested that at high total solids, these milks behave as weakly flocculated suspensions (Buscall et al., 1991). The storage-induced increase in apparent viscosity may be due to the rearrangement of the three-dimensional structure, resulting in increased number and/or strength of bonds between casein micelles. It appears that the storage of the concentrates for long periods for long periods of time (greater than 8 hours) there are irreversible change in structure, as indicated by greatly enhanced apparent viscosity under high shear. Clearly, there was a transition from reversible to irreversible aggregation of the particles during aging of concentrated milks. From the study by Bienvenue et al. (2003), it was shown that the irreversible increase in viscosity during storage was probably related to the increase in casein micelle diameter, due to aggregation and fusion of casein micelles.

Temperature also has an effect on viscosity of milk. When you apply to heat to a milk sample, the thermal energy causes the milk particles to move. This movement due to heat is called Brownian motion. As the temperature is lowered, there is less Brownian motion and the viscosity increases. Since we are on the subject of heat, the viscosity of milk can be increased by heat treatments as well. The reason of this is the potential for the whey proteins to denature and attach to casein micelles. During denaturation, these proteins unfold, exposing charged areas and attached to the micelles via salt bridges with calcium phosphate, hydrophobic interactions, and the formation of disulfide bonds. Moderate heating does not appear to affect the size of the casein micelles although these treatments cause the whey protein to denature and bind to micellar $\kappa$-casein. More extensive heat treatment causes some degree of micellar aggregation and an increase in particle size. 
Another aspect that affects micelle size and viscosity is the amount of soluble calcium phosphate (Walstra et al., 1999). This is influenced by temperature. At lower temperatures, the calcium is transformed from the colloidal form (attached to micelles) to a more soluble form. This leads to an expansion of the micelles due to the partial to complete dissociation of casein proteins (especially $\beta$-casein). Some of these dissociated proteins have the potential to form aggregates with other dissociated proteins or with other micelles. At high temperatures, the soluble calcium phosphate is converted to colloidal and the micelles contract, causing a decrease in viscosity. The $\mathrm{pH}$ also plays a role in viscosity. As the $\mathrm{pH}$ decreases, the charges on the micelles start to balance out and, once the isoelectric point of the proteins is reached, the micelles aggregate, leading to an increase in viscosity (Walstra et al., 1999).

\subsection{3: Rationale and Objective of the Experiment}

As mentioned earlier, rheology is very important in the design and quality assurance in the production of dairy products. Textural properties are very important for sensory attributes and consumer acceptance of these products. In the case of liquid dairy products, viscosity is very important, especially if being used to produce dairy powders or for ingredient substitution. The viscosity of material also affects sensory attributes and consumer acceptance. In production aspects (such as in the production of milk powder), if the feed stream is too viscous, there will be inadequate drying of milk and potential clogging of the spray drying equipment. In processing applications, milk products are subjected to various temperatures, all of which have the potential to affect not only its composition but also its flow properties. Concentrated milk products (such as UF retentate) are widely used throughout the dairy industry and processing parameters such as filtration temperature and the application of any shear stress from processing equipment all effect their viscosity and properties. There have been many studies showing the effects of temperature, 
concentration factor, and total solids on the viscosity and flow properties of these retentate.

However, few studies compare the viscosities of retentate with respect to filtration temperature and the application of a pasteurization step. Therefore, the objective of this study is to observe the effect of filtration temperature and the application of heat treatment on the viscosity and flow properties of whole milk UF retentate.

\section{2: Methodology}

Whole milk retentate was ultrafiltered to a concentration factor of $3 \mathrm{X}$ while being subjected to different filtration temperatures and heat treatments. This methodology for the pilot processing trials of the different retentate is described in detail in Section 2.0 of this thesis. The methodology for the compositional analysis methods are also discussed there. The rheological data obtained in this experiment comes in the form of flow curves (log viscosity vs. log shear rate) created by the software program of the Dynamic Rheometrics SR-5000 Rheometer (see Figure 3.4 for picture) with a water bath controlled temperature collar (see figure 3.6 for picture). The data points were converted to Excel to recreate the curves on a logarithmic scale. The rheometer is of cup and bob geometry (see figure 3.5 for picture) and a stress sweep was used to obtain the data points. The stress range used was 0.02 to $20.0 \mathrm{~Pa}$. The flow properties of the retentate were observed at three temperatures: $10^{\circ} \mathrm{C}, 40^{\circ} \mathrm{C}$ and $70^{\circ} \mathrm{C}$. There is a time delay of 10 minutes to allow the milk temperature to equilibrate to the desired test temperature. This time can be adjusted on the software program. There is also a lag time when changing the temperature of the water bath. To further study a treatment effect, the viscosity of the retentate at a shear rate of $500 \mathrm{~s}^{-1}$ for each sample at each temperature was observed. Each viscosity measurement was performed in duplicate for each treatment for each week. Since there wasn't an effect of week of processing on the viscosities of the retentate sample, the average retentate 
values were the combined values of both weeks $(n=4)$ Statistical Analysis was performed using a two-way ANOVA using MINITAB Version 13 with Tukey's Pairwise Comparisons. The two variables used were Treatment and Week. Week of processing was used as a variable to make sure there was not any variation in the lots of milk. MINITAB Printouts are presented in Appendix B.

Prior to analysis, a beaker was used to obtain milk samples from the milk cans in a cold storage room. Rheological tests were performed within 24 hours after processing. The samples were thoroughly mixed prior to collection as the retentate samples have a tendency to cream. A ladle was used to collect the sample in the beaker. Fifteen $\mathrm{ml}$ of refrigerated milk sample was added to the cup using a $20 \mathrm{ml}$ syringe. Once added to the cup, place the remaining milk sample back into a refrigerator until further use. The cup was placed in the opening on the rheometer and the bob was lowered into the sample. After the 10 minute delay, the test began automatically and ended automatically once the upper stress limit was reached. This procedure was repeated in triplicate for each sample, at each temperature for both sets of pilot trials. Since there was no effect of week of processing on the viscosity of the retentate, all the flow curves were combined for each treatment at each temperature for each week.

\section{3: Results and Discussion}

The rheological properties of the retentate are displayed in Figures 3.1 through 3.3 and Tables 3.1 through 3.3. All the samples displayed shear thinning behavior (see Figures 1 through 3 of this section). This concurs with a study by Velez-Ruiz and Barbosa-Canovas, in 2000 that stated that concentrated milks display Non-Newtonian behavior at total solids levels above $17 \%$. Since the samples were standardized to $24.75 \%$, this type of behavior was to be expected. Shoemaker et al. (1992) also showed shear thinning properties in concentrated milks. This is due 
to the fact that concentration of milk increases the volume fraction of casein micelles in milk. This is in accordance to Snoeren (1982), that states that viscosity and flow properties are a function of the volume fraction of protein present and the viscosity of the milk serum. The volume fraction itself depends on factors such as the degree of hydration of the protein as well as the protein content and composition. There were some interesting observations seen in the flow properties at the various temperatures. As the testing temperature increases, there is an increase in the degree of sharpness in the initial drop of viscosity with increasing shear rate. At $70^{\circ} \mathrm{C}$, this sharp decline is very apparent. At $40^{\circ} \mathrm{C}$, there is a faint increase in sharpness, but does not appear to be much difference than at $10^{\circ} \mathrm{C}$. A possible explanation for the observed behavior is that at $70^{\circ} \mathrm{C}$, there could have been significant whey protein denaturation, leading to their attachment to casein micelles or in the formation of agglomerates with other serum proteins, leading to a higher initial viscosity. If there was an increase in casein micelle size and agglomerate formation, these particles can lead to the formation of chain entanglements, which, in turn, can cause the sharp decline in viscosity with shear rate, displaying the well-defined shear thinning effect.

An unusual observation was that there was a point on the flow curves for the retentate where the viscosity started to display shear thickening behavior. At first, experimental error was suspected due to high shear rates but it turned out that this would not cause the viscosity to increase. At $10^{\circ} \mathrm{C}$, this phenomenon was only faintly apparent but at the higher temperatures $\left(40^{\circ} \mathrm{C}\right.$ and $\left.70^{\circ} \mathrm{C}\right)$, this phenomenon became more pronounced. A possible explanation for this behavior is that there is a gelation effect taking place. A study involving the gelation of proteins under shear conditions that if the proteins are heat-denatured there is tendency for the proteins to aggregate. This holds true if there are adequate amounts of minerals in the milk serum present to 
overcome electrostatic repulsive forces between the particles. In addition, if the proteins are denatured, the proteins can agglomerate via hydrophobic interactions. Further research is needed to verify these observations.

At $10^{\circ} \mathrm{C}$, there was a significant difference in viscosity $(\mathrm{p}<0.001)$ with respect to treatment. According to Table 4.1, the HF/PB treatment led to a retentate with a viscosity of $15.51 \mathrm{mPa}$ s followed by the CF/PB treatment which led to retentate viscosity of $13.12 \mathrm{mPa} \mathrm{s}$, followed by the CF/PA treatment which led to a retentate with a viscosity of $11.43 \mathrm{mPa}$ s and the $\mathrm{CF} /$ Raw treatment led to a retentate with a viscosity of $9.27 \mathrm{mPa}$ s. Individual significant differences exist between treatment $\mathrm{CF} / \mathrm{PA}$ and $\mathrm{CF} / \mathrm{PB}, \mathrm{CF} / \mathrm{Raw}$ and $\mathrm{HF} / \mathrm{PB}$. Other significant differences exist between treatment $\mathrm{CF} / \mathrm{PB}$ and $\mathrm{CF} / \mathrm{Raw}$ and $\mathrm{HF} / \mathrm{PB}$ and between $\mathrm{CF} / \mathrm{Raw}$ and $\mathrm{HF} / \mathrm{PB}$. There was not a significant effect of week of processing $(\mathrm{p}=0.451)$ on the viscosity results.

At $40^{\circ} \mathrm{C}$, there was not significant difference in viscosity $(\mathrm{p}=0.065)$ with respect to treatment. According to Table 4.2, the HF/PB treatment led to a retentate viscosity of $5.26 \mathrm{mPa}$ $\mathrm{s}$, the $\mathrm{CF} / \mathrm{PA}$ treatment led to a retentate viscosity of $5.52 \mathrm{mPa}$ s, the $\mathrm{CF} / \mathrm{PB}$ treatment led to a retentate viscosity of $5.65 \mathrm{mPa}$ s and the $\mathrm{CF} / \mathrm{Raw}$ treatment led to a retentate viscosity of 5.51 $\mathrm{mPa}$ s. There was an individual significant difference between the HF/PB and the CF/PB treatments. There was not an effect of week of processing $(\mathrm{p}=0.347)$ on the viscosity values.

At $70^{\circ} \mathrm{C}$, there was a significant difference in viscosity $(\mathrm{p}<0.001)$ with respect to treatment. According to Table 4.3, The HF/PB treatment led to a retentate viscosity of $5.52 \mathrm{mPa}$ $\mathrm{s}$, followed by the CF/PB treatment, which led to a retentate viscosity of $5.06 \mathrm{mPa}$ s, followed by the $\mathrm{CF} / \mathrm{Raw}$ treatment which led to a retentate viscosity of $5.05 \mathrm{mPa}$ s and the $\mathrm{CF} / \mathrm{PA}$ treatment which led to a retentate viscosity of $4.83 \mathrm{mPa}$ s. Significant differences exist between treatment 
$\mathrm{CF} / \mathrm{PA}$ and $\mathrm{CF} / \mathrm{Raw}, \mathrm{CF} / \mathrm{PB}$ and $\mathrm{HF} / \mathrm{PB}$. Other significant differences exist between treatment $\mathrm{CF} / \mathrm{PB}$ and $\mathrm{HF} / \mathrm{PB}$ and $\mathrm{CF} / \mathrm{Raw}$ and between $\mathrm{CF} / \mathrm{Raw}$ and $\mathrm{HF} / \mathrm{PB}$. There was not a significant effect of week of processing $(\mathrm{p}=0.446)$ of these viscosity values.

According to the results from Chapter 3.0, significant differences existed in ash, calcium, total protein and true protein (both casein and whey protein). Since there was not a significant difference in fat among the samples, it can be ruled at as a factor contributing to the viscosity differences. The same can be said for the non-protein nitrogen content in the retentate.

Ash can affect the viscosity by affecting the voluminosity of the casein micelle. According to a study by van Hooydonk et al (1986), divalent cations such as calcium cause significant changes in the voluminosity when bound to the casein micelle. If there are adequate minerals in the milk serum, there is the possibility for binding of protein to the casein micelle or in the formation of agglomerates, leading to a change in viscosity.

Total protein can have an effect on viscosity because it can affect the size of the casein micelles. Differences in true protein, whether in be whey protein, casein or both, can lead to an increase in the voluminosity of the casein micelles. Under proper conditions (e.g., protein denaturation or high serum mineral content), protein agglomerates can be formed leading to changes in viscosity. According to the results from the previous section, there was a significant treatment effect on the amount of true protein. Therefore, these protein differences could possibly account for the viscosity differences. However, more research is needed to determine if there were changes in casein micelle size, if agglomerates were formed, and if this affects the viscosity.

The $\mathrm{pH}$ can also play a role in viscosity. As the $\mathrm{pH}$ decreases, the charges on the micelles start to balance out and, once the isoelectric point of the proteins is reached, the micelles 
aggregate, leading to an increase in viscosity. As the $\mathrm{pH}$ is decreased, the calcium goes from colloidal to ionic form. This solubilization of calcium leads to an increase in voluminosity of the micelles, which can also increase viscosity. This concurs with a study by Hallstrom and Dejmek (1988), who observed that lowering of $\mathrm{pH}$ causes dissolution of colloidial calcium, which results in the disintegration and modification of the micellar structure, ultimately affecting the volume fraction and its viscosity. At higher $\mathrm{pH}$, the serum calcium becomes colloidal and under appropriate conditions, can precipitate out as calcium phosphate and form agglomerates. According to the results from the last section, there was a significant treatment effect on retentate $\mathrm{pH}$, which could have affected the retentate viscosity. However, the $\mathrm{pH}$ was taken at $30^{\circ} \mathrm{C}$ and the temperatures used were 10,40 and $70^{\circ} \mathrm{C}$, the $\mathrm{pH}$ values could have varied. Further research is needed to examine how the treatments affected $\mathrm{pH}$ at these temperatures.

The effect of temperature on viscosity was mentioned earlier in the paper. As the temperature of the milk decreases, the minerals (including calcium) solubilize and dissociate from the micelle, increasing the voluminosity. This can lead to an increase in viscosity. As the temperature of the milk increases, calcium returns to a colloidal state, causing the micelle to shrink, causing the viscosity to decrease. Temperature also affects viscosity by the influencing the motion of the molecules. When temperature is decreased, there is no thermal energy from heat and there is no Brownian motion. Since there is no motion in the molecules, the milk remains thick. As heat is added, there is more Brownian motion in the molecules. The motion of the molecules thins out the fluid, leading to faster flow rates under an applied stress (i.e., the viscosity decreases). According to my results, regardless of heat treatment, the viscosities of the retentate decreased with increasing temperature. 


\section{4: Conclusion}

Rheology is very important in many aspects of food processing from design process to quality control of food products and ingredients. In milk, several factors contribute to differences in rheological properties (especially viscosity). One of the key players in viscosity of milk is the chemistry of the casein micelles and its interactions with factors in its environment (e.g., $\mathrm{pH}$, temperature, other serum proteins). These differences can lead to changes in viscosity under specific flow conditions. From my results, there was a temperature effect on viscosity of the retentate. The retentate tested at $10^{\circ} \mathrm{C}$ had higher viscosities than the retentate at 40 and $70^{\circ} \mathrm{C}$. In terms of flow properties, as the temperature of analysis increased, there was a sharp decline in viscosity with shear rate, leading to a more pronounced shear thinning effect and there was a distinct shear thickening effect as shear rate increased. This behavior became more pronounced as the testing temperature increased. These results could be attributed to protein denaturation and its attachment to casein micelles or in the formation of protein agglomerates. In terms of viscosity differences, there was a treatment effect and the compositional differences are possible reasons for these differences. There was not an effect of week of processing on these results. 
Table 3.1: Viscosities of whole milk retentate at $500 \mathrm{~s}^{-1}$ at $10^{\circ} \mathrm{C}$

\begin{tabular}{|c|c|}
\hline Treatment & Viscosity $(\mathrm{mPa} \mathrm{s})^{\mathrm{a}}$ \\
\hline cold filtered (raw) & $9.27(0.000246)^{\mathrm{a}}$ \\
\hline cold filtered (pasteurized after UF) & $11.43(0.000061)^{\mathrm{b}}$ \\
\hline cold filtered (pasteurized before UF) & $13.12(0.000344)^{\mathrm{c}}$ \\
\hline Hot filtered (pasteurized before UF) & $15.51(0.000133)^{\mathrm{d}}$ \\
\hline
\end{tabular}

*standard deviation in parenthesis

Table 3.2: Viscosities of whole milk retentate at $500 \mathrm{~s}^{-1}$ at $40^{\circ} \mathrm{C}$

\begin{tabular}{|c|c|}
\hline Treatment & Viscosity (mPa s) \\
\hline Hot filtered (pasteurized before UF) & $5.26(0.0000751)^{\mathrm{a}}$ \\
\hline cold filtered (raw) & $5.51(0.0002371)^{\mathrm{ab}}$ \\
\hline cold filtered (pasteurized after UF) & $5.52(0.0001405)^{\mathrm{ab}}$ \\
\hline cold filtered (pasteurized before UF) & $5.65(0.0000608)^{\mathrm{b}}$ \\
\hline
\end{tabular}

*standard deviation in parenthesis

Table 3.3: Viscosities of whole milk retentate at $500 \mathrm{~s}^{-1}$ at $70^{\circ} \mathrm{C}$

\begin{tabular}{|c|c|}
\hline Treatment & Viscosity $(\mathrm{mPa} \mathrm{s})$ \\
\hline cold filtered (pasteurized after UF) & $4.83(0.0001)^{\mathrm{a}}$ \\
\hline cold filtered (raw) & $5.05(0.0000306)^{\mathrm{b}}$ \\
\hline cold filtered (pasteurized before UF) & $5.06(0.0000643)^{\mathrm{b}}$ \\
\hline Hot filtered (pasteurized before UF) & $5.52(0.0001193)^{\mathrm{c}}$ \\
\hline *standard deviation in parenthesis $^{-}$ & \\
\hline
\end{tabular}


Figure 3.1: Flow curve of $\log _{10}$ viscosity vs. $\log _{10}$ shear rate with respect to filtration temperature and heat treatment for whole milk UF retentate at $10^{\circ} \mathrm{C}$

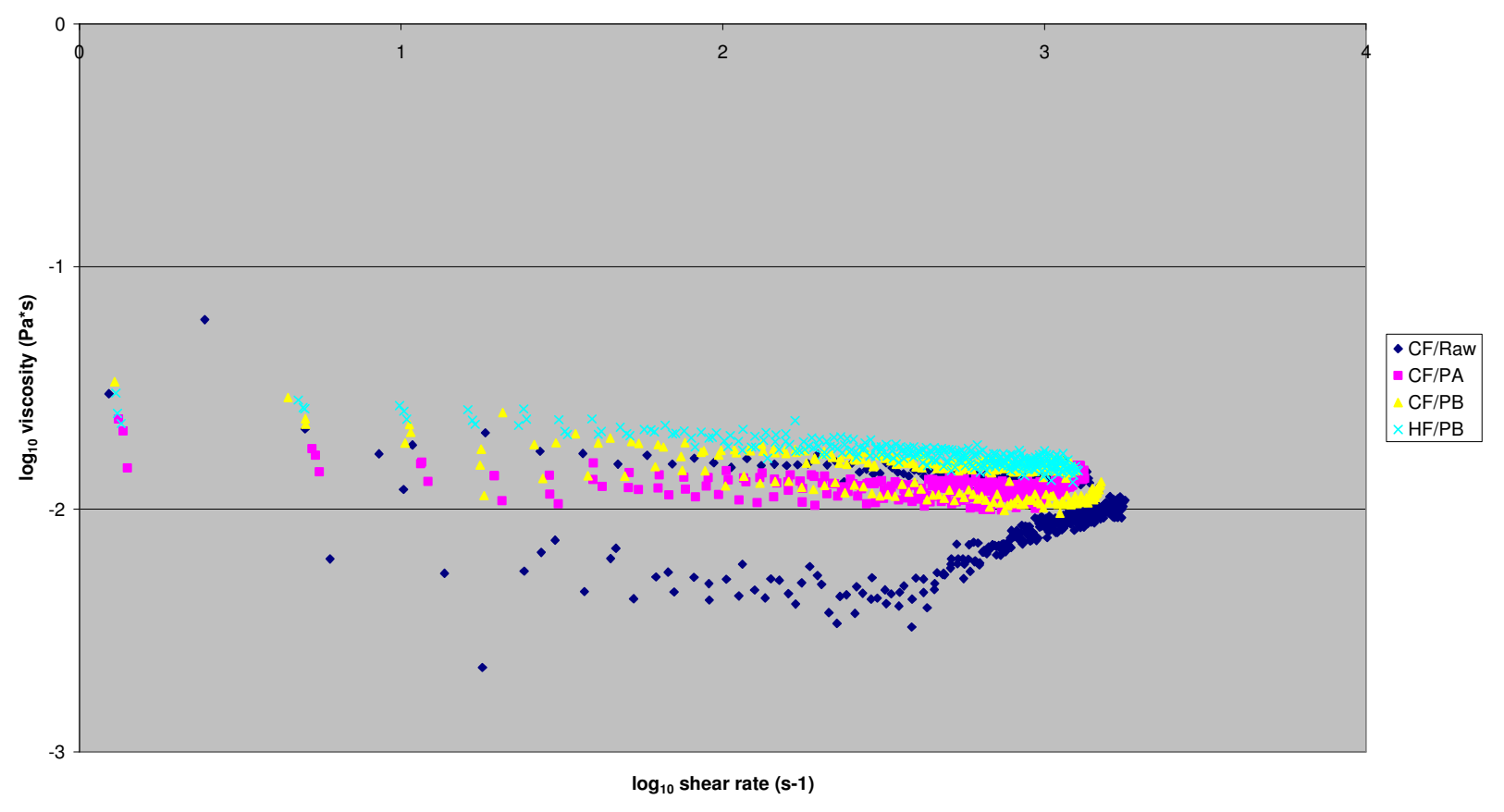


Figure 3.2: Flow curves of $\log _{10}$ viscosity vs. $\log _{10}$ shear rate for whole milk UF retentates subjected to various filtration temperatures and heat tretaments at $40^{\circ} \mathrm{C}$

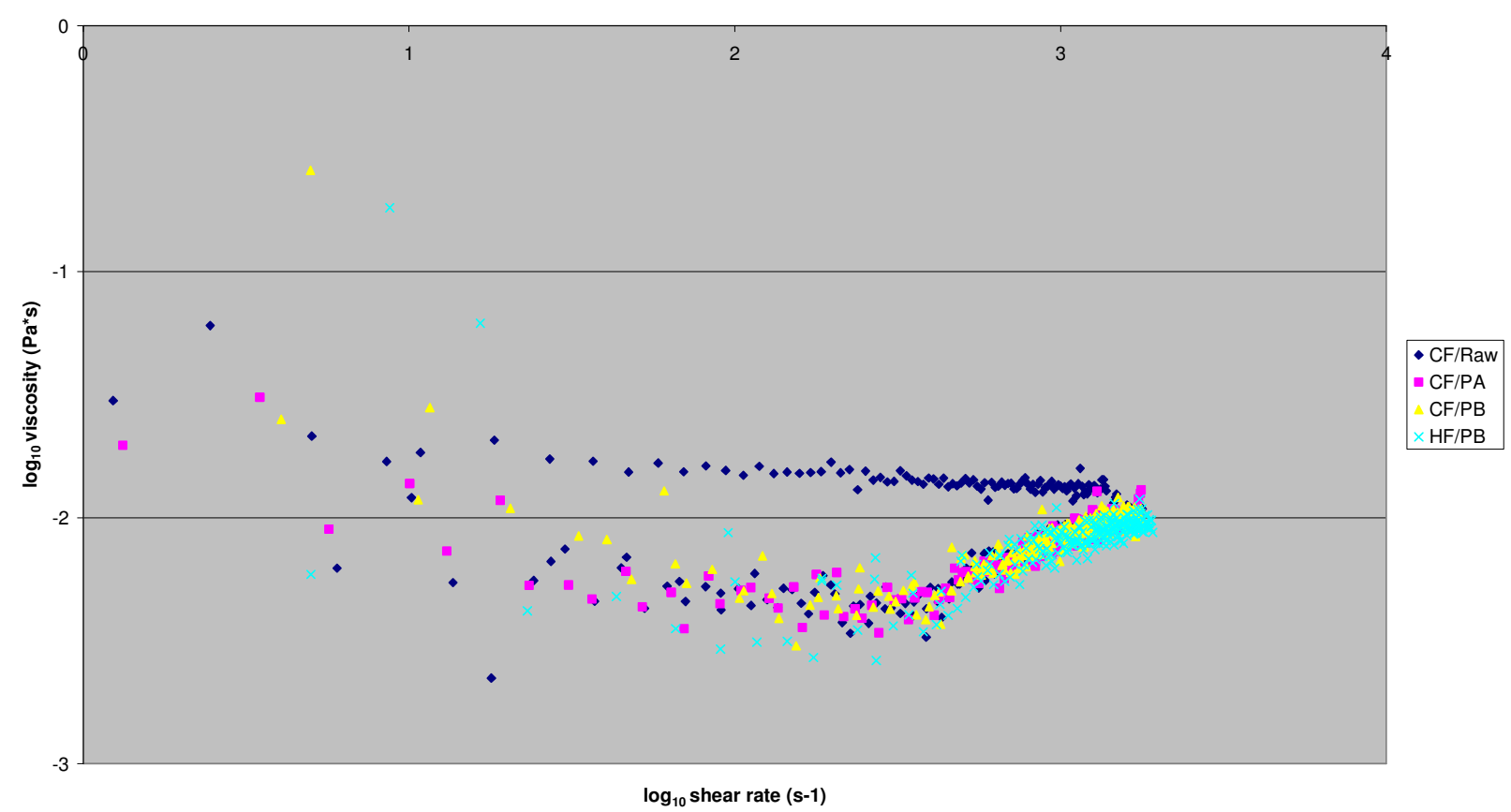


Figure 3.3: Flow curves of $\log _{10}$ viscosity vs. $\log _{10}$ shear rate with respect to filtration and heat treatment for whole milk UF retentate at $70^{\circ} \mathrm{C}$

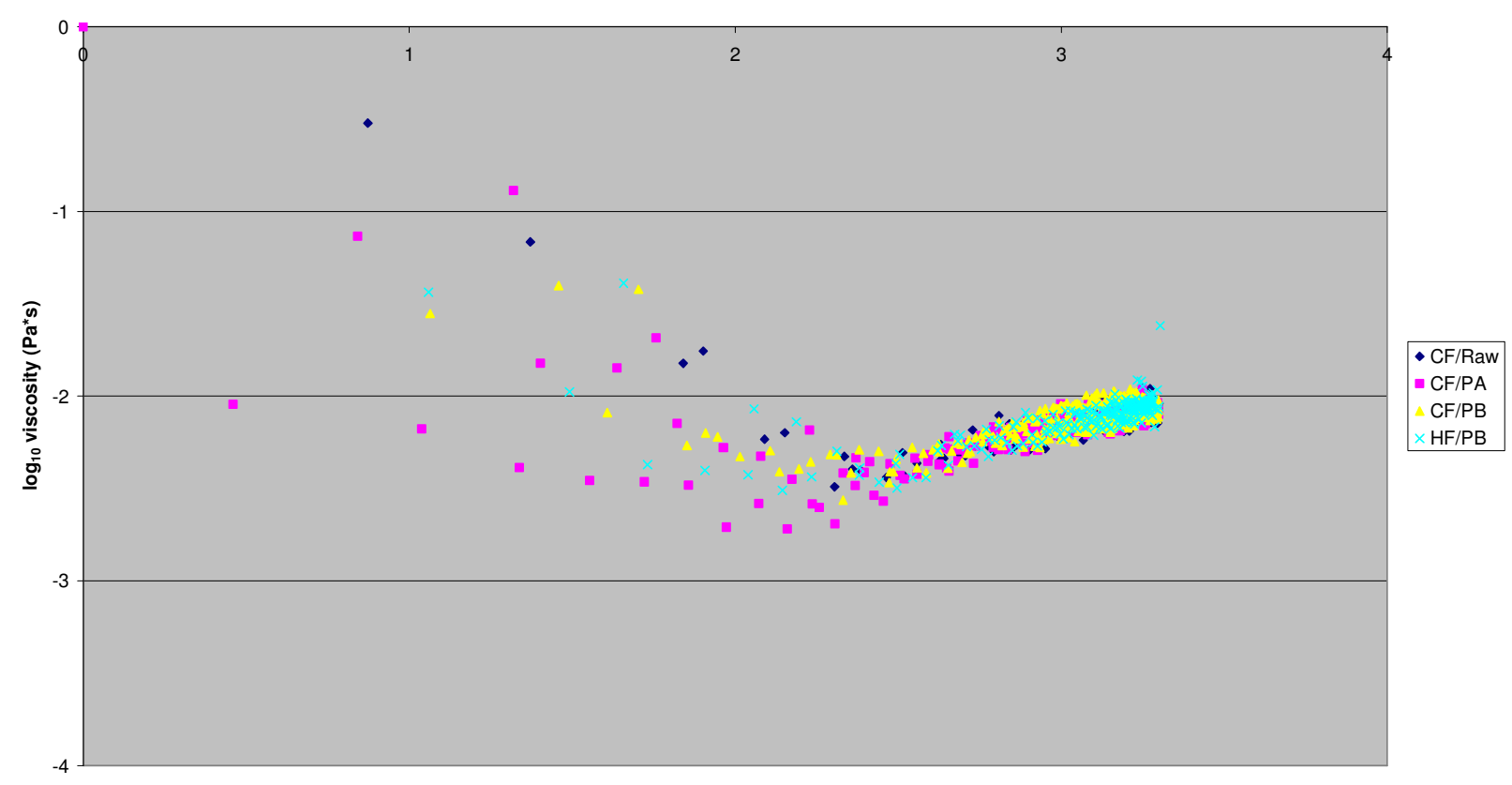

$\log _{10}$ shear rate (s-1) 


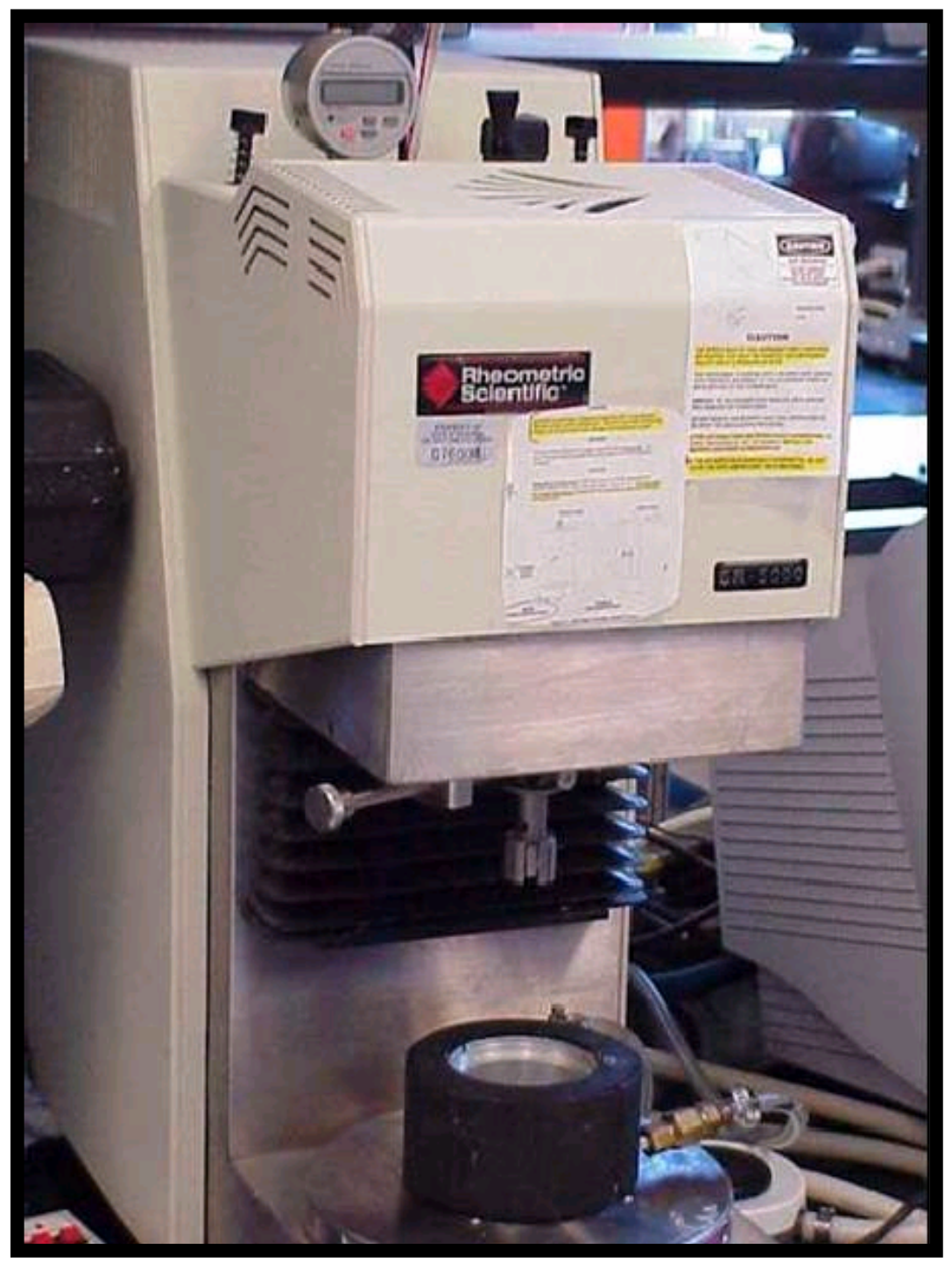

Figure 3.4: Photo of Dynamic Stress Rheometer used in all rheological analysis of the retentate 


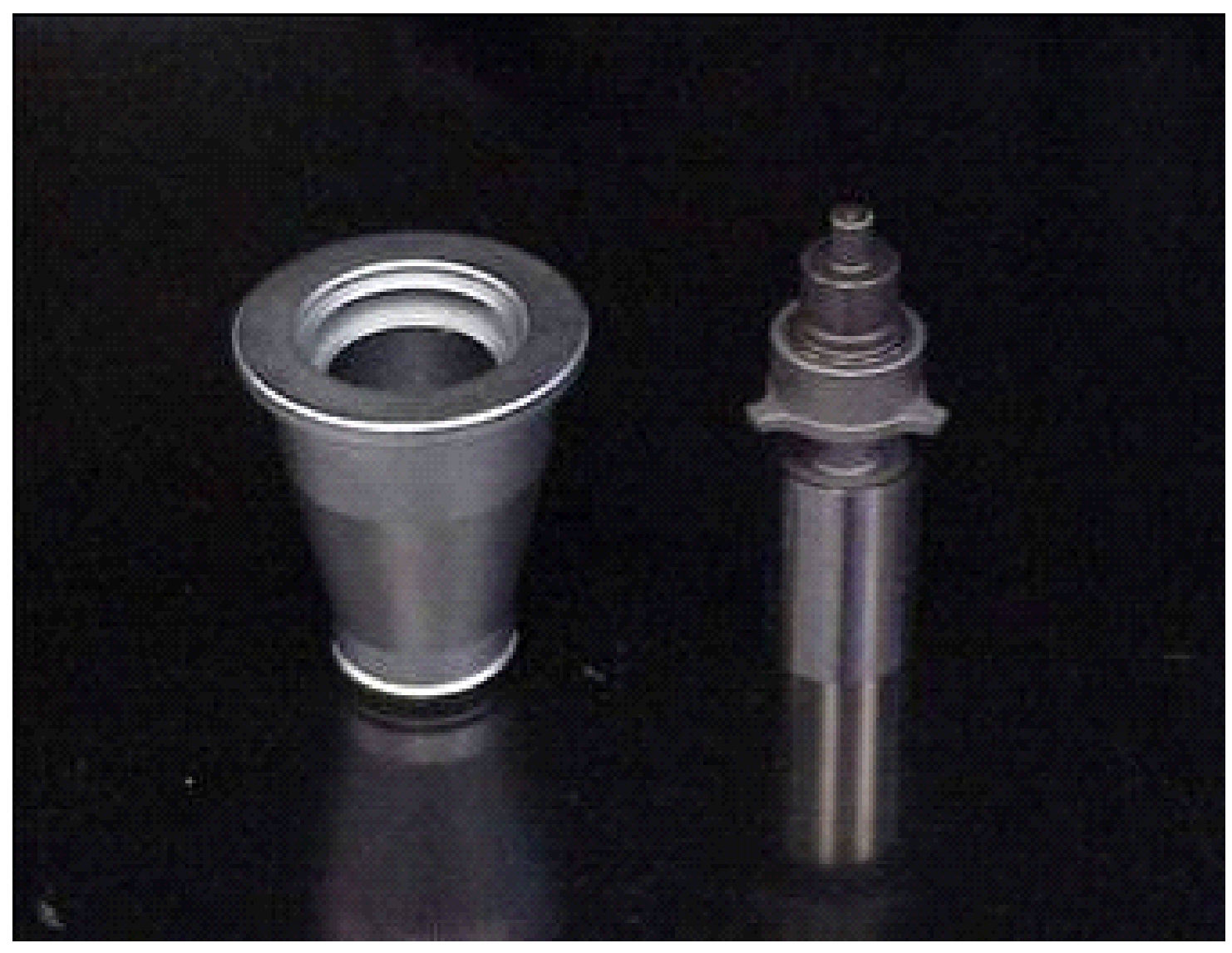

Figure 3.5: Photo of cup and bob used in rheological testing of whole milk UF retentate 


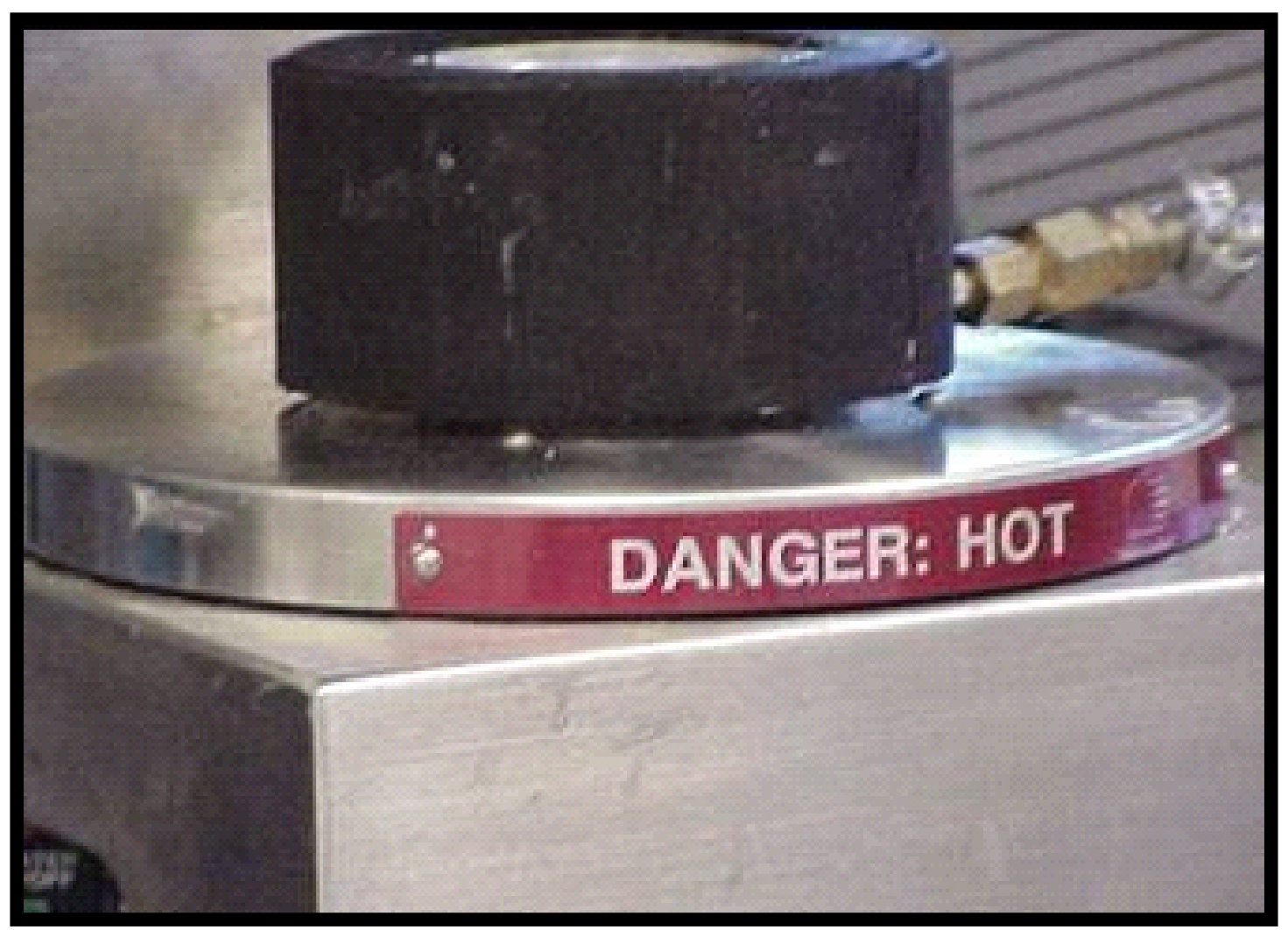

Figure 3.6: Photo of temperature collar used in sample temperature regulation for rheological measurements of all retentate samples 


\section{5: References Used}

Bienvenue, A., Jimenez-Flores, R, Singh, H. Rheological properties of Concentrated Skim Milk: Importance of Soluble Minerals in the Changes in Viscosity during storage. Maunscript. Dairy Products Technology Center, Cal Poly, San Luis Obispo. 2003.

Brule, G. and Faquant, J. Mineral balance in skim milk and milk retentate: effect of physicochemical characteristics of the aqueous phase. Journal of Dairy Research vol 48: 91-97. 1981.

Buscall, R., McGowan, J. and Mumme-Young, C.A. Rheology of weakly interacting colloidial particles at high temperature. Faraday Discussion Chemical Society vol 90 pp. 115127. 1991.

Hallstrom, M. and Dejmek, P. Rheological properties of ultrafiltered skim milk. I. Effects of pH, temperature and heat treatment. Milchwissenschaft vol 43 pp. 31-34. 1988.

Juernink, T.J.M. and de Kruif, K.G. Changes in milk on heating: viscosity measurements. Journal of Dairy Research vol 60 pp. 139-150. 1993.

Prentice, J.H. Measurements in the Rheology of Foodstuffs. Elsevier Applied Science Publishers. Essex, UK. 1984.

Prentice, J.H. Dairy Rheology: a concise guide. VCH Publishers. New York. 1992.

Shoemaker, C.F., Nantz, J., Bonnans and Noble, A.C. Rheological Characterization of Dairy Products. Food Technology pp 98-102, 104. January 1992.

Snoeren, T.H.M., Damman, A.J. and Klok, H.J. The viscosity of skim-milk concentrates. Netherlands Milk and Dairy Journal vol 26 pp. 305-316. 1982.

Snooeren, T.H.M., Klok, H.J., van Hooydonk, A.C.M. \& Damman, A.J. The voluminosity of casein micelles. Milchwissenschaft vol 39 pp. 461-463. 1984.

Sperling, L.H. Introduction to Polymer Chemistry $3^{\text {rd }}$ edition. Wiley Interface Publications. New York. 2001.

Van Hooydonk, A.C.M. The effect of various cations on the renneting of milk. Netherlands Milk and Dairy Journal vol 40 pp. 369-390. 1986 (a).

Velez-Ruiz, J.F. and G.V. Barbosa-Canovas. Flow and structural characteristics of concentrated milk. Journal of Texture Studies vol 31 pp. 315-333. 2000. 
Velez-Ruiz, J.F. and Barbosa-Canovas, G.V.. Rheological Properties of Selected Dairy Products. Critical Reviews in Food Science \& Nutrition vol 37 (4) pp. 311-359. 1997.

Walstra, P., Guerts, T.J., Noomen, A., Jellema, A. and van Boekel, M.A.J.S. Dairy Technology: Principles of Milk Properties and Processes. Marcel Dekker. New York. 1999 


\section{0: Effects of Composition of Retentate on Their Renneting Properties}

\section{1: Introduction to Renneting}

Most researchers believe there are two kinetic processes that contribute to the coagulation reaction: 1) the enzymatic hydrolysis of $\kappa$-casein and 2) the non-enzymatic coagulation of casein micelles and the formation and development of a cross-linked milk gel. The combination of these two processes results in the gross physical changes observed in milk as it coagulates (Carlson and Hill, 1987 (a)).

Milk coagulation is initiated by proteolytic enzymes used to coagulate milk. The most widely used enzyme of this type, calf chymosin, hydrolyzes $\kappa$-casein at one specific peptide bond located at site $\mathrm{Phe}_{105}-\mathrm{Met}_{106}$ along the molecule. Micelles stripped of $\kappa$-casein in this way are no longer soluble; hence, they flocculate irreversibly forming a loose gel matrix. When the matrix is ruptured by cutting or stirring, it collapses and expresses much of the water, whey proteins, and soluble sugars contained in milk. As a result, two separate phases are formed: the aqueous phase or whey, and the high protein phase (the curd). The whey is usually discarded or immediately processed to recover whey proteins and/or lactose before disposal. The highprotein phase (the curd) is processed further and made into cheese. If the gel is handled properly and at the right time, most of the milk fat remains entrapped in the curd (Carlson and Hill, 1987 (a)).

As mentioned earlier, enzymatic hydrolysis is the first step in the coagulation of milk. The reaction involves the hydrolysis of $\kappa$-casein to form para- $\kappa$ casein and a macro peptide. The rate of hydrolysis can be determined by measuring the amount of end products released. The reaction rate is directly proportional to enzyme concentration. The rate is $\mathrm{pH}$ dependent and reaches a maximum of around 5.6. The rennet coagulation time of milk increases with $\mathrm{pH}$ in the 
range from 5.2 to 7.0. Above $\mathrm{pH}$ 7.0, para kappa-casein molecules become progressively more stable and do not really aggregate (Ernstrom, 1974). Below pH 5.2, the measurement of the renneting process in milk is complicated by isoelectric aggregation of the casein micelles. Between pH 5.5 and 6.6, the rate of aggregation increases with $\mathrm{pH}$ (Mehaia and Cheryan, 1983). At $\mathrm{pH} 7.5$, rennet was activated at such a rate that only $40 \%$ conversion could be reach after an extended period of time ( 5 hrs.). Further breakdown of k-casein could be achieved by adding extra portions of rennet at different time intervals during incubation (van Hooydonk et al., 1986 (b)). The accessibility of the Phe-Met bond for chymosin might well be a function of the protrusion of the CMP part of $\kappa$-casein into the serum. For instance, at $\mathrm{pH} 6.0$, the protrusion is probably minimal, allowing for a higher probability for an effective collision between enzyme and substrate (van Hooydonk et al., 1984). Adsorption of chymosin onto (partly) converted micelles reduces the number of catalytically active enzyme molecules. This inhibition effect is probably not significant during early stages of the reaction but would increase with degree of proteolysis (Holmes et al., 1977). According to Guerts and Walstra (unpublished), chymosin appears to interact preferably with $\beta$-casein at low $\mathrm{pH}$ values. It remains uncertain whether these interactions take place with the intact micelle.

The enzyme can bind to other peptides in solution (i.e., competitive inhibition). At $\mathrm{pH}$ values greater than 7.0 and temperatures higher than $50^{\circ} \mathrm{C}$, most milk-clotting enzymes will denature and become deactivated. If deactivation takes places concurrently with $\kappa$-casein hydrolysis, the overall reaction rate will be influenced. Under appropriate conditions, it is possible to completely denature the enzyme before complete hydrolysis of $\kappa$-casein takes place. In this way, the enzymatic phase can be effectively stopped at less than $100 \%$ conversion. The deactivation of rennet enzymes is of practical importance for several reasons: If partial 
deactivation takes place during hydrolysis, the coagulation time will be greatly increased and cheese plant throughput will be reduced. If complete deactivation occurs before $\kappa$-casein is completely, a soft and slowly firming coagulum results. Under extreme deactivation, a coagulum may not form Deactivation after coagulation but during the later stages of cheese production results in reduction of $\alpha_{\mathrm{s} 1}$ and $\beta$-caseins and leads to low flavor production in cheese (Carlson and Hill, 1987 (a)).

Various cations can affect the renneting properties of milk. Aggregation can be accelerated by the absorbed cations shielding the negatively charged groups of the casein. It has been suggested that cationic material binds to sites in the interior of the micelle and not at the surface because the electrophoretic potential of the micelles appear to be unaffected (Green, 1982). Adsorption of cations would increase the hydrophobicity of the rennet-treated micelles and promote aggregation. For example, it has been shown that the accelerating effect of calcium of rennet coagulation time was due to a specific interaction of unknown nature and not the simple reduction of the surface charge of renneted micelles (Green, 1982). Removal of the micellar calcium phosphate in such a way that serum composition remained unaltered prolonged the renneting process. This suggests that not only is the calcium ion concentration important but also the amount of micellar calcium phosphate.

Addition of $\mathrm{NaCl}$ decreases the binding of calcium, possibly due to the exchange of casein-bound calcium ions with sodium ions (Parker and Dagleish, 1981). Addition of NaCl not only increases the ionic strength but also the concentration and the activity of the divalent cations. According to Dagleish (1983), the activation energies for coagulation were increased with increasing ionic strength and that at all temperatures; the reaction rate was decreased with increasing ionic strength. This will have a significant influence on the electrostatic repulsion and 
ionic bond formation due to screening of the charges. All divalent cations reduced the voluminosity of the casein and para-casein micelles (van Hooydonk et al., 1986(a)).

Magnesium appeared to be the least effective than other cations. (van Hooydonk et al., 1986(a) The highest reduction in voluminosity of the original micelles was obtained with $\mathrm{Zn}$. A possible reason for this is a strong interaction of this cation or its phosphate complex with micellar calcium. The voluminosity tends to decrease if more of the divalent cation is bound to the micelle. The finding that the addition of divalent cations always leads to an increase of undissolved complexes containing calcium and phosphate suggest that the interactions between these complexes and casein may be more important for the observed changes in voluminosity than direct association of divalent cations with casein. If an additive causes a redistribution of the micelles in such a way that the total number is decreased, the total volume of the outer layer may be theoretically decreased without a reduction in thickness (van Hooydonk et al., 1986(a)).

Cheese milk is normally enriched with calcium chloride to accelerate the renneting process. The acceleration is due to the combined effect of increased calcium concentration and drop in $\mathrm{pH}$. Addition of calcium had no effect of the rate of enzymic reaction if the $\mathrm{pH}$ was kept constant. The shortening of gelation time and renneting time (time at which firmness of curd is sufficient for cutting are thus entirely due to an increase in the rate of aggregation (van Hooydonk et al., 1986(a)). Keep in mind that a critical amount of calcium is needed to induce aggregation of the casein micelles. Removal of calcium causes an increase in voluminosity and dissociation of casein (mainly $\beta$-casein).

It also seems possible to explain the function of $\mathrm{Ca}^{2+}$ or other cations in terms of specific effects. Studies have found that the acceleration of coagulation for most additives which had both a positive charge and hydrophobic properties. Although $\mathrm{Ca}^{2+}$ lacks hydrophobic properties, 
it appears to have a specific function beyond simply further reducing the surface charge of renneted micelles. Whether specific Ca-bridges are formed is questionable, but the binding of $\mathrm{Ca}^{2+}$ to the caseins may contribute observed effects of ionic strength and temperature, since such binding is increased by increasing temperature and by decreasing ionic strength (Parker and Dalgleish, 1981).

Genetic variance of the $\kappa$-casein also effects cationic interactions with the micelle. All studies on this subject suggest that $\kappa$-casein variant A have prolonged coagulation time and curd firmness compared to B variants. Milks containing different $\kappa$-casein variants, on average, differ in casein composition, micelle size distribution and salt content (Schaar, 1984). Citrate and pH were found to be higher and phosphate and calcium contents lower in milk containing $\kappa$-casein $\mathrm{A}$ variant. These above mentioned traits for the A variant can lead to milks having abnormally long renneting times (over 60 minutes). This can be attributed to the higher $\mathrm{pH}$ and decreased amounts of total and ionic calcium. The A variant of $\kappa$-casein contains one negatively charged residue more than the B variant (Schmidt et al., 1966). The extra negative charge in the casein macropeptide increases the electrostatic or steric repulsion between substrate and enzyme. Although the enzymic reaction proceeds more slowly, it does not explain the total change in gelation time.

The second kinetic process is the flocculation of the casein micelles. Recent studies have shown the micellar suspensions reach limiting agglomeration states, making it difficult to apply an accurate kinetic theory to the process. However, the rate of reaction is strongly related to the extent of $\kappa$-casein hydrolysis. When less than $60-80 \%$ of the $\kappa$-casein is hydrolyzed, the micelles flocculate slowly, if at all. After this "critical" degree of hydrolysis is reached, flocculation 
becomes rapid and the rate-limiting step shifts to the hydrolysis of the $\kappa$-casein (Carlson et al., 1987 (b)).

The most commonly used theory to describe flocculation kinetics is the von Smoluchowski model (Carlson et al., 1987 (b)). In fact, he was the man who came up with the original theory describing the kinetics of agglomeration of colloidal particles. His theory predicts that the rate of decrease of independent particles (increase in agglomeration rate) should follow second-order kinetics. This applies to charged particles with mutual repulsive and attractive forces. This theory, the rate constant is a function of the Boltzman constant (related to entropy), the absolute temperature, and the viscosity of the suspension fluid. To sound more precise and scientific, the kinetic equation is based on the steady-state analysis of the rate at which two particles encounter one another as they move about in Brownian motion in a fluid with a certain viscosity value. Another stipulation is that you are assuming that the particles are equal size spheres. For many colloids, the value of the rate constant is actually much smaller than the one predicted by the rate equation. The difference is attributed to the existence of a "potential energy" barrier that prevents them from actually colliding when Brownian motion brings them into close proximity (von Smoluchowski, 1917). This introduces as to the DVLO theory.

According to Dalgleish (1983), if temperature dependence of aggregation is to be explained on the basis of a DVLO mechanism, it must be postulated that the surface charge is temperature dependent and that it is approximately zero at all temperatures above $60^{\circ} \mathrm{C}$. Moreover, the dependence of reaction rate on ionic strength is also incompatible with a DVLO model, where increases in ionic strength should decrease the repulsion between the charged surfaces, and allow closer approach of the particles. 
For two particles to agglomerate there is a potential energy barrier that must be overcome. This is very similar to an activation energy required for a reaction to take place. The potential energy has two components: an attraction potential, due to London-van der Waals forces between particles and a repulsive potential which arises because an electric double layer surrounding the particles (the "hairy" $\kappa$-casein layer represents this layer in casein micelles). If only a repulsive potential exists, the particles will not agglomerate since no force would hold them together. However, since there is an attractive potential, though it results from so calledlong range interactions, they dominate at short distances. Therefore, if the energy barrier is low enough to overcome, agglomeration will occur. This theory can be applied to casein micelles as long as certain properties are taken account: (1) the micelles are highly porous; (2) the micelles carry a surface charge due at partially to presence of $\kappa$-casein on the surface (Carlson and Hill, 1987(b)). Dalgleish (1983) also adds that how well the particles collide also effects rate of coagulation and states that even though particles may collide, the attractive or cohesive forces may be too weak to ensure a permanent attachment.

If a surface potential barrier is not responsible for inefficient collisions, then the strengths of the cohesive forces must be considered. Hydrophobic bonds are known to be sufficiently temperature dependent to explain temperature dependence, being weak at low temperatures and stronger at much higher temperatures. However, to explain to coagulation on the basis of a hydrophobic model is incomplete since it will explain the influence of salt or calcium ion concentration on the aggregation process (Dalgleish, 1983).

There is another kinetic model that relates the Haymaker constant (and hence voluminosity) to the potential energy barrier. The $\zeta$ potential relates to the attractive and repulsive forces. For agglomeration to occur, the $\zeta$ potential should be close to or equal to zero. 
A negative value indicates repulsive forces are dominant and a positive value indicates the attractive forces are dominant. According to experimental values, a native micelle has a potential of $-20 \mathrm{mV}$ and renneted particles in which most of the $\kappa$-casein has been hydrolyzed is $10 \mathrm{mV}$. The results from $\zeta$ potential determination can be summarized as follows: the potential increases with increasing $\mathrm{pH}$, the potential increases with increasing temperature, the potential is the same for large, and small particles, the potential is unaffected by calcium concentrations between 0.003 and $0.01 \mathrm{M}$ and the potential is reduced by a factor of at least 2 following $\kappa$ casein hydrolysis (Carlson and Hill, 1987(b)).

Two conceptual difficulties arise when one applies this colloidal stability theory to micelle-milk serum systems. The first concerns the dependence of the potential energy function on the interparticle distance. The problem is that the maximum in the potential energy function occurs at a distance of 5 to $10 \AA \AA$. At this separation distance, other forces in addition to London and van der Waals become important. These include ionic charge interaction and hydrophobic interactions. Neglecting the impact of these forces may introduce serious errors into the stability analysis. The second conceptual problem relates to the assumption of a uniform surface potential on the micelles. Since at least a portion of the surface potential is due to the presence of $\kappa$-casein on the micelles and since interactions occur at such close range, it is not feasible to assume that the charge distribution on the surface is not uniform throughout the coagulation process, especially at high conversions. Instead, it is more likely that there are areas on the micelle surface where the potential is very small and areas where the potential is high due to the presence of remaining $\kappa$-casein. In this scenario, steric effects will also influence agglomeration rate (Carlson and Hill, 1987(b)). 
There are three methods that can be used to measure the instantaneous rate of agglomeration: (1) viscosity measurements, (2) particle counting methods, and (3) turbidity measurements.

Due to the complexity of the relationship between the state of agglomeration and viscosity, viscometry is a method that is seldom used. Particle counting is the most direct method of determining the state of agglomeration of a colloidal system. It is also one of the most difficult measurements to carry out experimentally, especially for milk micelle agglomerates, since these are fragile structures that are easily disrupted. The most commonly used method to determine the state of agglomeration of milk micelles involves turbidity. For solutions or suspensions of small particles (particle sizes less than $\lambda / 20$ ), the turbidity is related to the weightaverage molecule weight of the molecules (Carlson et al., 1987 (c)).

Formation of a suitably firm milk gel is important. Firmness must be properly developed before the curd is ruptured because this prevents the loss of casein protein and the escape of fat globules from the milk gel matrix. When a gel formation occurs, cross-links are formed between chains of flocculating micelles when sufficient hydrolysis has taken place. Measurement of gel firmness development has been conducted with a wide variety of instruments (e.g. Rheometer). The devices all provide a relative measure of shear modulus with respect to time. From experimental studies, it is apparent that enzyme concentration in the milk has a strong influence on rate, but not on the extent of gel firmness development (Carlson et al., 1987(d)).

When the milk gel (coagulum) is first formed, it has essentially no strength or firmness since it only contains enough cross-links to create a gel. The formation of additional cross-links firms the gel and, more importantly, causes the gel matrix to surround and entrap fat globules and bacteria. Such entrapment is essential to the production of the characteristic flavors and 
textures by which many types of cheese are distinguished. Therefore, it is important that the rate and extent of cross-linking be known, so that the curd is cut at the proper time. If the curd is cut too soon, losses of fat and protein will be caused by the "disruption" of the weak gel. If the curd is cut too late, there will be a needless delay in the process.

There are two assessment commonly used to test curd firmness. In one method, the cheese maker inserts his finger obliquely in the coagulum, and then pulls it out perpendicular to the surface of the vat. By observing how the curd breaks, the cheese maker can tell if it should be cut. An alternative method is that the back of a hand can be placed on the curd and pressure is applied to test the firmness or "springiness" of the coagulum. There are some obvious limitations to these methods: it takes experience to be able to properly evaluate the firmness and strength of the curd. For research purposes, there is no way to use these techniques quantitatively (Carlson and Hill, 1987(d)). These methods have inspired the creation of two objective tests that can determine curd firmness. The strength of the coagulum can be measured in terms of its yield strength, which is the maximum stress that can be applied before the curd will rupture. The firmness of the curd is related to its shear modulus. The value of the shear modulus in the gel system is directly related to the number of cross-links in the gel (Flory, 1953). More highly linked gels will exhibit a higher shear modulus, a fact that can be used to explain the increase in rigidity (firmness) of the milk coagula. As mentioned earlier, at the gel point, there is only the bare minimum number of cross-links formed. Therefore, the shear modulus is essentially zero. Further cross-linking causes the modulus to increase until it reaches a maximum value. The max value is determined by the maximum in cross-link density (Carlson and Hill, 1987(d)). 


\subsection{1: The MMV Method of Cheese making}

The MMV method, named after the inventor's name, was created at a time in which there was a desire for cheese making continuously. Primarily, one selects a cheese to be made with a known composition. Then milk or a milk mixture is ultrafiltered until the protein and fat concentration corresponds to that of the targeted cheese (Maubois et al., 1980). An advantage of using Ultrafiltration, $\alpha$-lactoalbumin and $\beta$-lactoglobulin are completely retained with casein by the retentate and thus contribute significantly to cheese yield, while in traditional cheese making, these two proteins are lost in the whey. The resulting highly concentrated, liquid retentate of 5:1 to 10:1 volume concentration ratios (VCR) are called pre-cheese by the inventors. Then these liquid precheeses are automatically injected or dosed with measured amounts of starter culture, rennet, color, and salt. In a matter of minutes, a fresh cheese emerges and is removed from its form by pneumatic means and transported on pallets to the ripening room (Hansen, 1981). Different cheese types can be made simply by changing the initial composition of the milk with cream by ultrafiltering, with or without, diafiltration, to optimum concentration and by changing the dosing sequence. Increased average yields of 8 to $15 \%$ reduced amounts of rennet (as much as $80 \%$ ) and better control over cheese weights result.

From 1969 to 1979, the ten years that followed the introduction of MMV concept, was one of extensive exploration. In France, Camambert, St. Paulin and soft rennet cheeses were found highly adaptable to MMV procedures and in Denmark, Feta cheese was made with some success. In the United States, early research utilizing MMV principles led to the making of Cheddar, mozzarella, cottage, cream, and ricotta cheeses. For process cheese manufacture, the concept of replacing up to $50 \%$ of natural Cheddar cheese with highly concentrated retentate reinforced by freeze-dried retentate was applied with success. At the same time, workers in 
England and the United States deviated from MMV principles to make cheese including Cheddar and cottage from UF milk retentate of 2:1 VCR (Kosikowski and Fernandez, 1986). Thereafter, the retentate, unlike MMV pre-cheese, was subjected to traditional cheese making. To keep this method separate from the other, the acronym LCR for low concentration retentate cheese making. Advantages of LCR cheese making include, increased manufacturing efficiency, improved quality of marginal cheese, reduced rennet requirements, and potentially higher yield. Retentate treated with rennet coagulate more rapidly than fresh milk and give curd that is firmer. Cut into cubes, the retentate curds cook out more rapidly in the vat and show better texture and definition. A unique feature of UF milk retentate, which is directly related to volume, concentration, and calcium phosphate levels, is its strong buffer capacity. This poses a potential technical problem in cheese manufacturing by making it more difficult to attain optimum $\mathrm{pH}$ for quality. In addition, an inability to reduce $\mathrm{pH}$ and repress growth of spoilage or food-poisoning organisms invokes public health concern. Fortunately, it is possible to reduce buffer capacity, and avoid problems by utilizing treatments involving pre-acidification. Simultaneous lactic acid fermentation in the UF, diafiltration or retentate washing with water, calcium removal by sodium chloride addition and use of lactic acid starters capable of penetrating the buffer barrier. In future ultrafiltration Cheddar cheese making, one can expect to see more applications of various combinations of mesophilic starters, S. lactis, S. cremoris with thermophilic starters $S$. thermophilus, and L. bulgaricus at incubations near $37^{\circ} \mathrm{C}$. In addition, more extensive use of starter systems that produce large numbers of bacteria, and of microbial flavor enzymes is possible (Kosikowski, 1986).

Excellent melting Mozzarella cheese was attained and increases in cheese were directly related to retentate concentration. Yield efficiency, based on casein recovery, was higher in 
retentate cheese than in controls. Cheese from UF whole milk using LCR retentate generally showed improved physical properties over non-retentate control whole milks. If preacidification is used as a pre-treatment, retentate Mozzarella had a significantly firmer curd than non-concentrated. Non-retentate cheese that is pre-acidified had a higher than normal moisture level that may have resulted from losing excess fat to whey, thus upsetting the compositional balance. The anionic species of the acid influences the salvation of proteins from milk, which increases the ability of the fibrous network to imbibe water (Kosikowski, 1986).

Spangler et al. (1990) reported that Gouda made from retentate with a VCR of 5x created a Gouda with similar characteristics similar to traditionally made Gouda than LCR milk. Conventional made Gouda is often kept in a brine solution for a longer period of time because it has been shown UF cheeses tend have increased structure and a more open structure resulting in quicker salt diffusion. Previous research has shown that the use of a plastic cheese coating may help with increasing curd fusion. A problem with using UF retentate for cheese making is that high levels of casein, $\mathrm{Ca}$, and $\mathrm{P}$ increase buffering capacity and affects cheese-making aspects such as lactic acid production, coagulation kinetics, curd rheology, enzyme activity, and water holding capacity. Micelle-bound $\mathrm{Ca}$ and $\mathrm{P}$ increasingly solubilize into the serum phase of milk at lower $\mathrm{pH}$ thus UF at lower $\mathrm{pH}$ can transfer additional $\mathrm{Ca}$ and phosphate into permeate for subsequent production of cheese with proper mineral contents.

In research of UF Mozzarella, UF at lower retentate $\mathrm{pH}$ led to some improvement in the resulting cheese texture, but problems with excess whey protein with flavor, textural and functionality defects are still prevalent. Although permeate flux declines rapidly at a lower $\mathrm{pH}$ but the production of retentate better suited for cheese making is preferable to the production of defective cheese. There is increased susceptibility to proteolysis with increased whey proteins. 
Microfiltration can be used as a way of decreasing the amount of whey proteins. Besides the high buffering capacity, it has been noted that Cheddar cheese made from UF milk has abnormal texture and structure, and may be improved by reducing the firming rate by lowering the temperature. It has been suggested that longer setting times might be required to allow sufficient casein aggregation. Texture might be improved by increasing the time before cutting the curd and decreasing rennet concentration (Green et al., 1981).

\subsection{2: Rationale and Objective of Study}

UF of milk for cheese making has been used in Europe for many years and has been proven useful for production of a wide variety of cheeses. One of the reasons for this is that the composition of retentate can be altered in such a way to promote optimum cheese production. One of the most critical aspects of cheese making is time that it takes for the milk to coagulate or rennet coagulation time (RCT). The size and shape of the casein micelle are very important for coagulation by rennet. Hence, the composition of the retentate (especially protein and calcium levels) can dictate the rennet coagulation of UF retentate. According to the literature, most of the retentate made for cheese making are ultrafiltered at $50^{\circ} \mathrm{C}$. There were few studies on making cheese from cold filtered UF retentate. There is also little research done on the affect of time of pasteurization (before UF vs. after UF) on rennet coagulation properties. The purpose of this project is to observe how UF temperature and heat treatment affect rennet coagulation time.

\section{2: Methodology}

Summary of Pilot Trials for Processing UF retentate

A series of four processing temperature/heat treatment combinations were used in this experiment. The retentate that were used were processed by the same procedure at the Cal Poly DPTC Pilot Plant under the supervision of Jerry Mattas. The details of these pilot trials were 
described in Chapter 2.0 of this thesis. Compositional data was acquired using the same procedures as in Chapter 2.0 of this thesis. Calcium analysis was performed under the supervision of Dr. Albert Censullo of the Department of Chemistry and Biochemistry. This compositional data will be important in explaining the rationale of the rennet coagulation time results. Statistical analysis was run using MINITAB Version 13 and a General Linear model of two-way ANOVA and using Tukey's Pairwise Comparison. The two variables used were Treatment and week of processing. All coagulation tests were performed within 24 hours after processing.

\section{Rennet Coagulation Time}

$100 \mathrm{ml}$ of milk was heated in a flask in a $30^{\circ} \mathrm{C}$ water bath until the milk is equilibrated with the water temperature (approximately 30 minutes). During this lag time, the American Rheometrics SR-2900 Rheometer was set up for the experiment. The water bath attached to the rheometer was heated to $30^{\circ} \mathrm{C}$ prior to experimentation. The rheometer is of cup and bob geometry with a frequency of $0.1 \mathrm{~Hz}$. After 30 minutes, $22 \mu \mathrm{l}$ of rennet was added into $100 \mathrm{ml}$ of milk with a micropipetter and was mixed for 30 seconds using a stirring rod. Using a syringe, $17 \mathrm{ml}$ of the renneted milk was added into the cup and place in rheometer. The bob was lowered into the cup and the rheometer was started. The number of seconds that it takes to reach this step was recorded and then added to value given on the rheometer. The rennet coagulation time was determined as the time required for the G' value to reach $1 \mathrm{~Pa}$. (plus the extra lag time mentioned earlier) Since there wasn't an effect of week of processing on the results, the values for both weeks were combined for analysis $(n=4)$. 


\section{3: Results and Discussion}

There was a significant treatment effect $(\mathrm{p}<0.001)$ on the rennet coagulation time of the retentate. The HF/PB treatment produced a retentate, that had a rennet coagulation time of 739.9 seconds, the $\mathrm{CF} / \mathrm{PB}$ treatment which produced a retentate with a coagulation time of 708.5 seconds, the CF/PA treatment produced a retentate with a coagulation time of 348.6 seconds, and the $\mathrm{CF} / \mathrm{Raw}$ treatment produced a retentate with a rennet coagulation time with 234.2 seconds. Individual significant differences were seen between the $\mathrm{CF} / \mathrm{PA}$ treatment and the $\mathrm{CF} / \mathrm{PB}$, $\mathrm{CF} / \mathrm{Raw}$ and $\mathrm{HF} / \mathrm{PB}$ treatments, between the $\mathrm{CF} / \mathrm{PB}$ and $\mathrm{CF} / \mathrm{Raw}$ treatments and between the $\mathrm{CF} / \mathrm{Raw}$ and $\mathrm{HF} / \mathrm{PB}$ treatments. There was not an effect of week of processing $(\mathrm{p}=0.903)$ on these values.

Compositionally speaking, one possible explanation for the differences in coagulation time could be due to the amount of whey protein nitrogen in the retentate. Since there was a significant treatment effect on the amount of whey protein nitrogen in the retentate, these differences in whey protein nitrogen could contribute to the differences in casein micelle size rennet coagulation time. It has been stated that the bigger the micelles, the longer the coagulation time. This is in agreement with a study by Park et al. (1996) which stated that the prolongation of gelation time may be caused by the electrostatic repulsion and by the by stearic hinderance that arose from the adsorption of $\beta$-lactoglobulin to the surface of the casein micelle. This concurs with a study by Ekstrand et al. (1980), which stated that the largest sized micelles, which have low levels of $\kappa$-casein, have the longest coagulation time. According to a study by Park et al. (1996), one major contributor to an increased rennet coagulation time is the crosslinking between $\beta$-lactoglobulin and $\kappa$-casein. Park et al. (1999) also stated that the larger casein micelles had longer rennet coagulation times at $30^{\circ} \mathrm{C}$ than smaller casein micelles. However, 
further research is needed to determine if the casein micelle size was affected by treatment and if it was a contributor to rennet coagulation time differences

According to results from a study by Ekstrand et al. (1980) is that an increase in monomeric caseins, especially $\beta$ and $\alpha_{s 1}$ are the cause for increased coagulation time in large micelles. With the addition of a heat treatment, more calcium and caseins are apt to binding the micelles, reducing the percentage of $\kappa$-casein and increasing the rennet coagulation time. Since there were significant differences in the amount of casein nitrogen present, this could be a contributor the differences in rennet coagulation.

An important variable is the amount of serum calcium with respect to total calcium. According to my results, there was a significant treatment effect $(\mathrm{p}<0.001)$ on this value. There was not a significant effect of week of processing $(\mathrm{p}=0.267)$ on this value. Significant differences were found between treatments $\mathrm{CF} / \mathrm{PA}$ and both $\mathrm{CF} / \mathrm{PB}$ and $\mathrm{CF} / \mathrm{Raw}$, between treatment $\mathrm{CF} / \mathrm{PB}$ and $\mathrm{CF} / \mathrm{Raw}$ and between treatment $\mathrm{HF} / \mathrm{PB}$ and $\mathrm{CF} / \mathrm{PA}$ and $\mathrm{CF} / \mathrm{Raw}$. According to Table 2.1, the HF/PB treatment led to a retentate in which the percentage of serum $\mathrm{Ca}$ with respect to total $\mathrm{Ca}$ in the retentate was $39.66 \%$, the $\mathrm{CF} / \mathrm{PB}$ treatment led to a retentate in which the percentage of serum $\mathrm{Ca}$ with respect to total $\mathrm{Ca}$ is $41.14 \%$, the $\mathrm{CF} / \mathrm{PA}$ treatment led to a retentate in which the percentage of colloidial $\mathrm{Ca}$ with respect to total $\mathrm{Ca}$ is $47.92 \%$ and the $\mathrm{CF} / \mathrm{Raw}$ treatment led to a retentate in which the percentage of serum $\mathrm{Ca}$ with respect to total $\mathrm{Ca}$ with 59.88\%. When the Phe-Met bond is cleaved, the micelles are bridged together with calcium ions to overcome charge differential and form a gel. Therefore, if there is a relatively small amount of ionic calcium, it is going to take longer for the milk to coagulate. Schreiber (2001) also stated that because of the reduction of ionic Ca percentage in heat treated milk, the strength of the rennet gel also decreased. Since there were significant differences in the percentage of 
serum $\mathrm{Ca}$ with respect to total $\mathrm{Ca}$, this could be a contributing factor to the differences in rennet coagulation time.

Significant differences in rennet coagulation time could be attributed to differences in the $\mathrm{pH}$ of the milk. The $\mathrm{pH}$ affects rennet coagulation time because as the $\mathrm{pH}$ lowers, the micelles begin to dissociate and allow more ionic calcium into the milk. This is good for cheese making because the increase in the coagulation rate of renneted micelles arises from the neutralization of the negative charge within the micelles, with the decrease in repulsion allowing the close approach of micelles, thereby promoting the hydrophobic interactions necessary for gel formation to occur (van Hooydonk et al., 1986 (b)). Since there were significant differences in $\mathrm{pH}$, this could be a possible contributor to the differences in rennet coagulation time.

\section{4: Conclusion}

In conclusion, there was a significant effect of filtration temperature and heat treatment on the rennet coagulation time of whole milk UF retentate. These differences could be due to differences in composition of the retentate, especially the amount of whey protein and casein, the amount of ionic $\mathrm{Ca}$ in the retentate and due to $\mathrm{pH}$ differences. There was not any effect of week of processing on the differences in results. 


\section{5: References Used}

Carlson, A., Hill, C.G., Jr., Olsen, N.F. Kinetics of Milk Coagulation. 1. The Kinetics of Kappa-Casein Hydrolysis in the presence of Enzyme Deactivation. Biotechnology and Bioengineering vol 29 pp 582-589. 1987 (a).

Carlson, A., Hill, C.G., Jr, Olson, N.F. Kinetics of milk Coagulation. 2. Kinetics of the Secondary Phase: Micelle Flocculation. Biotechnology and Bioengineering vol 29 pp. 590-600. 1987 (b).

Carlson, A., Hill, C.G., Jr., Olson, N.F. Kinetics of Milk Coagulation. 3. Mathematical Modeling of the Kinetics of Curd Formation following enzymatic hydrolysis of kappa-caseinparameter estimation. Biotechnology and Bioengineering vol 29 pp. 601-611. 1987(c).

Carlson, A., Hill, C.G., Jr. The Kinetics of Milk Coagulation. 4. The Kinetics of the GelFirming Process. Biotechnology and Bioengineering vol 29 pp. 612-624. 1987 (d).

Dalgleish, D.G. and Law, A.J.R. pH-induced dissociation of bovine casein micelles. II. Mineral solubility and its relationship to casein release. Journal of Dairy Research vol 56 pp. 727-735. 1989.

Dalgleish, D.G. Coagulation of renneted bovine casein micelles: dependence on temperature, calcium ion concentration and ionic strength. Journal of Dairy Research vol $50 \mathrm{pp}$. 331-340. 1983.

Davies, D.T. and White, J.C.D. The use of ultrafiltration and dialysis in isolating the aqueous phase of milk and in determining the partition of milk constituents between the aqueous and disperse phase. Journal of Dairy Research pp. 171-190. 1960.

Ekstrand, B., Larsson-Raznikiewicz, M., Perlmann, C. Casein Micelle Size and Composition Related to the Enzymatic Coagulation Process. Biochimica et Biophysica Acta pp. 361-366. 1980.

Ernstrom, C.A. Chapter 12 in Fundamentals of Dairy Chemistry. The Avi Publishing Company. Westport, Connecticut. 1974.

Fernandez, A. and Kosikowski, F.V. Physical Properties of Direct Acidified Mozzerella Cheese from Ultrafiltered Whole Milk Retentates. Journal of Dairy Science vol 69 pp. 643-648. 1986. 1953.

Flory, P. Principles of Polymer Chemistry. Cornell University Press. Ithaca, N.Y.

Green, M.L., Turvey, A. and Hobbs, D.G. Development of structure and texture in Cheddar Cheese. Journal of Dairy Research vol 48 pp 343-355. 1981. 
Green, M.L. Effect on the composition and properties of casein micelles of interaction with ionic materials. Milk coagulation. Journal of Dairy Research vol 49 pp. 87-98. 1982.

Hansen, M.L., Glover, F.A., Scurlock, E.M.W.; Marshall, R.J. and Hatfield, D. Effect of use of milk concentrated by Ultrafiltration on the manufacture and ripening of cheddar cheese. Journal of Dairy Research vol 48 pp 333-341. 1981.

Holmes, D.G., Duersch, J.W. and Ernstrom, C.A. Journal of Dairy Science vol 60. starts on pg.862. 1977.

Kosikowski, F. New Cheese Making Procedure Ultilizing Ultrafiltration. Food Technology pp. 71-77. June 1986.

Lucey, J.A. and Fox, P.F. Importance of Calcium and Phosphate in Cheese Manufacture: A Review. Journal of Dairy Science vol 76 pp. 1714-1724. 1993.

Maubois, J.L., Mocquot, G. and Vassal, L. Preparation of cheese using Ultrafiltration. US patent 4,205,080. 1980.

Mehaia, M.A. and Cheryan, M. Coagulation studies of ultrafiltration-concentrated skim milk Milchwissenschaft vol 38 pp 708-710. 1983.

Murphy, J.M. and Fox, P.F. Fractionation of Sodium Caseinate by Ultrafiltration. Food Chemistry vol 39 pp. 27-38. 1991.

Park, S-Y., Nakamura, K. and Niki, R. Effects of $\beta$-Lactoglobulin on the Rheological Properties of Casein Micelle Rennet Gels. Journal of Dairy Science vol 79 pp. 2137-2145. 1996.

Park, S-Y., Niki, R. and Sano, Y. Size effects of casein micelles on rennet gels in the presence of $\beta$-lactoglobulin. International Dairy Journal vol 9 pp. 379-380. 1999.

Parker, T.G. and Dalgleish, D.G. Binding of calcium ions to bovine beta-casein. Journal of Dairy Research vol 48 pp. 71-76. 1981.

Schaar, J. Journal of Dairy Research vol 51. starts on pg. 397. 1984.

Schmidt, D.G., Both, P. and de Koning. Journal of Dairy Science vol 49 starts on pg. 776. 1966.

Schreiber, R. Heat induced modifications in casein dispersions affecting their rennerability. International Dairy Journal vol 4/7 pp. 553-558. 2001. 
Spangler, P.L., Jansen, L.A., Amundson, C.H., Olson, N.F. and Hill, C.G., Jr. Ultrafiltered Gouda Cheese: Effects of preacidification, Diafiltration, Rennet and Starter Concentration and Time to Cut. Journal of Dairy Science vol 74 pp. 2809-2819. 1991.

3 Van Hooydonk, A.C.M., Olieman, C. and Hagedoorn, H.G. Netherlands Milk and Dairy Journal vol 38. starts on pg. 207. 1984.

2 Van Hooydonk, A.C.M., Boerirrigter, I.J., Hagedoorn, H.G. pH-induced physicochemical changes of casein micelles in milk and the effect on renneting. 2. Effect of $\mathrm{pH}$ on renneting of milk. Netherlands Milk and Dairy Journal vol 40 pp. 297-313. 1986 (b).

1 Van Hooydonk, A.C.M. The effect of various cations on the renneting of milk. Netherlands Milk and Dairy Journal vol 40 pp. 369-390. 1986 (a).

Von Smoluchowski, M. Physical Chemistry vol 92 starts on pg. 129. 1917. 
Figure 4.1: Bar graph of rennet coagulation time (RCT) with respect to filtration temperature and heat treatment for whole milk UF retentates

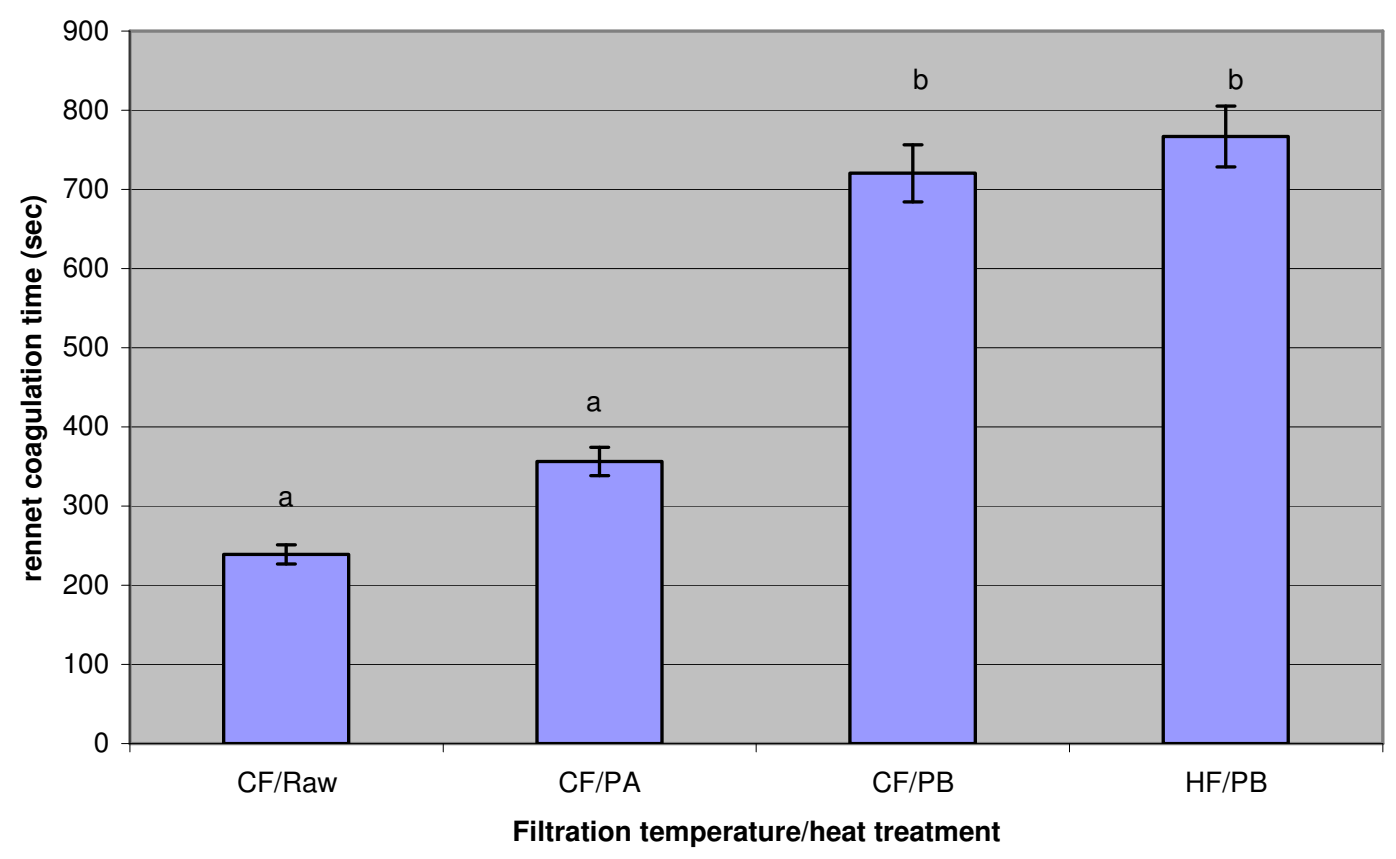

Table 4.1: Rennet Coagulation Time of whole milk retentate

\begin{tabular}{|c|c|}
\hline Treatment & Rennet Coagulation Time (sec) \\
\hline CF/Raw & $234.2(7.13)^{\mathrm{a}}$ \\
\hline CF/PA & $348.6(58.22)^{\mathrm{a}}$ \\
\hline CF/PB & $708.5(43.03)^{\mathrm{b}}$ \\
\hline HF/PB & $739.9(90.09)^{\mathrm{b}}$ \\
\hline *standard deviation in parenthesis & \\
\hline
\end{tabular}




\subsection{Concluding Remarks}

We were successful in studying the effect of filtration temperature and heat treatment on the composition of whole milk Ultrafiltration retentate and these compositional differences affect rheological properties. Overall conclusions that we can draw from this study are:

1) There were significant compositional differences observed with respect to filtration temperature and heat treatments. Significant differences were seen in whey protein and casein nitrogen, total protein and non-casein nitrogen, total ash, serum and total $\mathrm{Ca}$ and $\mathrm{pH}$.

2) The retentate displayed shear thinning behavior and the composition of the retentate are possible contributors to these differences

3) There was a well-pronounced shear thinning effect on the retentate as temperature increases.

4) With increasing temperature and shear rates, the retentate start to display shear thickening behavior

5) There was a significant effect of filtration temperature and heat treatment on the viscosity of the retentate at all three testing temperatures.

6) There was a significant effect of filtration temperature and heat treatment on rennet coagulation time. Compositional differences in the retentate are the possible cause for this.

7) The week of processing had no significant effect on any of the results 
Some suggestions for further research include:

- Using the retentate to make various types of cheese and observes differences in yield and textures compared to cheeses made from normal whole milk.

- Use the retentate as a method of ingredient substitution in various dairy products and see how composition affects functional properties (e.g., foaming, gelation).

- To study the effect of the treatments on the size of casein micelles and how they affect viscosity and rennet coagulation time.

- To further study why the retentate display shear thickening behavior with increasing shear rate.

This thesis project is an extremely valuable tool with lots of practical applications to the dairy industry. With the different filtration temperatures and heat treatment, you can tailor make you own retentate with desired compositions for an extensive variety of uses. From the rheological data, you can design filtration systems and determine processing parameters for any process of your choosing. Finally, ultrafiltration can be used for cheese making on a continuous process. An important parameter in cheesemaking is the rennet coagulation time. One of the biggest contributors to rennet coagulation time is the composition of your retentate. This project can be used as a start-up plan for a cheesemaking operation. 


\section{Appendix A: Introduction to Casein Micelles}

Casein micelle chemistry is so critical to understanding the topics and results of this paper that it deserves s section of its own.

In milk, there are two types of milk proteins: casein and whey. Casein makes up approximately $82 \%$ of the total protein in milk with whey making up the other $18 \%$. However, the state in which these proteins are found are quite different: the caseins are primarily found in big clusters of other caseins known as micelles (Walstra, 1990). The whey proteins either are found in the aqueous phase of the milk or can be found attached to these micelles.

Micelles are roughly spherical protein aggregates, mostly between 40 and $300 \mathrm{~nm}$ in diameter and are voluminous, containing an aqueous milk serum. There are 5 primary types of casein in these micelles: $\alpha_{\mathrm{s} 1}, \alpha_{\mathrm{s} 2}, \beta, \gamma, \kappa$ (Walstra, 1990). Despite consistencies in the types of caseins present, there is a considerable variation in composition, structure, and size distribution. The milk serum also varies in composition, especially in $\mathrm{Ca}$ and $\mathrm{P}$ salts. There is much debate over what model best describes the physical structure of a casein micelle. Originally, it was assumed that any subunits were "cemented" together by salt bridges of colloidal calcium phosphate (CCP) (Schmidt, 1982). However, studies that are more recent have shown that a number of factors are responsible for the stability of the micelles. The formation of $\mathrm{CCP}$ is an effective means of burying and storing $\mathrm{Ca}$ and phosphate within the casein micelle (which is critical in providing nutrition to young mammals). Several studies have shown that Ca can be removed from the casein micelle without disrupting the micelle itself (Dalgleish and Law, 1988). This suggests that CCP does not cement the micelle together but rather it helps control and modulates the effect of $\mathrm{Ca}$ and charged groups on caseins. Hydrophobic interactions and hydrogen have also been shown to be important in micelle integrity. At least three models have 
been proposed to try to answer this question. One type of model proposes that the micelle core is divided into three discrete subunits (sub-micelles) with distinctly different properties from an outside "hairy" layer (Walstra, 1990). Essentially, there are two-types of sub-micelles: those with $\kappa$-casein and those without.

This casein is pre-dominantly seen protruding from the core of the micelle (this is the hydrophilic region) and resembles flexible "hairs". These hairs are essential in providing stability against the flocculation of the micelles (Schmidt, 1982). The thickness of this "hairy" layer is about $7 \mathrm{~nm}$. The sub-micelles are held together by CCP. Studies using proton NMR that the sub-micelles have considerable freedom motion and the addition of CCP causes this flexibility to go away (Rollema et al, 1988). Another model suggests that the internal substructure resembles a mineralized, entangled, or cross-linked web of casein micelle chains. The most recent model proposes a dual-binding (polycondensation-type) mechanism for assembly. Amongst all the controversy, all that can be concluded from various studies involving light scattering is that the internal structure of the casein micelle is heterogeneous composed of regions of high, and low scattering power. It has also been suggested that nanoclusters could be contributing to variation is scattering intensity. One big problem of most micelle models is there is a lack of a plausible mechanism for assembly, growth and termination of growth (Horne, 1998). The Horne (polycondensation model) seems to fill in the gaps.

The dual-binding model (Horne, 1998) was designed to explain the assembly and structure of the casein micelle. This model is a condensation polymerization model that envisages two cross-linking routes for the assembly of the micelle: cross-linking of individual caseins through their hydrophobic regions and via colloidal calcium phosphate bridges. 
The formation and integrity of the micelles is seen as a controlled balance between attractive and repulsive forces within the micelle. Another feature of the model is that since $\kappa-$ casein can only hydrophobically bond with other caseins and acts as a chain terminator. The surface position of the $\kappa$-casein is strategically placed to fulfill its role as a chain terminator, which provides a plausible mechanism for controlling growth of the micelle (Horne, 1998). Selfassociation of the caseins is driven by hydrophobic interactions but electrostatic repulsive interactions are also important because these define the degree of polymerization and can be a limiting factor in the growth of the molecules. For example, increasing the $\mathrm{pH}$, which increases the protein charge, decreases the polymer size for both $\alpha_{s 1}$ and $\beta$ casein whereas increasing the ionic strength, which decreases the range of the electrostatic repulsion component (Payens et al., 1969). It is important to note that the shielding of electrostatic charge is a non-specific effect of ionic strength, which moderates the range of the electrostatic interaction but does nothing to change the magnitude of the charge (that is, the source of the interaction). Such changes in charge and the overcoming of these electrostatic repulsions can be accomplished in two ways: by lowering the $\mathrm{pH}$ and titrating away, a sufficient amount of the charge of the phosphoseryl and carboxyl groups to induce acid precipitation of the caseins at their isoelectric points (Holt, 1992). With this train of thought, a casein micelle is a hydrophobic colloid where the energy of interaction between molecules is calculated as the sum of the electrostatic repulsion with the hydrophobic attraction. The level of calcium binding is crucial to the aggregative stability of the protein (Horne, 1998). 
Dagleish and Parker (1980) found binding of calcium to as1 casein to increase with increasing $\mathrm{pH}$ and temperature but to decrease as the ionic strength increased. The aggregation of $\beta$-casein induced by calcium ions shows marked temperature dependence with no precipitation seen at low temperatures $\left(4^{\circ} \mathrm{C}\right)$. This is similar to behavior shown by Payens et al. (1969) in which they observed a self-association model in which individual molecules are seen at low temperatures and aggregates are shown at temperatures greater than $20^{\circ} \mathrm{C}$. The presence of a lag phase in the $\alpha \mathrm{s}_{1}$ aggregation by calcium has been interpreted as a nucleation and growth mechanism. $\kappa$-casein doesn't bind calcium to any great extent and has a difference means of overcoming electrostatic repulsion and aggregation (Dalgleish et al., 1981).

It is generally accepted that $\kappa-\mathrm{CN}$ molecules are located at the surface where it exists naturally. Although other caseins do not seem to have a role that requires well-defined structures, $\kappa-\mathrm{CN}$ appears to be tailor-made for its function as the interface between the calcium sensitive caseins and the milk serum. Individual molecules have been speculated to cross-link into disulfide-bonded polymers with a structure such that the hydrophilic tails project into the milk serum and the hydrophobic regions attach to the micelle core. In addition to its natural functions, $\kappa-\mathrm{CN}$ is readily hydrolyzed once milk is in the calf stomach, allowing for the formation of a coagulum that can be readily digested. Chymosin, an enzyme from the calf abomasum, cleaves $\kappa-\mathrm{CN}$ very specifically to produce an insoluble para $\kappa-\mathrm{CN}$, which remains at the surface of the micelle and causes the micelles to aggregate and form a clot (Holt and Horne, 1996).

The soluble macropeptide portion of $\kappa-\mathrm{CN}$ remains in the serum and presumably becomes a target for further enzyme attack. To perform these functions, $\kappa-\mathrm{CN}$ needs to bind to the calcium-casein complexes of the micelle core and must be able to prevent premature micelle 
aggregation. The chymosin cleavage site must be accessible to the enzyme and must be cleavable at about $\mathrm{pH} 6.5$ at which the $\mathrm{pH}$ is not normally active. Studies have shown that chymosin cleaved $\kappa-\mathrm{CN}$ at a Phe-Met bond to give a large peptide (known as the macropeptide or glycomacropeptide). Early studies showed that once the primary structure of the protein was known, $22.5 \%$ helix structures and $31 \%$ sheet structures were indicated for the protein with the helical structures more likely to be in the peptide region of the protein and the sheet structures more likely in the para $\kappa-\mathrm{CN}$ region (Creamer et al., 1998).

Interesting things start to happen to the structure of the micelle as various technological procedures are taken place on the milk. For example, heating milk at temperatures above $70^{\circ} \mathrm{C}$ results in thermal denaturation of the globular whey proteins in which the native conformation is disrupted and converted to a lower state of order (Walstra, 1999). Denaturation of the whey proteins can result in the exposure of reactive amino acid side groups that are normally buried in the native conformation. Of particular importance is the increased reactivity of the free thiol groups of $\beta$-lactoglobulin, which can be involved in thiol-disulfide exchange reactions with other denatured whey proteins and with $\kappa-\mathrm{CN}$ at the casein micelle surface. However, denatured whey proteins are more susceptible to aggregation via salt bridges and hydrophobic interactions (Walstra, 1999).

To elaborate further, when milk is heated slowly (e.g., laboratory waterbath conditions) about $80 \%$ of the denatured $\beta$-lactoglobulin associated with the casein micelles. In contrast, when milk was heated rapidly (e.g. direct heating systems) only about $50 \%$ of the denatured $\beta$ lactoglobulin was associated with casein micelles. It was proposed that the smaller aggregates formed under slow heating conditions might associate with the micelles more efficiently than the larger aggregates formed under rapid heating conditions. Consequently, a greater level of whey 
proteins associates with the micelles under slow heating conditions than under rapid conditions (Oldfield et al., 1998). Corredig and Dagleish (1999) suggested that, on heating milk, the $\alpha$ lactalbumin and $\beta$-lactoglobulin initially aggregate in the serum phase at a ratio dependent on the initial whey protein concentrations. These complexes subsequently associate with the casein micelle on prolonged heating. The interactions between the casein micelles and the denatured whey proteins should alter the physical properties of the micelles and the milk in which they are suspended. Juernik and DeKruif (1993) reported increases in the viscosity of milk with heating and related this to the association of whey proteins with the casein micelles. A diffuse layer of denatured whey proteins around the casein micelles could be observed when skim milk was heated under mild conditions. From previous studies, it has been shown that the rate of whey protein denaturation were more rapid then the change in casein micelle size. As with whey protein denaturation and the changes in the casein micelle size, the level of whey protein associated with the micelles increased with increasing temperature and increased holding time (Beaulieu et al., 1999).

Change in $\mathrm{pH}$ and the acidification of milk also have an effect on the structure of the casein micelle. According to a study by Visser et al. (1986), below pH 5.5, when sufficient calcium and phosphate ions have been released (solubilized), not only do the original casein micelles become visible but a number of smaller particles as well. This occurs until a pH of 5.2 is reached. According to a study by Van Hooydonk et al. (1986), virtually all of the inorganic micellar phosphate was transferred to the serum phase, whereas still $14 \%$ of the calcium was still present in the micelles. An explanation for the apparent $\mathrm{pH}$-dependence of calcium binding is not easily at hand. It could be that ester phosphate groups are not the main calcium binders but that carboxyl groups are also involved $(\mathrm{pK}=4.5)$. The slight decrease in negative charge in the 
$\mathrm{pH}$ range would affect the calcium binding but the increase in $\mathrm{Ca}^{2+}$ activity might compensate for this effect. Furthermore, a competition between micellar calcium phosphate and counter-ions for charge groups of the caseins may not be excluded. In fact, the $\mathrm{pH}$ of $\mathrm{Ca}$ binding may in fact be fortuitous. At this point, an aggregated corpuscular structure is observed, in line with the point where the onset of gelation takes place. Aggregation is indicated by the formation of large fields of casein particles of all sizes along with areas in the milk where no micelles are present. Upon lower of the $\mathrm{pH}$, the areas with the micelles seem to contract into smaller areas and individual casein particles are formed again resembling the original casein particles although larger but completely different in character because of the calcium phosphate lost. The particles formed this whey aggregate into a network, forming a gel.

Below $\mathrm{pH} 5.3, \beta$-casein is released from the casein micelle, and can act as a starting point for the aggregation of the other caseins. As soon as the $\mathrm{pH}$ of the system is sufficiently low and the major caseins are oppositely charged (Walstra, 1999). In the pH range of 5.2-4.8, a contraction takes place when $\beta$-casein becomes positively charged and the as1 casein is still negatively charged. This results in a further attraction between the two classes of caseins. The release of $\beta$-casein at intermediate $\mathrm{pH}$ values supports a proposed casein micelle model based on a 'skeleton' of as1 casein, in which $\beta$-casein can freely enter and be released (van Hooydonk et al., 1986). Decreasing the pH 6.7 to 6.0 causes a slight decrease in voluminosity for both normal casein and para k-casein micelles. The swelling effect due to micellar calcium phosphate solubilization is counteracted and in this region is dominated by the increased attraction between charged groups. The ionization of the carboxyl groups (pK 3.6 to 4.5 ) does not change in this region. It is uncertain what happens with the ester phosphate groups. Some decrease in negative charge is expected but if these groups are buried in the micellar calcium phosphate, there may be 
an increase in ionization after MCP solubilization. The number of positive charges increases due to the protonation of histidine residues. The resulting electrostatic interaction with negative groups is probably the cause of shrinkage in this region (van Hooydonk et al., 1986). In the pH region from 6.0 to 5.6, the micelle swells and the dissociation of casein reaches a maximum. All amino groups are fully charged and the net negative charge diminishes mainly due to the protonation of carboxyl groups but there may be some replenishment due to the protonation of the negatively charged ester-phosphate group.

The expansion of the micelle in this region is caused by the dominating effect of micellar calcium phosphate solubilization. In the $\mathrm{pH}$ region from 5.6 to 5.3, charge neutralization dominates the effect of micellar calcium phosphate (MCP) solubilization with respect to casein dissociated and the voluminosity of casein in renneted-milk. The voluminosity in normal milk still increases and reaches a maximum value around pH 5.3 (van Hooydonk et al., 1986). According to a study by Kalab (1976), during acidification of unheated milk, the micelles have a ragged surface near the $\mathrm{pH}$ of gelation, indicating that outer-layer submicelles are loosely bound to the micelles. This might increase the voluminosity more than at $\mathrm{pH} 5.6$ where these submicelles dissociate from the micelle. The considerable voluminosity caused by rennet at $\mathrm{pH}$ 5.3 is probably not only due to the removal of the relative hydrophilic part of k-casein but also the collapse of these loosely bound submicelles. Below pH 5.3, all MCP is solubilized and further charge neutralization cause a decrease of voluminosity and a precipitation of not only the dissociated casein fraction but also whole micelles (van Hooydonk et al., 1986).

Upon the heating of the milk, the amorphous calcium phosphate is precipitated. This precipitation is reversible if the heating is only momentary. It was shown that the point where precipitation occurs strongly depends on the $\mathrm{pH}$ of the milk serum. When the milk $\mathrm{pH}$ is 
lowered the higher the temperature before precipitation is increased. Upon cooling the system, the precipitate disappears completely at approximately the same temperatures at which it was formed, and the system becomes clear (no turbidity). From P-NMR studies, there is a special interaction between casein and calcium and phosphate ions.

This interaction was seen as a downfield shift in the NMR spectrum and was found for a system of polylysine-calcium phosphate (Holt, 1981). Polylysine strongly promotes the formation of a calcium phosphate precipitate whereas monomeric lysine had no effect on precipitation (Walstra, 1999). Molecules such as polyglutamate and glutamic acid hinder the precipitation. The hydrophilic C-terminal in combination with a rather compact configuration of the N-terminal where most of the lysine groups are found may prevent the 'alignment' of the calcium phosphate necessary for an enhanced precipitation in the form of an amorphous calcium phosphate complex. These findings further suggest that in the formation of casein micelles in the mammary gland, $\alpha_{\mathrm{s} 1}$ casein plus calcium and phosphate ions may play a central role through the formation of a $\alpha_{\mathrm{s} 1}$ casein-calcium phosphate complex. This complex may act as a backbone structure for the casein micelle to which $\kappa$-casein is attached via a calcium-ion mediated interaction with $\alpha_{\mathrm{s} 1}$ casein. As a result, the $\kappa$-casein, located at the micelle surface will be able to give the micelle its stability, partly via its contribution to the zeta potential, partly via its hydrophilic C-terminal part sticking out into solution. $\beta$-casein, the third major component of the micelle, may play an intermediate role since this protein can more or less freely enter and leave the casein micelle. From the reversibility of the calcium phosphate formed upon heating, it may be concluded that the precipitate will be of an amorphous nature since a crystalline precipitate would not re-dissolve so easily and rapidly (Holt, 1981). 
From this information, one may say that the calcium and phosphate ions interact with casein with a preference for $\alpha_{\mathrm{s} 1}$ casein in which lysine groups may play a role. Although a similar interaction with $\alpha_{\mathrm{s} 2}$ and $\beta$-casein may not be excluded, the "mobility of $\beta$-casein with respect to the casein micelle makes such a linkage less likely. The calcium phosphate system is strongly temperature and $\mathrm{pH}$ sensitive. 


\section{Appendix B: MINITAB Printouts for thesis project}

\section{General Linear Model: \% Ash retention versus Treatment, Week}

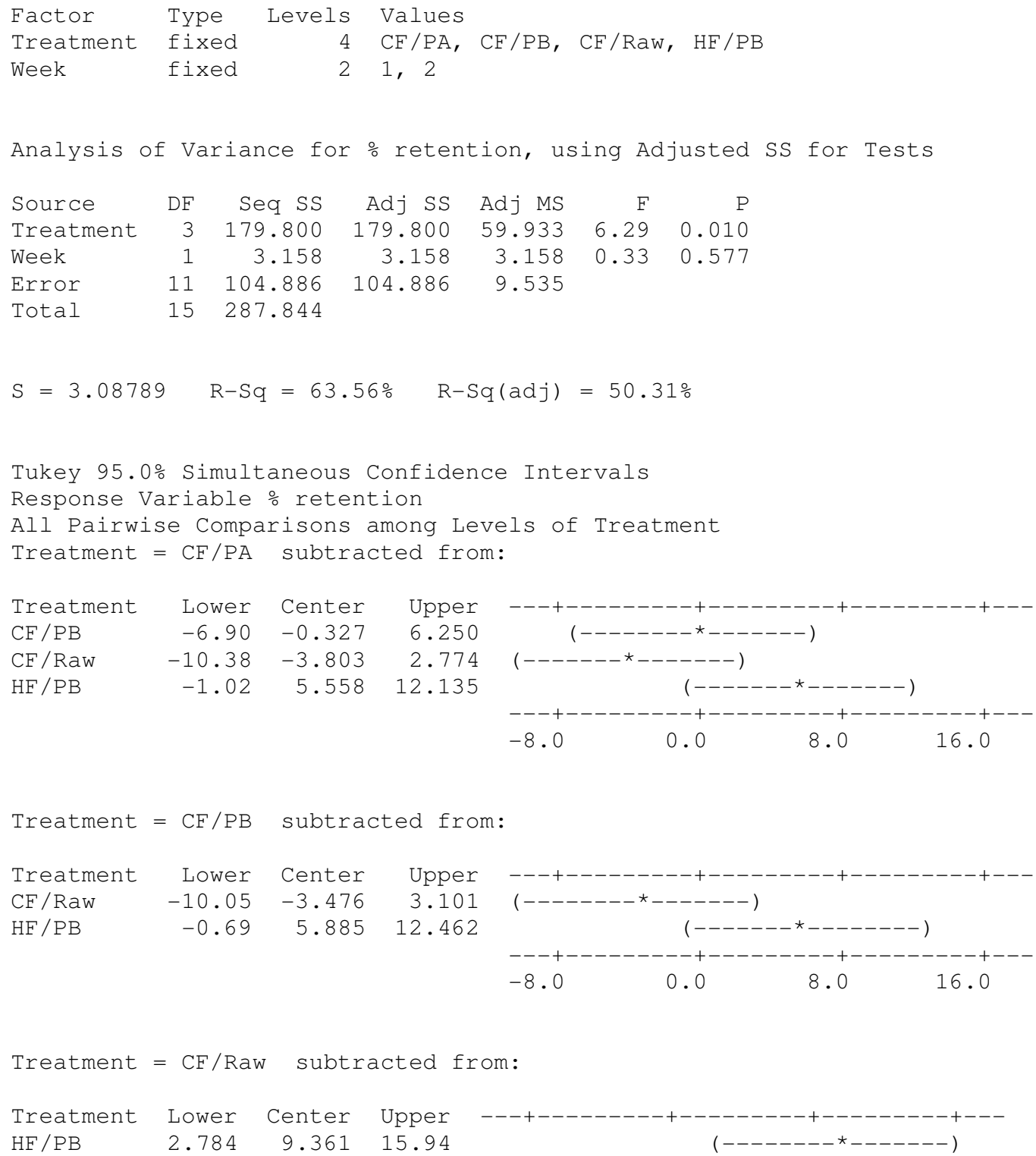




\section{General Linear Model: \% Fat retention versus Treatment, Week}

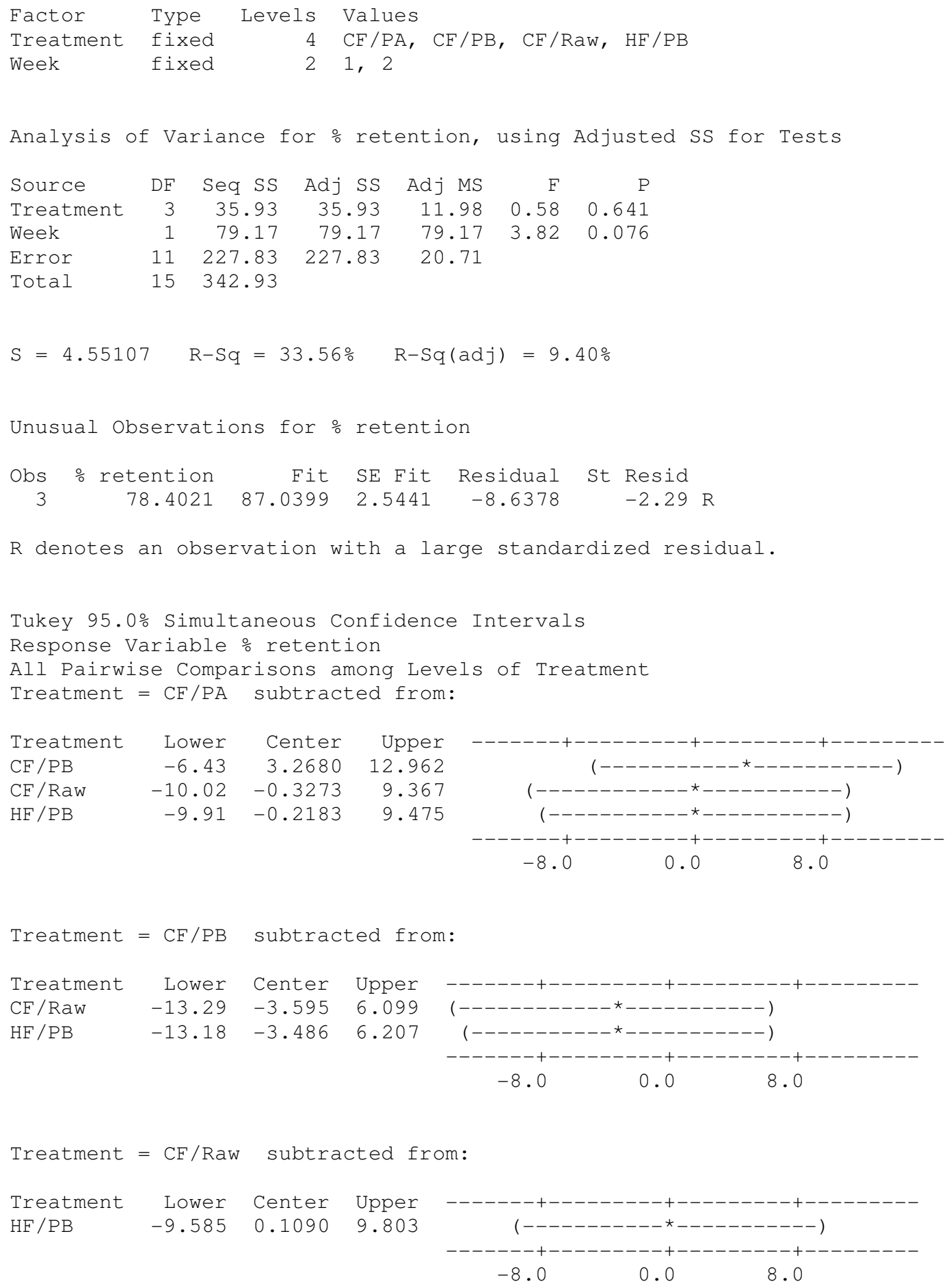




\section{General Linear Model: $\mathrm{pH}$ at $30^{\circ} \mathrm{C}$ versus Treatment, Week}

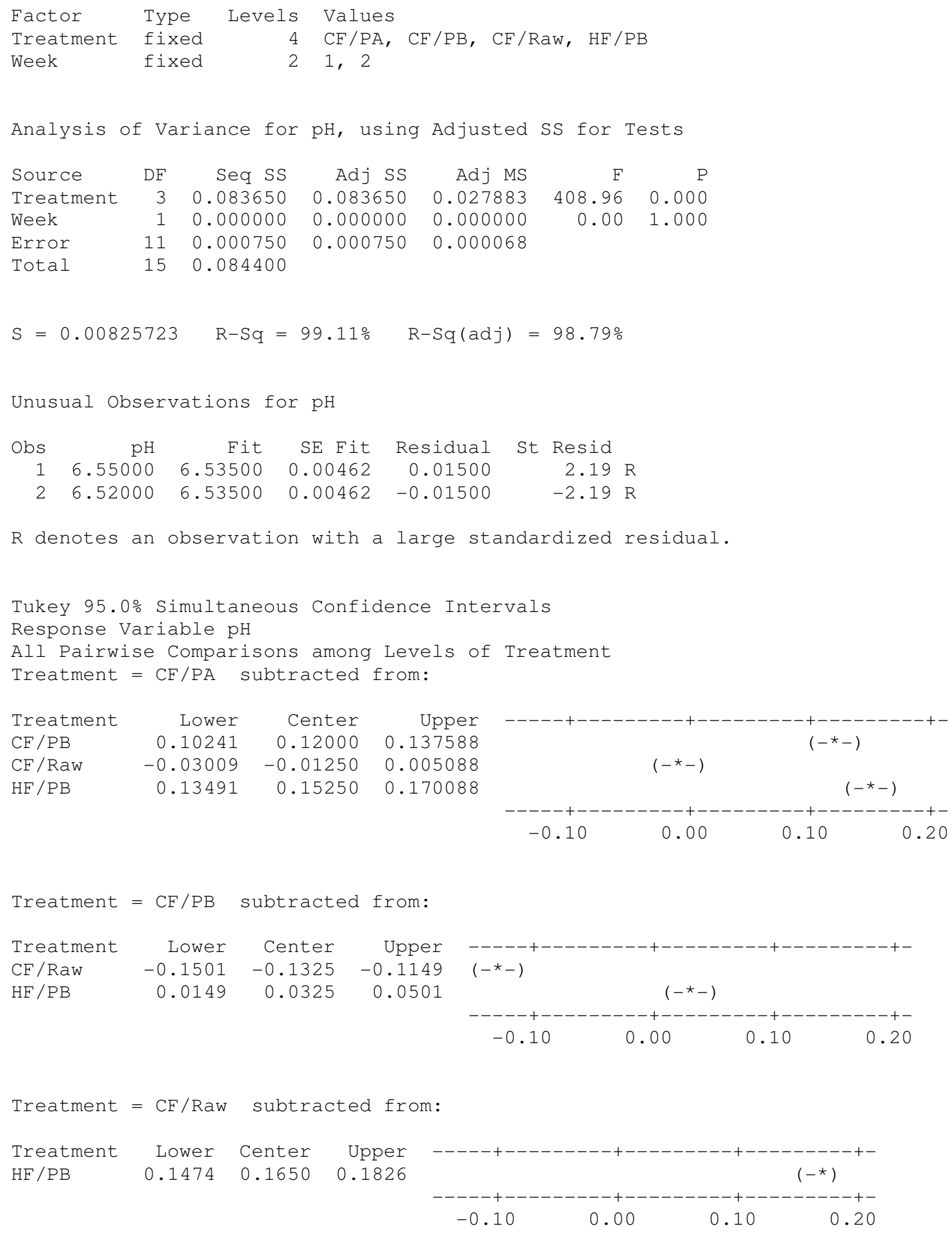




\section{General Linear Model: \% Calcium Retention versus Treatment, Week}

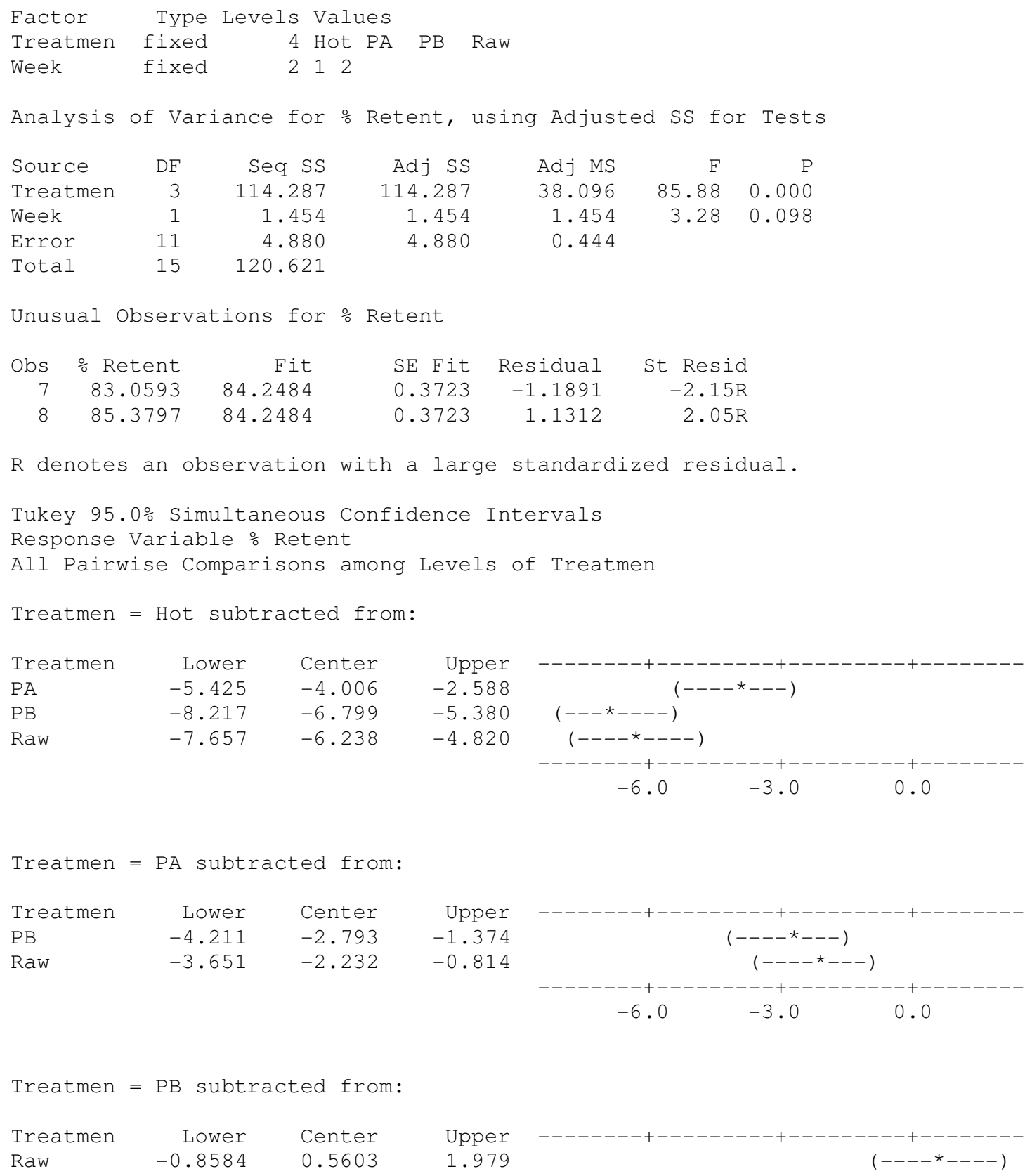




\section{General Linear Model: \%Ret-non-casein nitrogen versus Treatment, Week}

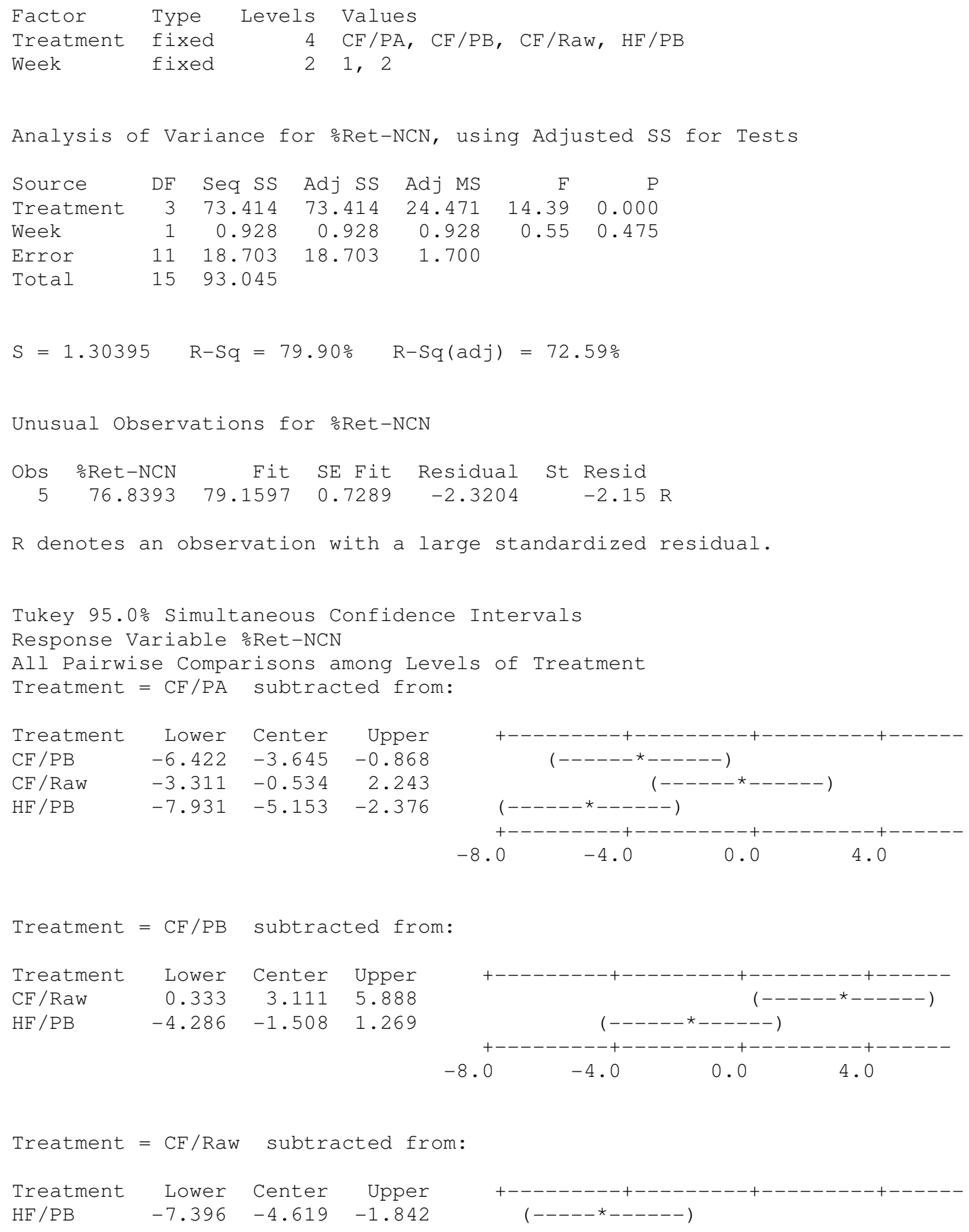

Treatment $=\mathrm{CF} /$ Raw subtracted from:

Treatment Lower Center Upper

$\mathrm{HF} / \mathrm{PB} \quad-7.396 \quad-4.619 \quad-1.842$ 


\section{General Linear Model: \% Ret-Total protein versus Treatment, Week}

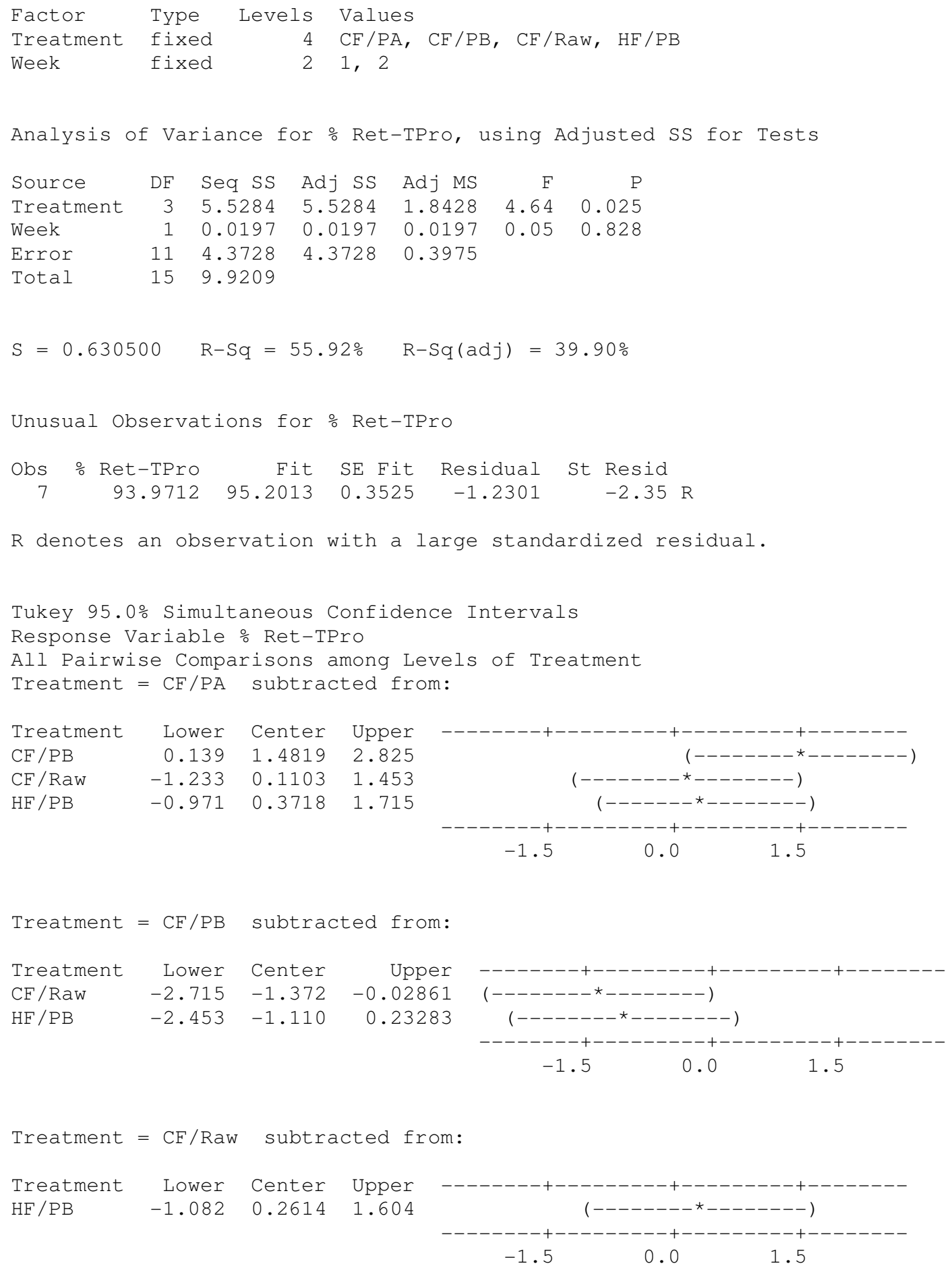


General Linear Model: \%Ret-Whey protein nitrogen versus Treatment, Week

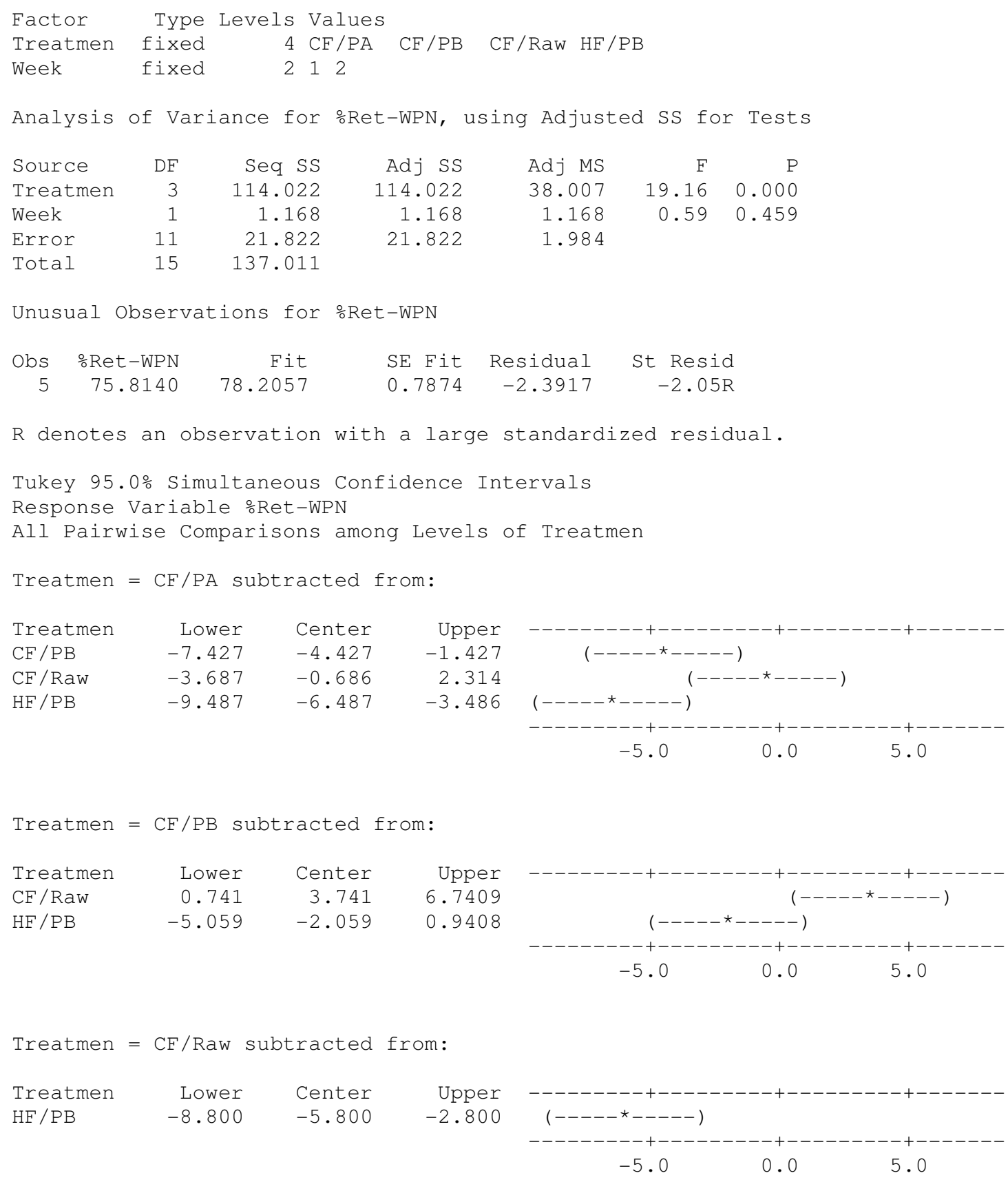


General Linear Model: \%Ret-casein Nitrogen versus Treatment, Week

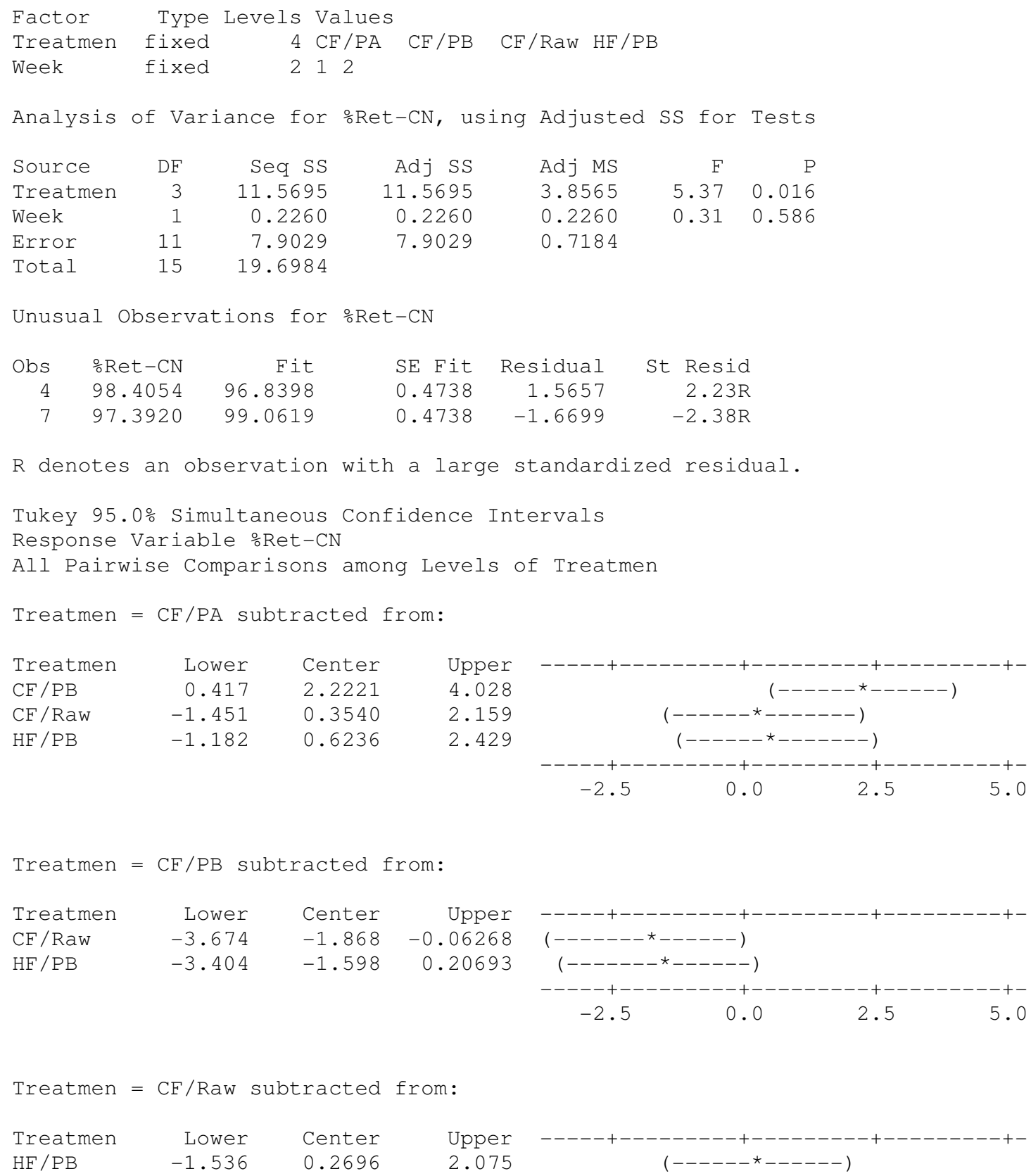


General Linear Model: \%Ret-True protein Nitrogen versus Treatment, Week

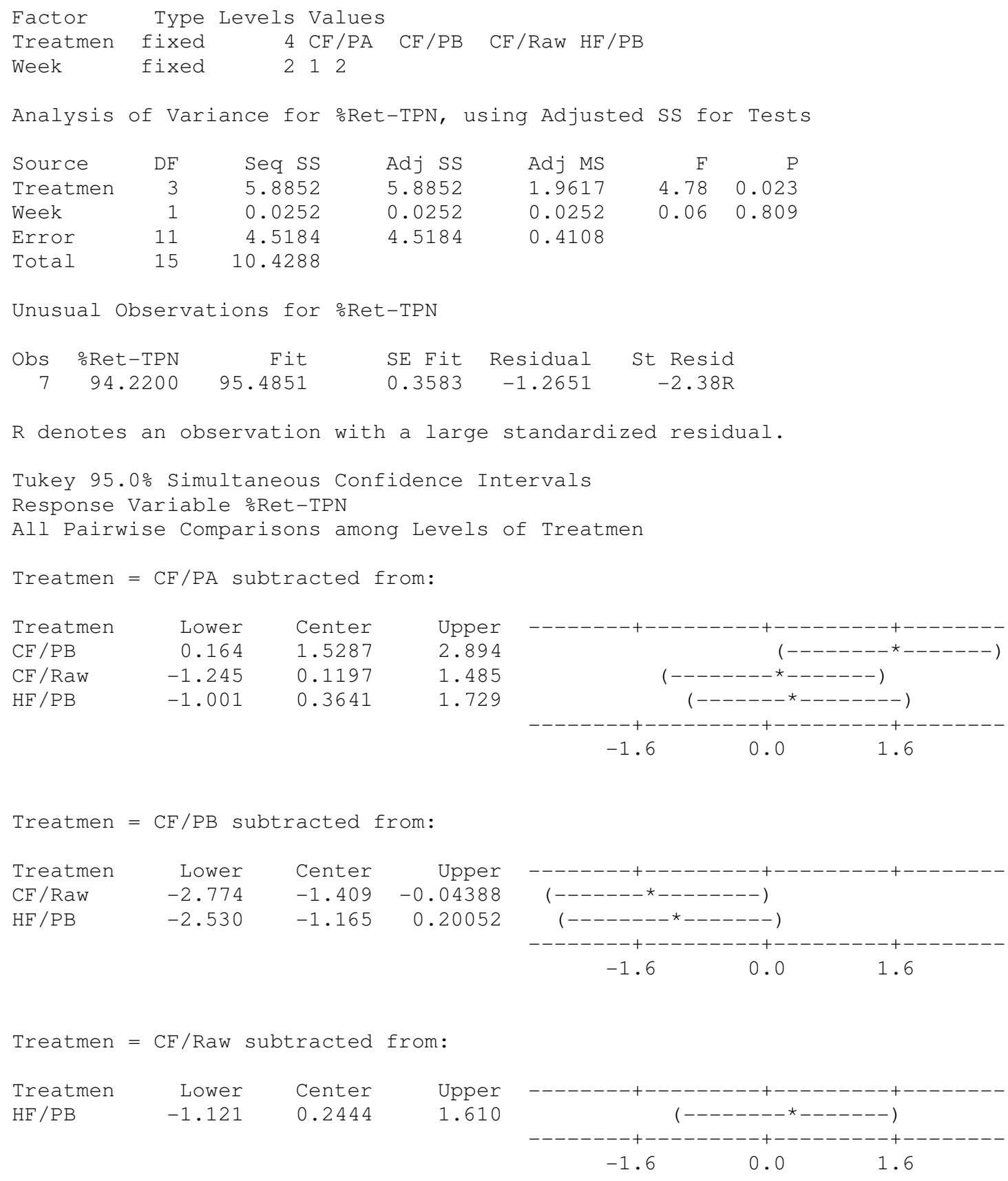




\section{General Linear Model: \%Ret-Non-protein nitrogen versus Treatment, Week}

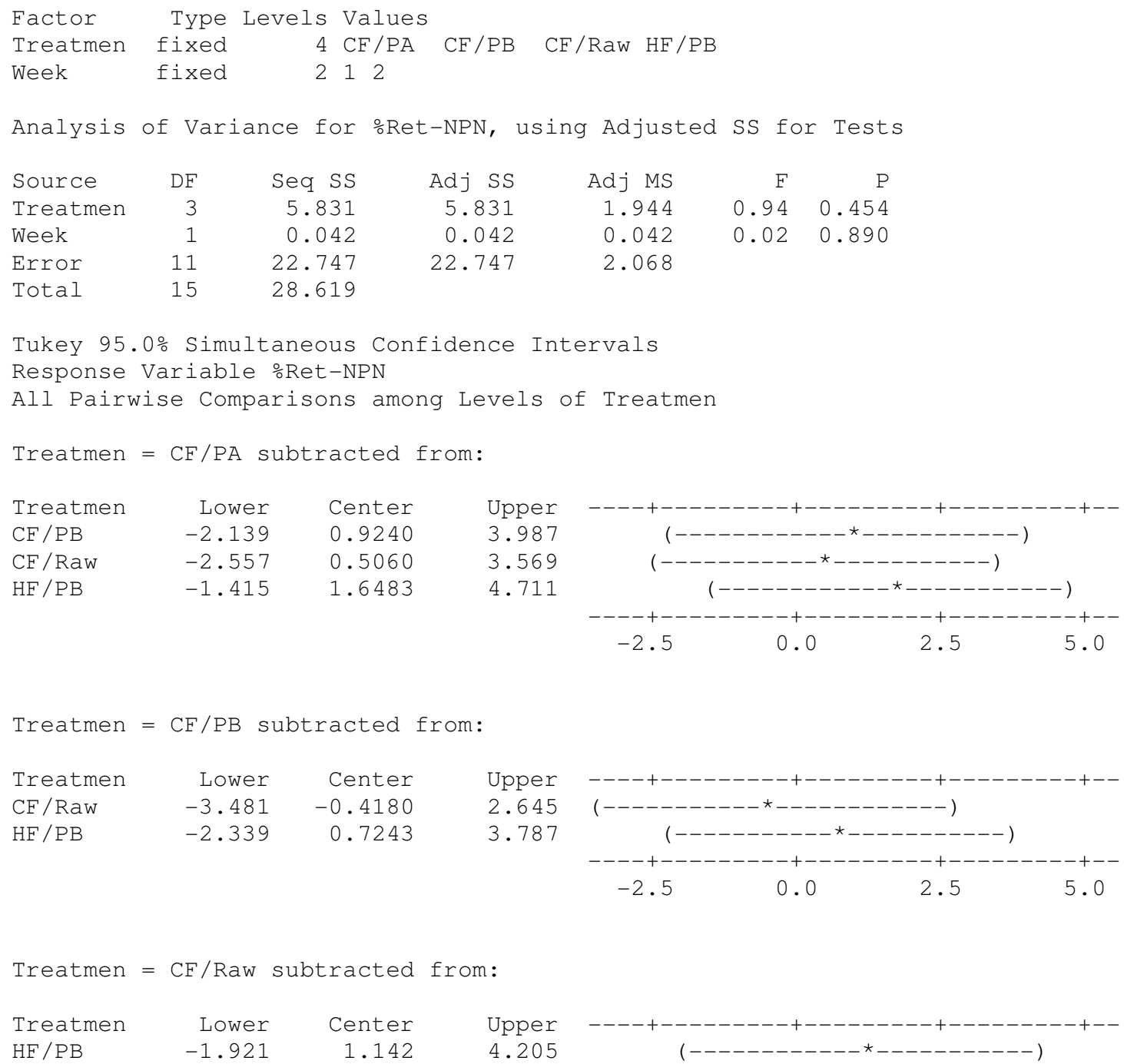




\section{General Linear Model: \% Retained-Total Nitrogen versus Treatment, Week}

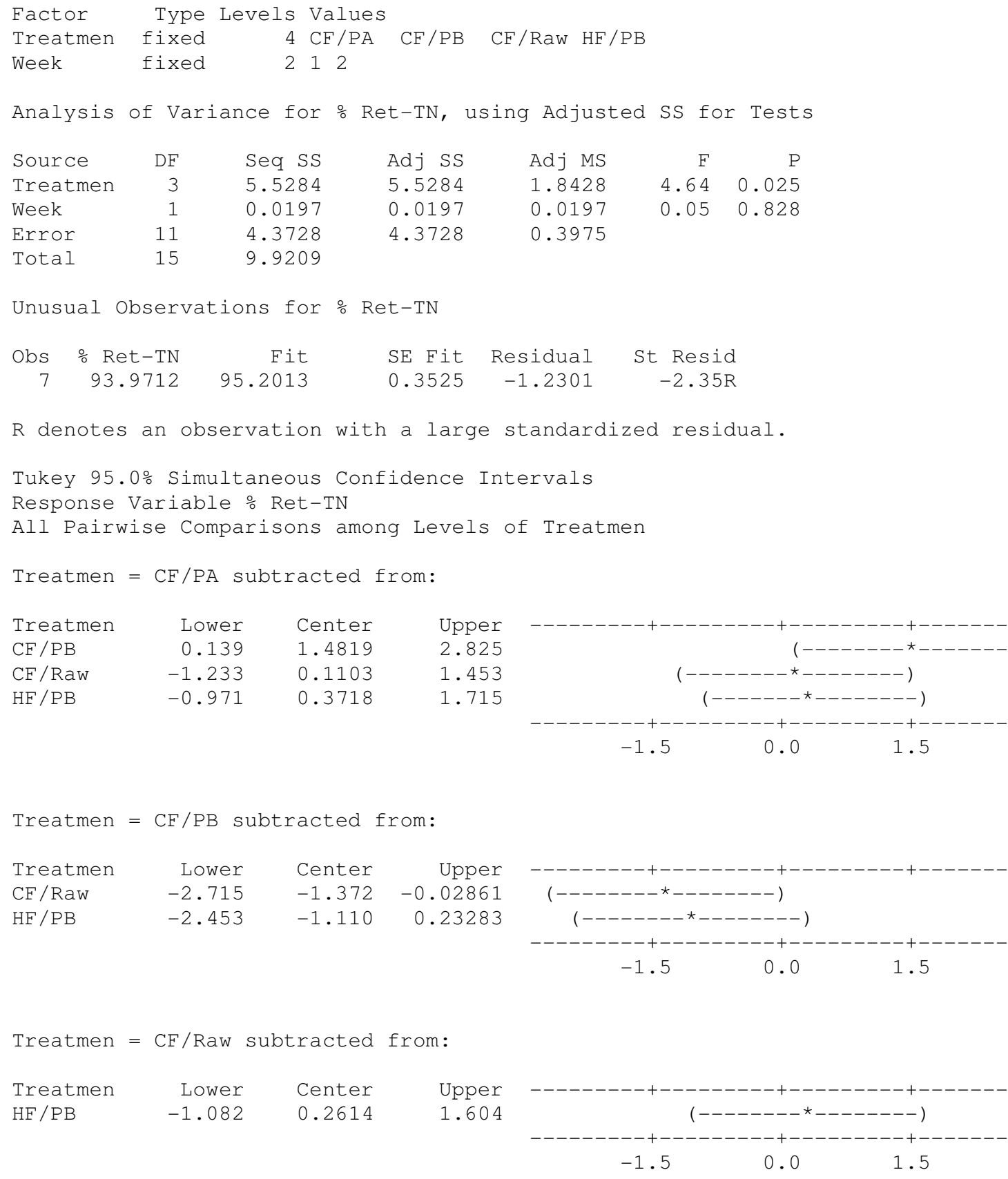




\section{General Linear Model: Viscosity at $10^{\circ} \mathrm{C}$ versus Treatment, Week}

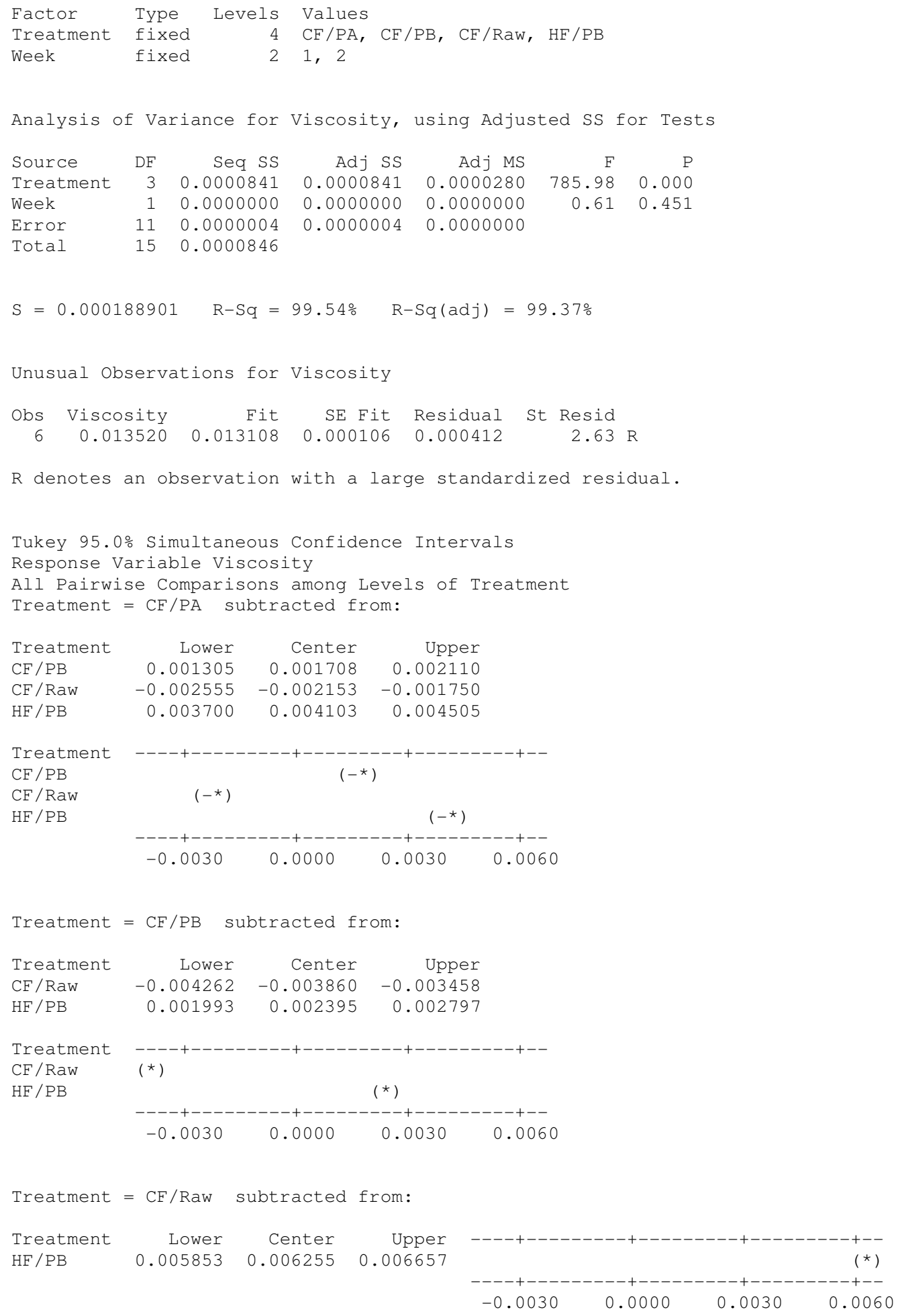




\section{General Linear Model: Viscosity at $40^{\circ} \mathrm{C}$ versus Treatment, Week}

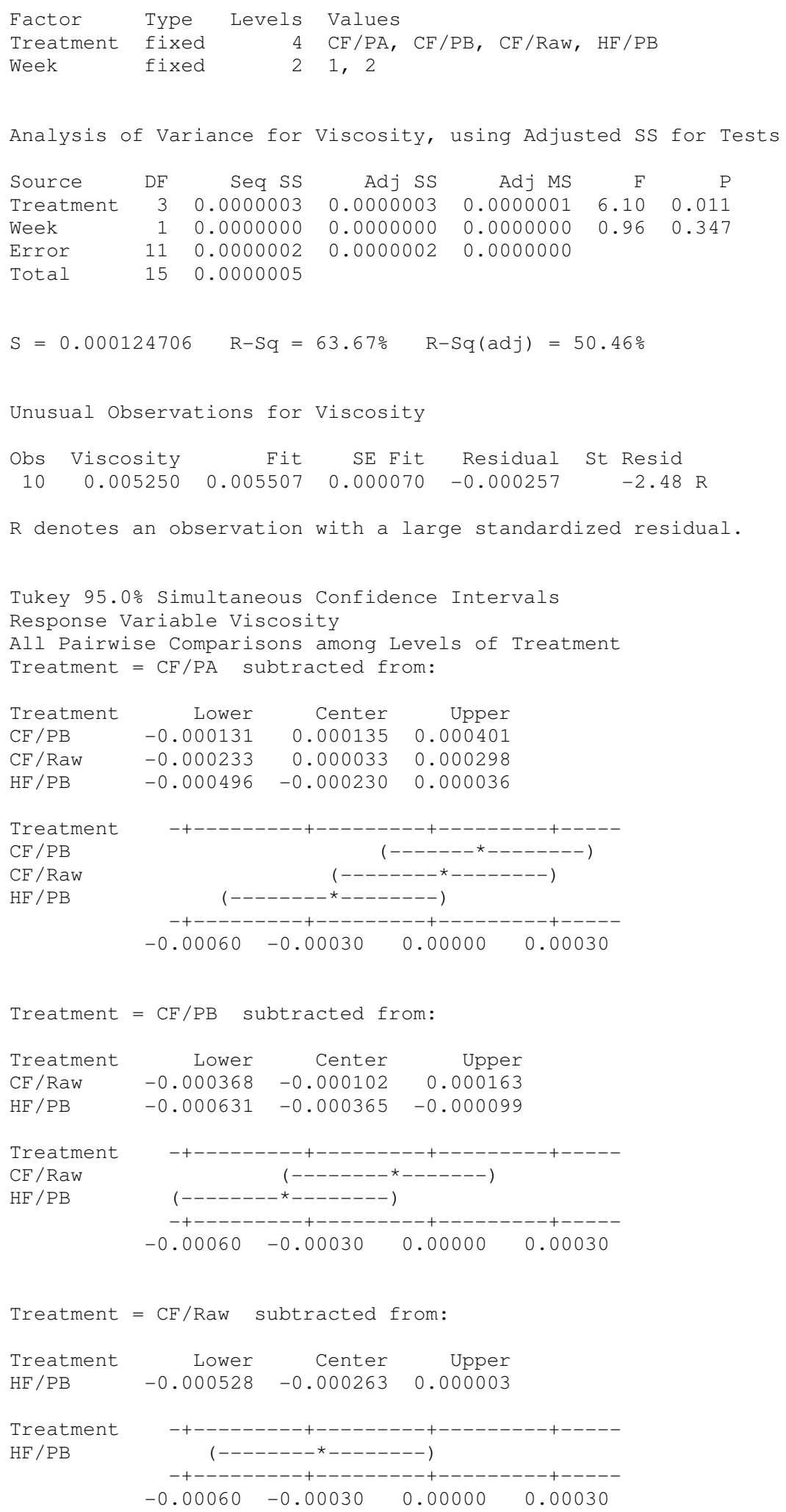




\section{General Linear Model: Viscosity at $70^{\circ} \mathrm{C}$ versus Treatment, Week}

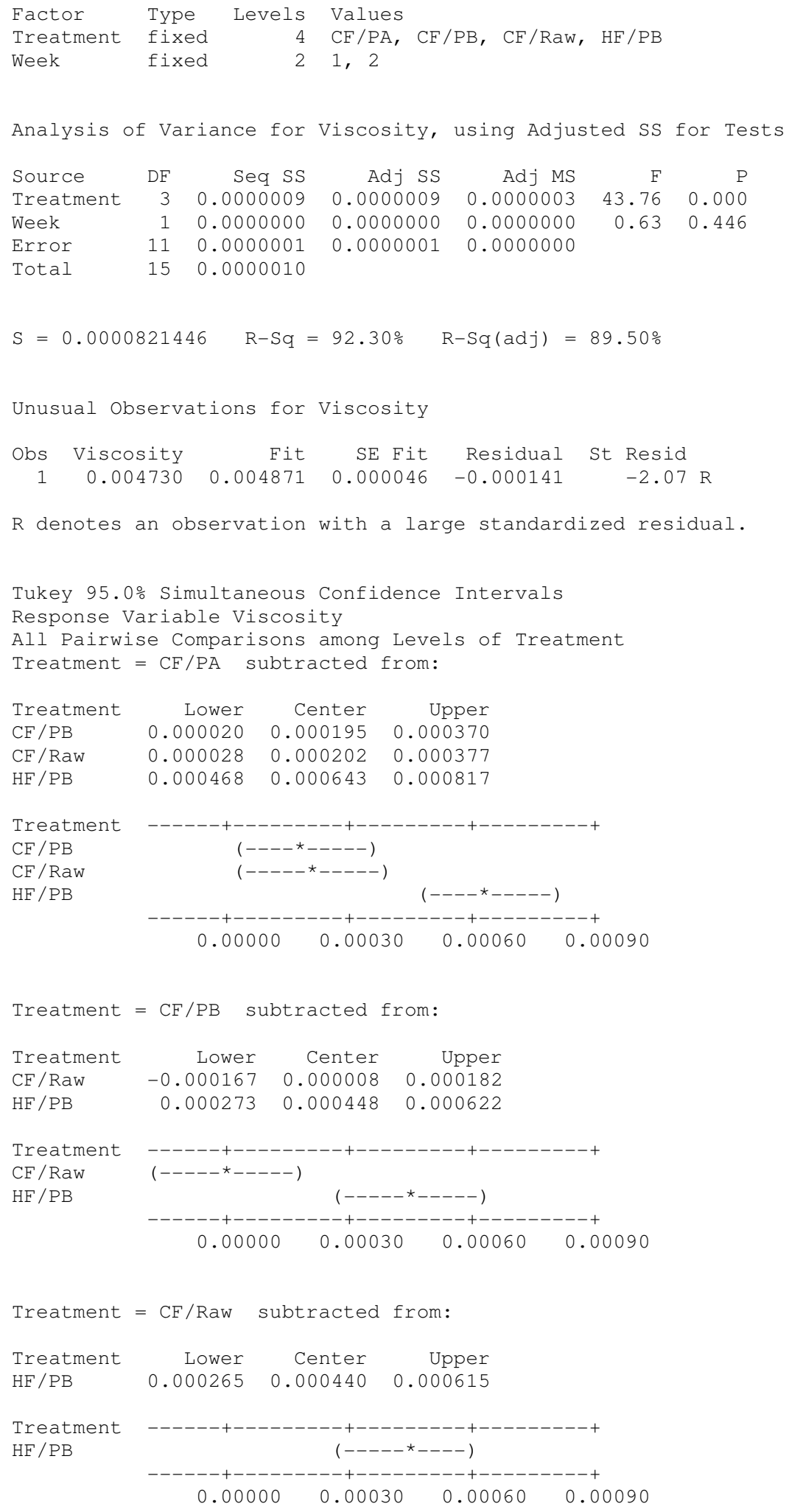




\section{General Linear Model: Rennet Coagulation Time versus Treatment, Week}

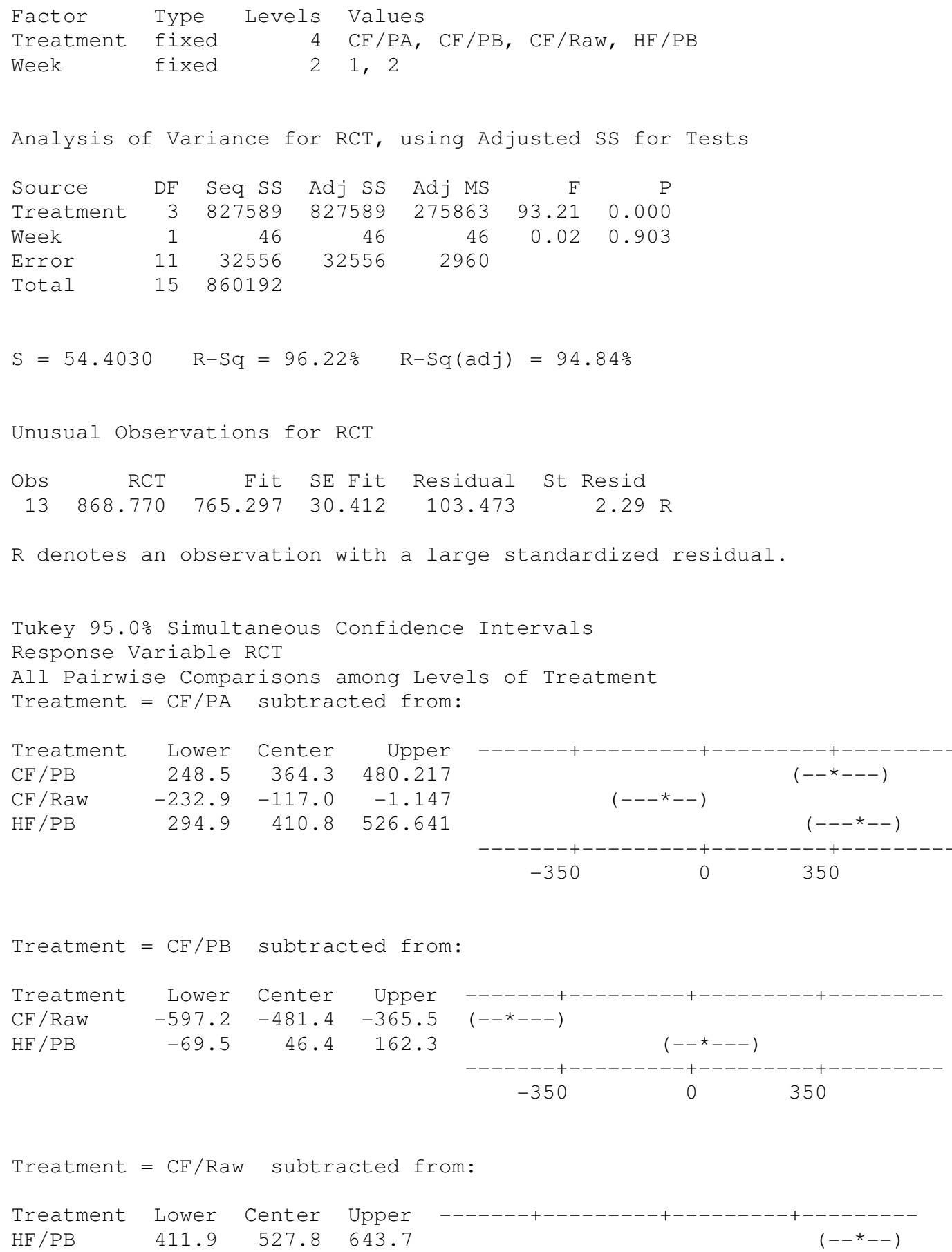




\section{General Linear Model: \% Serum Ca versus Treatment, Week}

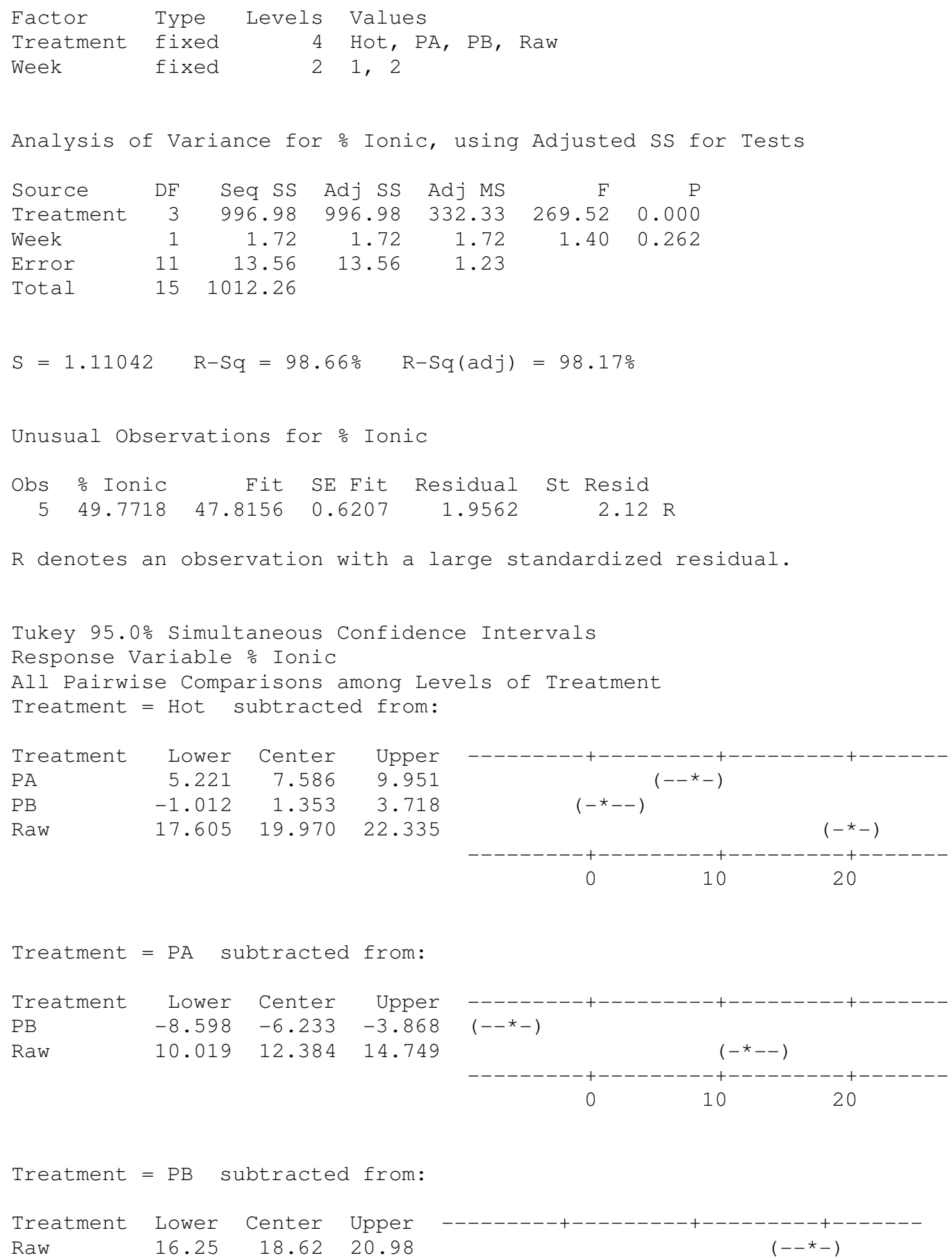

